\title{
An Exploration of Conceptual Teaching in Piano Study: Pedagogical Analysis of Three Selected Intermediate Piano Works by Two American Composers, William Bolcom and Lowell Liebermann
}

Justin Douglas Krueger

West Virginia University

Follow this and additional works at: https://researchrepository.wvu.edu/etd

\author{
Recommended Citation \\ Krueger, Justin Douglas, "An Exploration of Conceptual Teaching in Piano Study: Pedagogical Analysis of \\ Three Selected Intermediate Piano Works by Two American Composers, William Bolcom and Lowell \\ Liebermann" (2014). Graduate Theses, Dissertations, and Problem Reports. 662. \\ https://researchrepository.wvu.edu/etd/662
}

This Dissertation is protected by copyright and/or related rights. It has been brought to you by the The Research Repository @ WVU with permission from the rights-holder(s). You are free to use this Dissertation in any way that is permitted by the copyright and related rights legislation that applies to your use. For other uses you must obtain permission from the rights-holder(s) directly, unless additional rights are indicated by a Creative Commons license in the record and/ or on the work itself. This Dissertation has been accepted for inclusion in WVU Graduate Theses, Dissertations, and Problem Reports collection by an authorized administrator of The Research Repository @ WVU.

For more information, please contact researchrepository@mail.wvu.edu. 
An Exploration of Conceptual Teaching in Piano Study:

Pedagogical Analysis of Three Selected Intermediate Piano Works by Two American Composers, William Bolcom and Lowell Liebermann.

\title{
Justin Douglas Krueger
}

\author{
Research Document submitted to the \\ College of Creative Arts \\ at West Virginia University \\ in partial fulfillment of the requirements \\ for the degree of
}

\author{
Doctor of Musical Arts \\ in \\ Piano Performance
}
Peter Amstutz, D.M.A., Committee Chair and Research Advisor Cynthia Anderson, M.M.
William Haller, D.M.A.
Lucy Mauro, D.M.A.
Georgia Narsavage, Ph.D.

School of Music

Morgantown, West Virginia

2014

Keywords: Album for the Young, Seven Easy Pieces, Monsterpieces, William Bolcom, Lowell Liebermann, Conceptual Piano Teaching 


\begin{abstract}
An Exploration of Conceptual Teaching in Piano Study:

Pedagogical Analysis of Three Selected Intermediate Piano Works by Two American Composers, William Bolcom and Lowell Liebermann.
\end{abstract}

\title{
Justin Douglas Krueger
}

Music of contemporary classical composers is often neglected because of simple lack of familiarity or because some of the material is difficult; all too frequently, recent music is allotted very little time during the long-term course of a student's piano study. These circumstances may contribute to the current situation, in which, all too often, students may get little encouragement to explore music by contemporary composers.

This paper highlights some possible reasons for the lack of exposure which contemporary classical compositions sometimes receive. The discussion continues by outlining a broad conceptual teaching paradigm and then shows ways in which a conceptual approach is applicable to studio teachers, especially in regard to teaching contemporary pieces.

In support of that approach, this paper analyzes three collections of elementary to intermediate solo piano works of composers Lowell Liebermann and William Bolcom. The analysis demonstrates how these particular compositions can prove beneficial to a student's course of study.

The paper then concludes by summarizing the case for the importance of teaching contemporary compositions alongside the standard repertoire. 


\section{ACKNOWLEDGEMENTS}

To my Grandparents-William H. and Dorothy M. Van Grinsven, who entered eternal life during my first year of study at West Virginia University.

I would also like to thank several people who have embarked on this educational journey with me. First, thank you to my parents who gave me the first opportunity to explore music. To my family and friends who have been my supporters along the way. To my former piano teachers, Carlarae Van Grinsven, Jan Kaminski, Sally Orm, Elaine Moss, Dr. Sylvia Coats, and Dr. Andrew Trechak whose guidance has led me this far. A huge thank you to my teacher, committee chair, and research advisor, Dr. Peter Amstutz, who has been an incredible mentor during my time at West Virginia University. Thanks also to my committee members Prof. Cynthia Anderson, Dr. William Haller, Dr. Lucy Mauro, and Dr. Georgia Narsavage for your support along this journey. And finally, a special thank you to Kari, my wife and best friend, for your love, support, and encouragement throughout this endeavor. 


\section{CONTENTS}

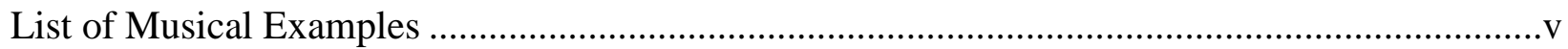

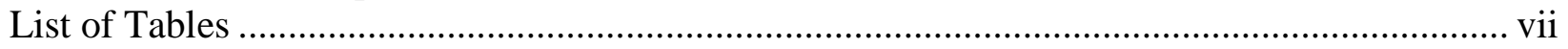

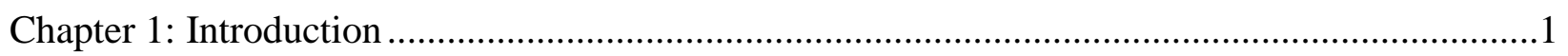

Chapter 2: An Overview of Conceptual Learning ........................................................... 14

Chapter 3: Bringing this Educational Theory to the Piano Studio.............................................24

Chapter 4: Lowell Liebermann and Album for the Young ...................................................... 31

Chapter 5: William Bolcom and Monsterpieces .......................................................................71

Chapter 6: Analysis of Bolcom's Seven Easy Piano Pieces ....................................................90

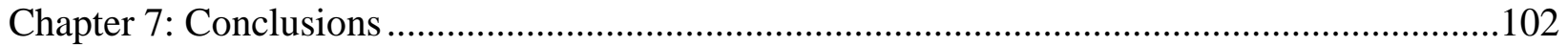

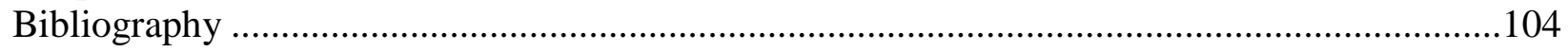




\section{LIST OF MUSICAL EXAMPLES}

Example 4.1: Liebermann's "Dance" from Album for the Young, mm. 1-2................................32

Example 4.2: Liebermann's "Song" from Album for the Young, mm. 1-4 ..................................34

Example 4.3: Liebermann's "Song" from Album for the Young, mm. 11-14.............................34

Example 4.4: Liebermann's "Endless Melody" from Album for the Young, mm. 13-17 ..............36

Example 4.5: Liebermann's "Boogieman" from Album for the Young, mm. 4-7 .......................36

Example 4.6: Liebermann's "Boogieman" from Album for the Young, mm. 15-18 .....................37

Example 4.7: Liebermann's "Ghost Waltz" from Album for the Young, mm. 1-6.......................38

Example 4.8: Liebermann's "Ghost Waltz" from Album for the Young, mm. 25-30....................38

Example 4.9: Liebermann's "Ostinato" from Album for the Young, mm. 7-11 …......................40

Example 4.10: Liebermann's "Marching Off to War" from Album for the Young, mm. 1-4........41

Example 4.11: Liebermann's "Marching Off to War" from Album for the Young, mm. 13-16.....42

Example 4.12: Liebermann's "Rainy Day" from Album for the Young, mm. 1-6.......................43

Example 4.13: Liebermann's "Rainy Day" from Album for the Young, mm. 20-25....................43

Example 4.14: Liebermann's "Broken Heart" from Album for the Young, mm. 1-6 ...................45

Example 4.15: Liebermann's "Lullaby" from Album for the Young, mm. 1-6 .........................46

Example 4.16: Liebermann's "Lullaby" from Album for the Young, mm. 19-24 .......................47

Example 4.17a: Liebermann's "Starry Night" from Album for the Young, mm. 1-4 ...................48

Example 4.17b: Liebermann's "Starry Night" from Album for the Young, m. 1 subdivisions ......49

Example 4.18: Liebermann's "Starry Night" from Album for the Young, mm. 5-8 ....................50

Example 4.19: Liebermann's "Hommage à Fauré" from Album for the Young, mm. 1-5 ............52

Example 4.20a: Liebermann's "Hommage à Fauré" from Album for the Young, mm. 11-15 .......52

Example 4.20b: Liebermann's "Hommage à Fauré" from Album for the Young, mm. 1-14 bass .53

Example 4.21a: Liebermann's "Funeral March for a Pet Rat" from Album for the Young, mm.

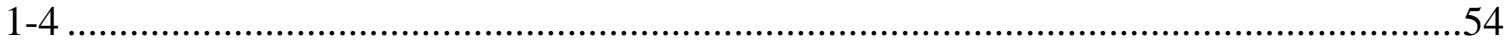

Example 4.21b: Liebermann's "Funeral March for a Pet Rat" from Album for the Young, mm.

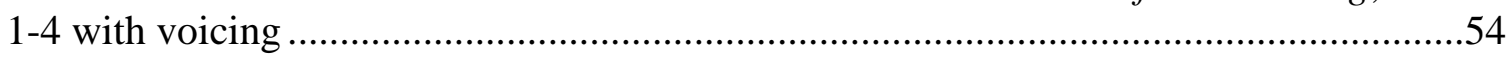

Example 4.22: Liebermann's "Funeral March for a Pet Rat" from Album for the Young, $\mathrm{mm}$.

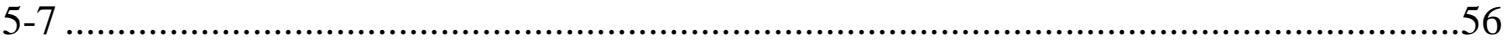

Example 4.23: Liebermann's "Hommage à Alkan" from Album for the Young, mm. 1-5...........57

Example 4.24: Liebermann's "Hommage à Alkan" from Album for the Young, mm. 23-27.........58

Example 4.25: Liebermann's "Hommage à Alkan" from Album for the Young, mm. 6-8............59

Example 4.26: Liebermann's "Hommage à Alkan" from Album for the Young, mm. 17-21.........59

Example 4.27: Liebermann's "Melancholy" from Album for the Young, mm. 1-2......................60

Example 4.28: Liebermann's "Melancholy" from Album for the Young, mm. 3-4.....................61

Example 4.29: Liebermann's "Barcarolle" from Album for the Young, mm. 4-6 .......................62

Example 4.30: Liebermann's "Barcarolle" from Album for the Young, mm. 16-18 ....................63

Example 4.31: Liebermann's "Barcarolle" from Album for the Young, mm. 36-38 ....................63

Example 4.32: Liebermann's "Barcarolle" from Album for the Young, mm. 34-35 ....................64

Example 4.33: Liebermann's "The Little Baby Rhino" from Album for the Young, mm. 1-5......65

Example 4.34: Liebermann's "The Little Baby Rhino" from Album for the Young, mm. 17-19...66

Example 4.35: Liebermann's "The Little Baby Rhino" from Album for the Young, mm. 9-10....66

Example 4.36: Liebermann's "Toccata" from Album for the Young, mm. 13-15 ......................67

Example 4.37: Liebermann's "Toccata" from Album for the Young, mm. 1-4 ..........................68

Example 4.38: Debussy's "Deux Arabesques, No. 1" mm. 8-11 ..............................................69 
Example 5.1: Bolcom's "The Mad Monster" from Monsterpieces, mm. 1-5 ............................73

Example 5.2: Bolcom's "The Sad Monster" from Monsterpieces, mm. 7-11 .............................75

Example 5.3: Bolcom's "The Bad Mister" from Monsterpieces, mm. 9-12 .............................76

Example 5.4: Bolcom's "The Bad Mister" from Monsterpieces, mm. 1-2 ................................76

Example 5.5: Bolcom's "The Glad Minister" from Monsterpieces, mm. 13-17 .........................77

Example 5.6: Bolcom's "The Plaid Miss" from Monsterpieces, mm. 5-9 .................................78

Example 5.7: Bolcom's "Badminton" from Monsterpieces, m. 1 ...............................................8

Example 5.8: Bolcom's "Big Mountain" from Monsterpieces, mm. 1-2 ...................................82

Example 5.9: Bolcom's "Big Mountain" from Monsterpieces, mm. 9-13 ................................82

Example 5.10: Bolcom's "A Boating Tune" from Monsterpieces, mm. 1-4 ...............................83

Example 5.11: Bolcom's "A Boating Tune" from Monsterpieces, mm. 17-18 ...........................84

Example 5.12: Bolcom's "A Boating Tune" from Monsterpieces, mm. 9-12 ............................84

Example 5.13: Bolcom's "The Bitty Town" from Monsterpieces, mm. 1-6..............................85

Example 5.14: Bolcom's "The Bitty Town" from Monsterpieces, mm. 15-17 ...........................86

Example 5.15: Bolcom's "Finale: The Big Bad Mr. Monster Strikes Again" from Monsterpieces,

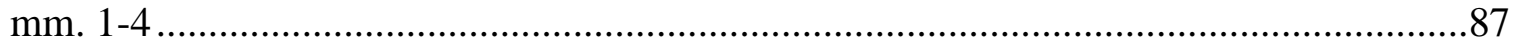

Example 5.16: Bolcom's "Finale: The Big Bad Mr. Monster Strikes Again" from Monsterpieces,

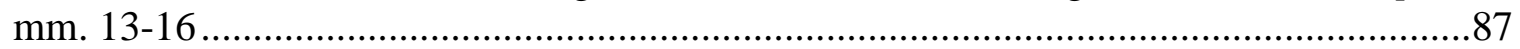

Example 6.1: Bolcom's "Pussycat Waltz No. 1" from Seven Easy Piano Pieces, mm. 5-8 .........91

Example 6.2: Bolcom's "Pussycat Waltz No. 1" from Seven Easy Piano Pieces, mm. 9-11 .......91

Example 6.3: Bolcom's "Winter Trek" from Seven Easy Piano Pieces, mm. 1-4 ......................93

Example 6.4: Bolcom's "Winter Trek" from Seven Easy Piano Pieces, 17-21 .........................94

Example 6.5: Bolcom's "Little Song" from Seven Easy Piano Pieces, mm. 1-3........................95

Example 6.6: Bolcom's "Little Song" from Seven Easy Piano Pieces, mm. 4-6........................96

Example 6.7: Bolcom's "Pussycat Waltz No. 2" from Seven Easy Piano Pieces, mm. 5-7 ..........96

Example 6.8: Bolcom's "Little French Invention: L'Orangerie" from Seven Easy Piano Pieces,

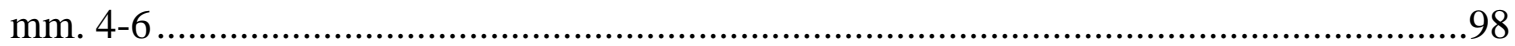

Example 6.9: Bolcom's "Carillon" from Seven Easy Piano Pieces, mm. 10-14 ........................99

Example 6.10: Bolcom's "Pussycat Waltz No. 3" from Seven Easy Piano Pieces, 1-4 ..............100

Example 6.11: Bolcom's "Pussycat Waltz No. 3" from Seven Easy Piano Pieces, mm. 10-14 ..100 


\section{LIST OF TABLES}

Table 1.1: CAPMT 2013-2014 Piano Solo Music ...................................................................2

Table 1.2: WSMA 2013-2014 Piano Solo Repertoire .............................................................

Table 1.3: OMEA 2013-2014 Piano Repertoire ................................................................

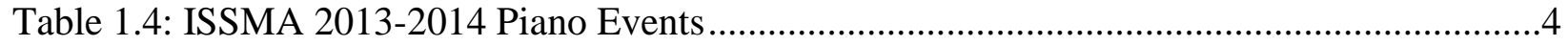

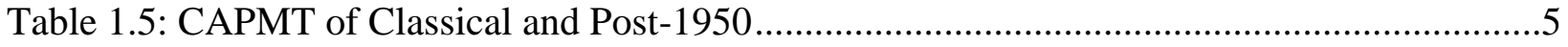

Table 3.1: Eleven Musical Concepts ..............................................................................26 


\section{Chapter One}

\section{Introduction}

Author, educator, and pianist Scott McBride Smith, in a book entitled The Well-

Tempered Keyboard Teacher, discusses a phenomenon surrounding the limited variety of piano works being performed in competitions and recitals. Smith views this situation as a crisis. He states,

"The range of piano literature presented in today's concert recitals has become very narrow. It is depressing to see the same few pieces recurring over and over again in the few live piano concerts available to modern audiences, especially considering that the piano repertoire itself is so large and varied."

He offers two possible reasons for this situation, suggesting,

"there is a simple 'trickle down' effect, reflecting the reality of what major concert artists choose to feature on live programs, which are then taught to talented students who wish to emulate those master pianists. Or, because so many gifted pupils spend so much time on a limited number of difficult pieces, hoping to win important scholarships and competitions - and these same students later become teachers - the narrow selection of pieces simply reflects their own restricted experience, which they then pass on to the next generation." ${ }^{2}$

The situation described here can be disheartening, especially for teachers who seek to expose their students to new and engaging repertoire. As Smith says, "It's time for a revolution."3

However, this revolution is likely to be an uphill battle for both students and teachers

alike. An examination of competition repertoire lists from five different state music organizations: the California Association of Professional Music Teachers (CAPMT), the Illinois Grade School Music Association (IGSMA), the Indiana State School Music Association (ISSMA), the Ohio Music Education Association (OMEA), and the Wisconsin School Music Association (WSMA), offers insight into reasons behind the limited supply of repertoire being

\footnotetext{
${ }^{1}$ Marienne Uszler, Scott McBride Smith, and Stewart Gordon, The Well-Tempered Keyboard Teacher (New York: Schirmer, 1999), 154.

2 Ibid., 154.

${ }^{3}$ Ibid., 154.
} 
selected and performed. For example, the 2013 OMEA list, in the most advanced level for high school piano students, features just one work by a living composer, William Bolcom. This beautiful composition, "The Graceful Ghost Rag," is unambiguously tonal and was written in 1970, over 40 years ago! The WSMA competition list of the same level is even more limited, including no music written after 1950. The following charts represent the proportions of different periods of piano literature from similar levels of playing.

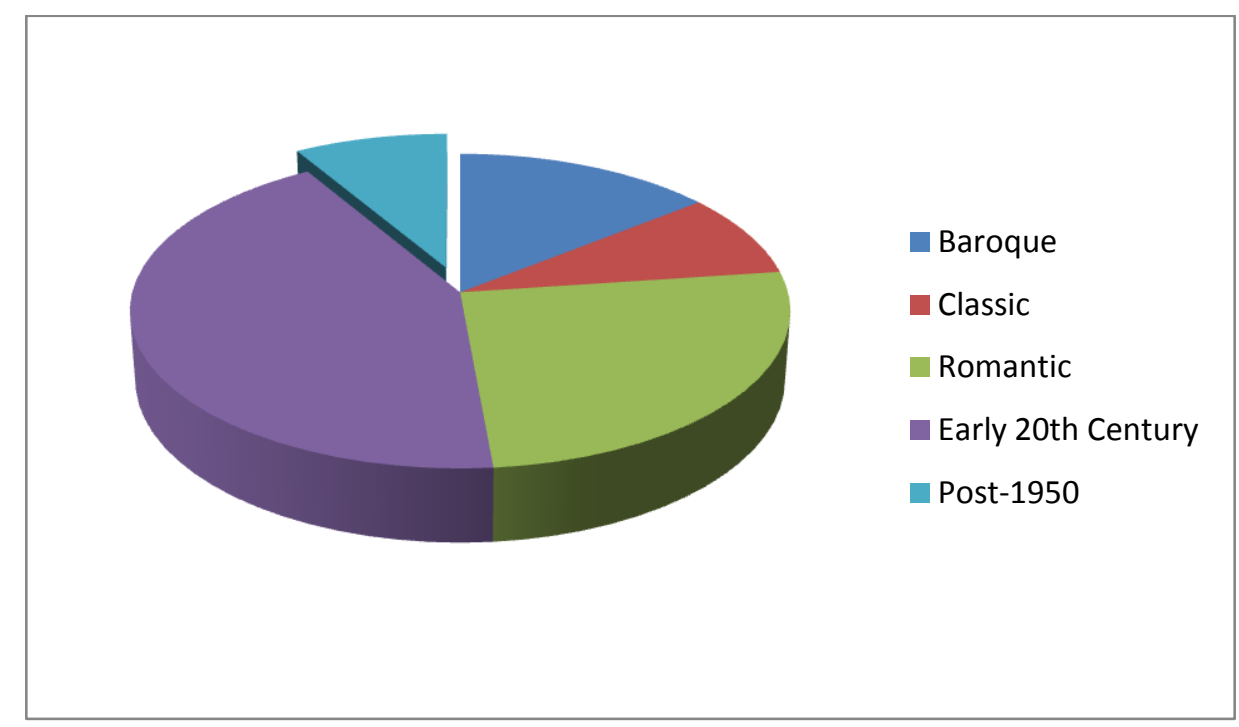

Table 1.1 CAPMT 2013-2014 Piano Solo Music ${ }^{4}$

\footnotetext{
4 "2013-2014 CAPMT Piano Competition: Piano Auditions Guidelines," accessed Dec. 5, 2013, http://capmt.org/California_Association_of_Professional_Music_Teachers/Student_Programs_files/201314\%20Piano\%20Auditions.pdf
} 


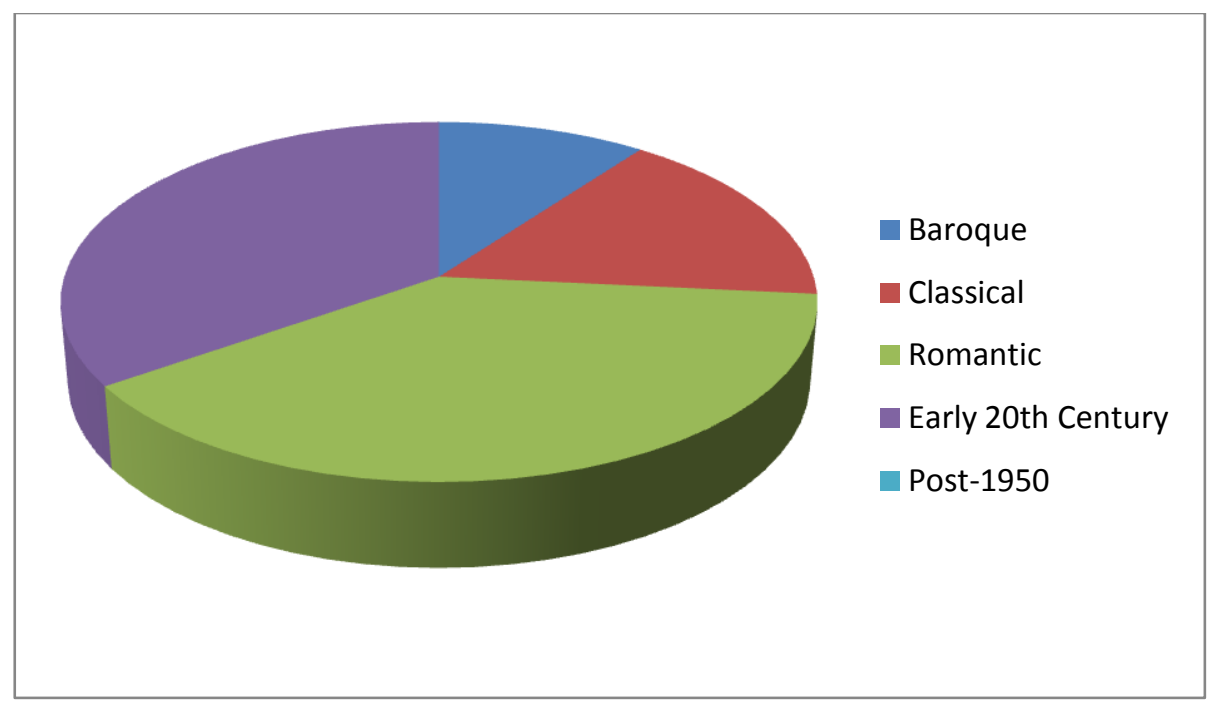

Table 1.2 WSMA 2013-2014 Piano Solo Repertoire ${ }^{5}$

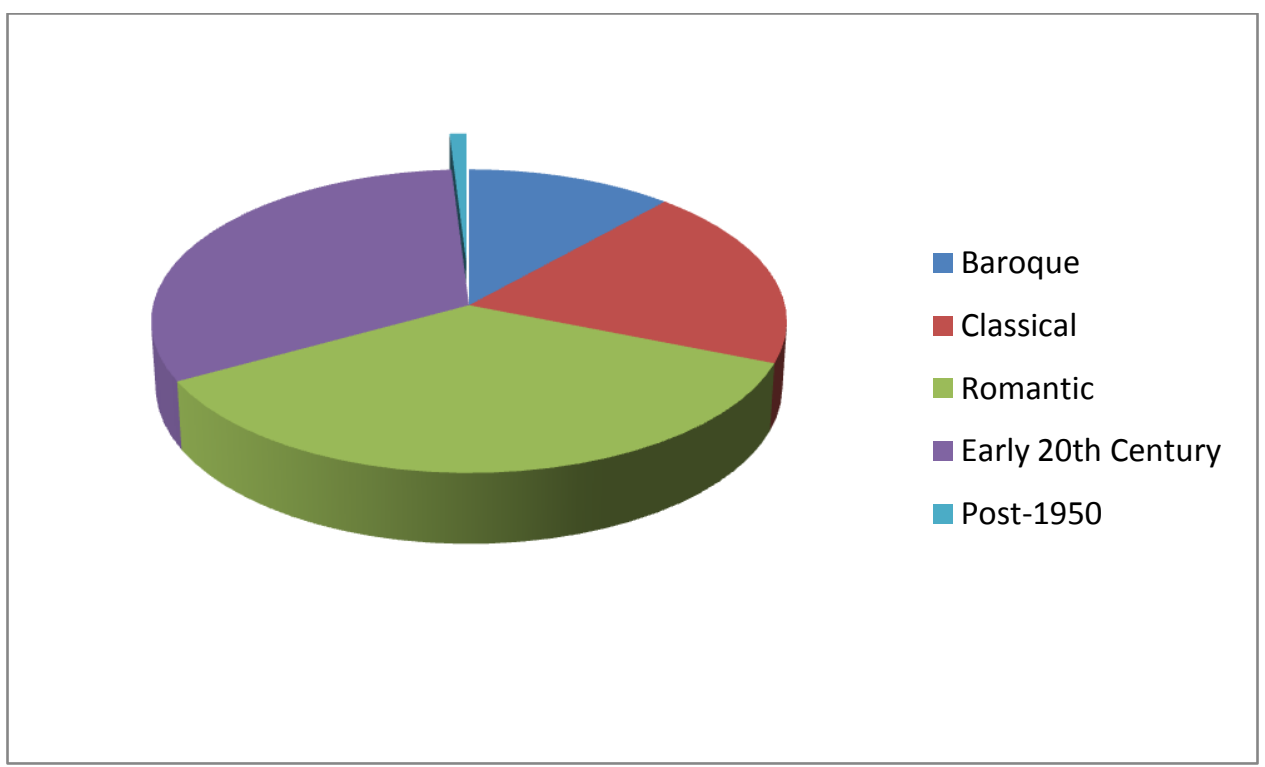

Table 1.3 OMEA 2013-2014 Piano Repertoire ${ }^{6}$

\footnotetext{
5 "WSMA 2013-2014 Festival Music List," accessed Dec. 5, 2013, http://www.wsmamusic.org/music_list/search_13-14.html

6 "Ohio Music Education Association: Solo and Ensemble Required Music List - High School," accessed Dec. 5, 2013, http://www.omea-ohio.org/SEP/HS.html
} 


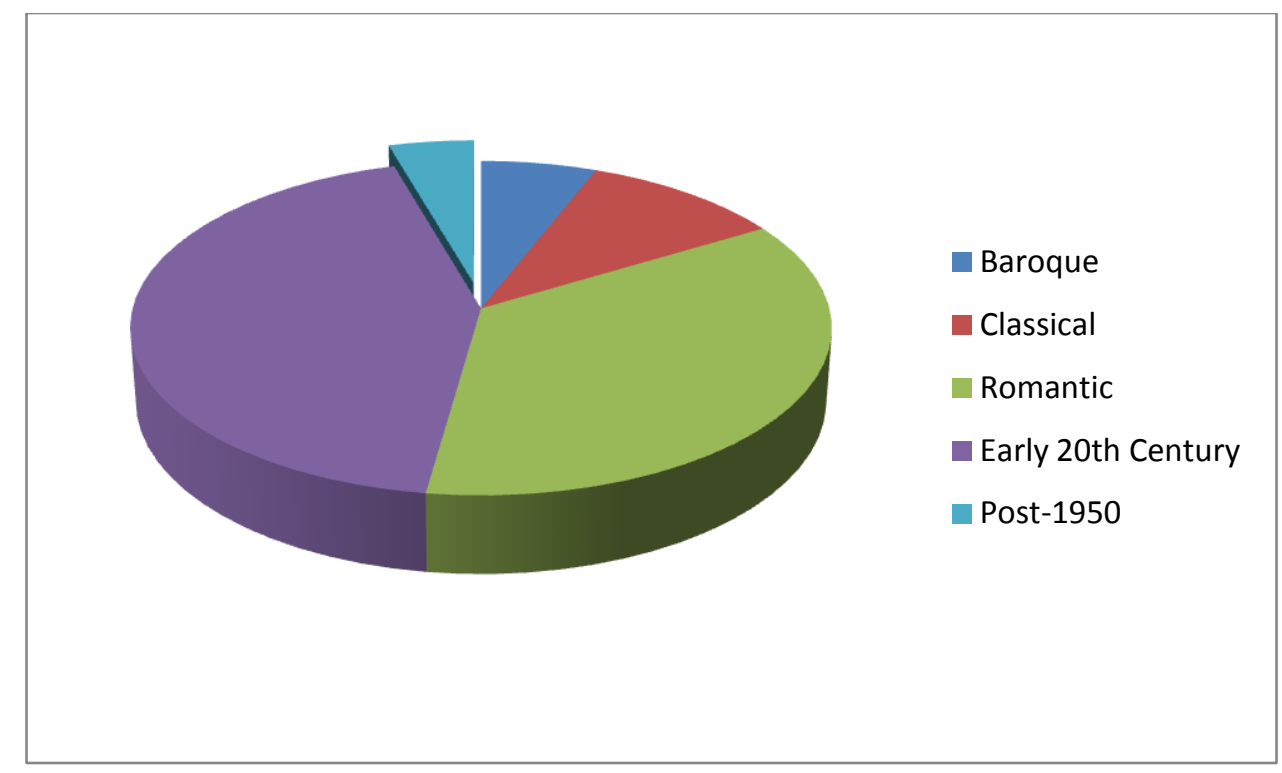

Table 1.4 ISSMA 2013-2014 Piano Events ${ }^{7}$

A glance at the CAPMT repertoire list reveals even more imbalance. Although the Classical and Post-1950 portions look roughly the same in size (and do indeed include the same number of possible entries at three each), further examination of these three entries is necessary. The three Classical entries are listed under Beethoven, Haydn, and Mozart, but allow a student to select almost any of the sonatas. The post-1950 works are typically much more specific and require specific pieces rather than complete volumes. A more accurate comparison of Classical to Post-1950 in this case can be seen in the following chart.

\footnotetext{
7 "Indiana State School Music Association: Required Music List Group I Piano Events," accessed Dec. 5, 2013, http://www.issma.net/downloads/pianogrp1.pdf
} 


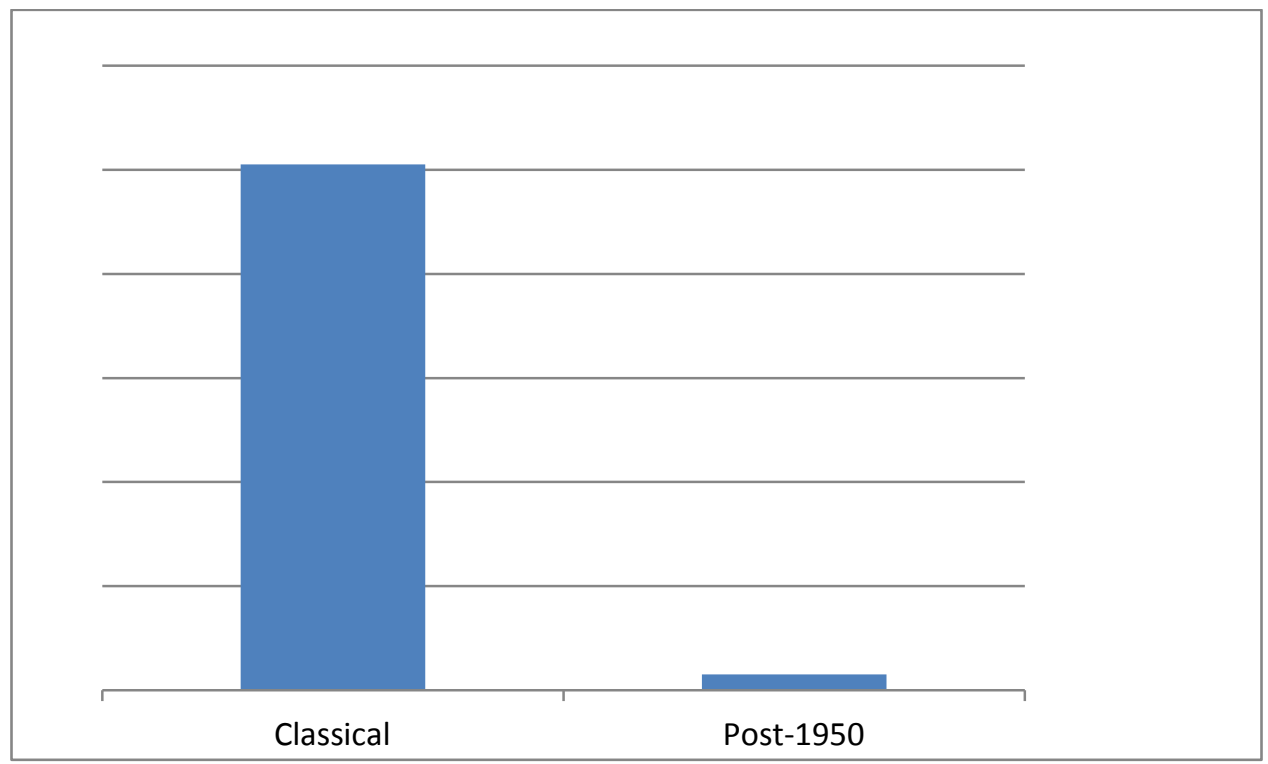

Table 1.5 CAPMT comparison of Classical and Post $-1950^{8}$

Similar listings are found on the other competition lists where particular composers or volumes are all grouped together. The IGSMA list includes several more current pieces than the lists from other states. However, the composers included on this list are still highly limited, and contributions of several important living composers, for example, Lowell Liebermann and William Bolcom, are disregarded.

All these data suggest how little emphasis is placed on the recent composers of classical music in the formative years of a student's study, when he or she is often introduced and exposed to classical music for the first time. However, this does not reflect the entirety of the problem surrounding the lack of familiarity with contemporary composers. A second piece of the puzzle lies in college audition requirements. For example, the prestigious Juilliard School of Music requires works from the Baroque, Classic, and Romantic periods. The other pieces required,

\footnotetext{
8 "2013-2014 CAPMT Piano Competition: Piano Auditions Guidelines," accessed Dec. 5, 2013, http://capmt.org/California_Association_of_Professional_Music_Teachers/Student_Programs_files/201314\%20Piano\%20Auditions.pdf
} 
however, do not necessitate that a student play a composition from the 20th or 21 st centuries. ${ }^{9}$

The University of Wisconsin-Madison does require a composition from the 20th century in addition to Baroque, Classic, and Romantic compositions; however, compositions by Debussy or Bartók can satisfy this requirement. ${ }^{10}$ While these composers are indeed part of the 20th century, their works differ significantly in style, tonality, form, etc. from those by most composers who are presently writing for the piano.

Programs given by major concert artists, as well as by symphony orchestras around the country, also contribute to the lack of contact with our present-day composers. And although the list of contributors to the limited scope of performed repertoire continues, the problem remains the same: the works of living composers are often neglected in favor of the pieces written by composers of the past centuries.

It is vital for music educators to promote new repertoire and to support composers of the present generation. By programming these contemporary composers, teachers and students help to build and encourage music in the present culture. Support for these composers allows for the establishing of new ideas, sounds, and concepts previously unexplored. By studying new works by living composers, students are developing their own sense of musical taste and, even more importantly, encouraging a form of art which has the power to influence future generations. Although many of these benefits may seem to be largely subjective, it is important, as with other ideas and innovations, to promote the progress of music in order to avoid its becoming a relic of the past.

\footnotetext{
9 "Bachelor of Music and Diploma Audition Dates, Pre-Screening and Live Audition Repertoire for Fall 2014," accessed Dec. 5, 2013, http://www.juilliard.edu/apply-audition/application-audition-requirements/bachelor-musicand-diploma/bachelor-music-and-2\#piano

10 "School of Music, University of Wisconsin-Madison: Piano Undergraduate Admission Requirements," accessed Dec. 5, 2013, http://music.wisc.edu/performance/piano
} 
Nevertheless, the purpose of this study is not to argue the benefits to culture when new music is promoted. Rather, this research will show practical ways in which piano teachers can explore music written within the past fifty years with their students. This exploration will not abandon learning traditional repertoire, but will seek to enhance a student's overall experience of classical music. In order that this type of learning and teaching can take place, piano teachers may have to re-examine the ways in which they teach. An educator's approach to teaching may need to be re-evaluated, and the possibility and potential for a student's growth and exposure to a wider variety of music increase exponentially.

This approach requires that a teacher not limit piano lessons to learning specific repertoire; rather, a student's study of the piano needs to be founded upon learning concepts that are universal to all musical study. These concepts will be examined in more detail later in the paper. The underlying premise is that by learning specific concepts that are universal to all music through a variety of pieces, students are then able to take these concepts and transfer them to learning other pieces.

Dr. Christine Carter, a professor at the Manhattan School of Music, supports this idea. She states, "We are hardwired to pay attention to change, not repetition. ${ }^{11}$ When studying a variety of pieces which focus on particular concepts, more learning can take place than by simply repeating a passage or a piece over and over. Dr. Carter continues, "Functional magnetic resonance imaging has demonstrated that there is progressively less brain activation when stimuli are repeated. The fact is, repeated information does not receive the same amount of processing as new information. And on some level, we all know this. Constant repetition is boring and our boredom is telling us that our brains are not engaged." Dr. Carter basically is suggesting that, in

\footnotetext{
${ }^{11}$ Noa Kageyama and Christine Carter, "Why the Progress You Make in the Practice Room Seems to Disappear Overnight," accessed Dec. 5, 2013, http://www.bulletproofmusician.com/why-the-progress-in-the-practice-roomseems-to-disappear-overnight/
} 
order to promote continuous learning, teachers must find ways to keep students engaged; often this means varying the material which they are using to teach and keeping it focused on conceptual learning. Not only does variety keep a student interested, but it also has the potential to keep an instructor's teaching fresh and exciting.

This study will continue by showing how concept-based learning works. It will be based on the work of educational theorist Jerome Bruner and will show how this style of teaching benefits both teachers and students. ${ }^{12}$ The research will also examine specific concepts which are universal to all music. This analysis of concepts will be grounded in the research of Dr. Sylvia Coats. ${ }^{13}$ Following the exploration of this methodology, an analysis of works by Lowell Liebermann and William Bolcom will be conducted with relation to particular musical concepts. These concepts will then be compared with those in other pieces in the standard repertoire to show how they can be utilized together to enhance a student's learning and understanding of a particular concept.

Regarding the sources already available that are relevant to this topic, there is an abundance of literature that discusses various educational ideas and theories. For the purposes of this study, I will draw primarily on the writings of Jerome Bruner along with those of several other scholars who build upon elements of his work. The idea of conceptual learning is deeply rooted in both the fields of education and psychology; for this reason, articles from prominent educational and psychological journals provide valuable insights. One of these articles, "Conceptual Learning: The Priority for Higher Education," by Effie MacLellan, a research professor in education, focuses on the ongoing importance of conceptual learning. Her research emphasizes the significance of conceptual learning, not only in the earlier grades of education,

\footnotetext{
12 Jerome Bruner, The Process of Education (Cambridge: Harvard University Press, 1999).

${ }^{13}$ Sylvia Coats, Thinking As You Play (Bloomington, IN: Indiana University Press, 2006).
} 
but also into the college level. ${ }^{14}$ The broader demonstration of conceptual learning is especially useful for the current research, because it validates the usefulness of presenting concepts to piano students, regardless of age, and it shows how concepts are important throughout a student's learning career.

An article entitled "On the Role of Concepts in Learning and Instructional Design," by David Jonassen, a research education scholar, is also useful. This study clearly defines the significance of concepts in education. Through various examples, Jonassen is able to articulate what he means by concepts and how they are applied to education. ${ }^{15}$ Connecting his study and examples to particular concepts relative to music leads to conclusions that help to communicate the central role that concepts play in music education.

A study which directly connects music concepts and their relationship to psychology is also relevant to the current study. Psychologists Caroline Palmer and Rosalee Meyer present a research experiment which contrasts the differences between motor and concept learning. The conceptual experiment is largely the foundation of the research presented in the current paper. By demonstrating the benefit of conceptual learning, Palmer and Meyer's article gives validity to the reasons behind the current research paper and reveals potential applications to real-world situations. ${ }^{16}$

Jerome Bruner's The Process of Education provides a pivotal resource for the educational portion of this research. Bruner conducted pioneering research that highlights the importance of

\footnotetext{
${ }^{14}$ Effie Maclellan, "Conceptual Learning: The Priority for Higher Education," British Journal of Educational Studies, Vol. 53, No. 2, (June 2005): 129-147.

${ }^{15}$ David H. Jonassen, "On the Role of Concepts in Learning and Instructional Design," Educational Technology Research and Development, Vol. 54, No. 2, (April 2006): 177-196.

${ }^{16}$ Caroline Palmer and Rosalee K. Meyer, "Conceptual and Motor Learning in Music Performance," Psychological Science, Vol. 11, No. 1, (January 2000): 63-68.
} 
conceptual learning. His work is integral to the educational-theory portion of this research document and is widely acknowledged to be one of the standard sources in its field. ${ }^{17}$

In considering how this type of educational theory can be applied in music teaching, I will draw upon the work of several pedagogues in the piano world. Sources pertaining to piano pedagogy are becoming more and more available as programs at universities across the country continue to grow and develop. Several piano pedagogy sources are very helpful in their presentation of material regarding conceptual teaching. A work critically important in this research is Sylvia Coat's book, Thinking as You Play. In this work, she talks largely about the principles behind teaching and lesson development, as well as educational philosophies. She points out broad issues of learning styles and, of particular interest in this study, the discussion which focuses on and defines teaching concepts, versus teaching individual pieces to students. ${ }^{18}$

A second source from the pedagogy side is Beth Gigante Klingenstein's, The Independent Piano Teacher's Studio Handbook. In this book she presents a wide variety of topics that range from establishing a piano studio as a business to evaluations of piano methods that teachers use with their students. She presents a brief, yet very important, summary that emphasizes the main premise driving the current research regarding conceptual teaching. ${ }^{19}$

An extremely important pedagogical book is entitled The Well-Tempered Keyboard Teacher. It was written by three authors who have contributed immensely to the field of piano pedagogy. They include Scott McBride Smith, Marienne Uszler, and Stewart Gordon. Their book contains valuable discussions about choosing repertoire and about the directions that

\footnotetext{
17 Jerome S. Bruner, The Process of Education (Cambridge: Harvard University Press, 1960).

${ }^{18}$ Sylvia Coats, Thinking As You Play (Bloomington, IN: Indiana University Press, 2006).

${ }^{19}$ Beth Gigante Klingenstein, The Independent Piano Teacher's Studio Handbook (Milwaukee, WI: Hal Leonard Corporation, 2009).
} 
teachers often take with their students. It suggests the possibility of rethinking and reshaping the process through which repertoire choices are made. ${ }^{20}$

Finally, while there are multiple resources which pertain to the music composed by William Bolcom and Lowell Liebermann, there is little available regarding analyses of these specific pieces. Album for the Young by Lowell Liebermann is explored in a dissertation by Adam Clark. As in this current research, Clark begins by building a case for why Liebermann's Album for the Young merits exploration. Clark continues by presenting background on the composer, followed by an examination of the entire set of pieces. Clark's analysis, however, looks at the pieces primarily from a music-theory perspective, noting elements of form and harmony. Clark also examines passages that provide challenges for choosing fingering and provides several viable solutions helping students to accomplish musicality in specific sections. ${ }^{21}$ Unlike Clark's dissertation, the current study examines the pieces from a conceptual perspective that shows how specific pedagogical aspects of these pieces may be transferred to other piano literature.

William Bolcom's music has also received extensive scholarly attention; for his solo piano music, this has focused primarily on his concert works such as the etudes, bagatelles, and rags. However, his teaching pieces are only lightly represented in scholarly research. Because of the newness of his collection, Seven Easy Piano Pieces, the current study appears to be the first research to date which discusses this set of pieces. Bolcom's Monsterpieces has received slightly more attention in discussions of its pedagogical value for intermediate students. Two dissertations discuss the effectiveness of Bolcom's work and how it utilizes contemporary

\footnotetext{
${ }^{20}$ Marienne Uszler, Scott McBride Smith, and Stewart Gordon, The Well-Tempered Keyboard Teacher (New York: Schirmer, 1999).

${ }^{21}$ Adam Clark, ""Modern Marvels:" A Pedagogical Guide to Lowell Liebermann's Album for the Young, Op. 43"

D.M.A. diss., University of Cincinnati, 2008.
} 
compositional and playing techniques such as tone clusters, including the technique of playing them. These dissertations are: "Exploring New Techniques in Contemporary Piano Music: a Guide for the Intermediate-Grade Student,"22 by Chia-Shan Yang and "The Development of Extended Piano Techniques in Twentieth-Century American Music" ${ }^{23}$ by Reiko Ishii. Each of these papers briefly discusses characteristics of one or two of the individual Monsterpieces, but neither reviews the collection as a whole.

Short articles or reviews of contemporary piano literature also provide a potential starting point for discussion of new repertoire. One such document relevant to this study was written by Sarah Evans. Her article provides a broad overview of Liebermann's work, Album for the Young. She highlights some particular challenges of his collection, but her work only touches the surface of the conceptual breadth and depth of this contemporary collection of pieces. $^{24}$

In no way do I wish to suggest that studying and performing the standard repertoire is a problem that needs to be remedied in our studios. After all, the timelessness of these masterworks and composers is the reason that they continue to appear in competitions and on concert programs. Furthermore, simply allowing students the opportunity to engage with contemporary music by living composers does in no way guarantee more substantial growth. Growth of course is dictated by multiple factors. Rather, this discussion seeks to make a case for studying contemporary music alongside the standard repertoire. By using the art music of today's composers in addition to the standard repertoire, we offer students a greater variety of piano literature and are able to reinforce concepts universal to all music.

\footnotetext{
${ }^{22}$ Chia-Shan Yang, "Exploring New Techniques in Contemporary Piano Music: a Guide for the Intermediate-Grade Student" D.M.A. diss., University of Washington, 2004.

${ }^{23}$ Reiko Ishii, "The Development of Extended Piano Techniques in Twentieth-Century American Music" D.M.A. diss., The Florida State University, 2005.

${ }^{24}$ Sarah Evans, "Lowell Liebermann's Album for the Young, Op. 43: A fresh approach to classical teaching literature." Clavier Companion 1, no. 1 (2009): 48-51.
} 
It should also be noted that the analysis presented in this discussion is not drawn from traditional music-theory analysis. The purpose is not to discuss formal organization or harmonic structure. Rather, the purpose of the analysis conducted in the current research is to show how concepts universal to playing the piano can be drawn from the highlighted excerpts and connected to other works. All this information leads to conclusions which connect the learning process, methodology, and analysis, in order to give educators a new perspective which can result in revitalizing and reenergizing their own teaching, their students' learning, and the world's experience of the music being written today. 


\section{Chapter Two}

\section{An Overview of Conceptual Learning}

As piano teachers, we bring a diverse set of backgrounds and experiences to the profession. Some of us may be education majors; others of us might have stuck strictly to a performance track in our education. Perhaps some of us run our own business teaching privately. Some of us might work in a university setting or another type of musical institution. Some of us might have no higher education in music, but nonetheless are quite adept at playing the piano from our earlier education. For some of us, piano teaching is our sole profession, our primary source of income. Others of us might teach in addition to working in a church setting or perhaps in a music store. Some of us might juggle teaching between an adjunct position in a university and within a home studio. Some of us might not fit any of the descriptions just listed. However, whatever our background or experience, it is important for us and for our students that we have at least some grasp of educational theory. An understanding of even the most basic concepts explained by some of the pioneers of education equips us as teachers with ideas that can help our teaching become more effective and beneficial.

In order to understand "conceptual learning," we must first define what a "concept" is within this context. In an article on educational theory, Professor David H. Jonassen offers several characteristics of a concept. Together these help to provide a larger definition and to provide a framework for further discussion. Jonassen states, "Concepts are the basis for meaning making and communication. Communicating without concepts is impossible." ${ }^{25}$ He continues, "Concepts play essential roles in human reasoning, including categorization, learning, memory, deductive inference, explanation, problem solving, generalization, analogical inference, language

\footnotetext{
${ }^{25}$ David H. Jonassen, "On the Role of Concepts in Learning and Instructional Design," Educational Technology Research and Development, Vol. 54, No. 2 (April 2006): 177.
} 
comprehension, and language production. By partitioning the world into classes, concepts decrease the amount of information that we must learn, remember, communicate, and reason about. ${ }^{26}$ Just by reading these definitions, it becomes easy to see how they might fit into a piano-teaching paradigm. Traits such as categorization, memory, and even language comprehension all are elements that intrinsically help our students better understand the material we teach. For example, the concept of rhythmic notation presents a problem which challenges many students.

To put this into a practical situation, let us imagine teaching students how to count quarter notes, then half notes and whole notes, and later eighth notes and sixteenth notes as five unique and separate ideas. Assuming 4/4 time and beginning with quarter notes, we show our students examples of quarter notes and explain to them that these note values receive one beat or count. We then proceed to teach half notes as double the value of the quarter note and similarly a whole note as double the value of the half note. By halving the value of the quarter note, we are then able to teach the eighth note, and then the sixteenth note. Here there is already a need to show the connection among the different note values, and whereas it is important for a student to understand these relationships, I propose that it is more efficient to examine their relationship from a different presentation of rhythm.

Especially with young beginning students, simply explaining the definition of rhythm is abstract and frustrating. It is possible that the piano lesson is his or her first encounter with this term. Making the abstract tangible to these students is the challenge, and examples which can bridge this gap include the steadiness of a heartbeat, the marching of a band, or even the ticking of a clock. In looking at rhythm this way, students are able to connect this abstract concept with experiences they already find familiar. Once this connection is established, quarter notes can be

\footnotetext{
${ }^{26}$ Ibid., 178.
} 
likened to one heartbeat or one tick of the clock, half notes compared to two heartbeats or steps of the marching band. The same can be done for the other note values as well. Conceptual learning in this case presents the concept of rhythm (which both examples do), but in a relatable way showing how each of these note values is related to something bigger such as the marching of a band rather than focusing on the differences such as note values being doubled or halved. The desired result is the same; however, the manner in which it is taught is more efficient.

From this rhythmic-notation example, the main notion of transfer is not the fact that a student has learned note values, although this needs to happen as well. Rather, the idea of transfer relates to an understanding or comprehension of rhythm. If a student is able have an understanding of rhythm that encompasses a variety of note values, he or she will be more equipped to deal with subsequent pieces. If a student simply learns the value of a quarter note in a piece, he or she will only be able to understand quarter notes until further study reveals other note values, the idea of binary and ternary rhythms, rests, etc. However, if a student is able to see some of these note values under the larger concept of rhythm, this understanding of rhythm can be transferred to any piece which contains similar rhythmic values. The idea of transfer allows a student to take concepts learned from one piece and apply them when working on any repertoire containing those concepts. To facilitate further growth, a simple melody which explores rhythmic values of quarter, half, and whole notes can be used to teach a student rhythm. Once a student has gained this knowledge, he or she can then transfer the learned concept of rhythm to longer or more complex pieces which also feature similar note values.

The more clearly we understand concepts, rather than individual facts, the more effectively we can apply the principles we have learned as we encounter new problems. Jonassen shows exactly why this type of transfer is possible. To understand Jonassen's vocabulary in the 
following excerpt, we need to know what he means by "propositions." On a simple level, propositions, or propositional knowledge, which will be discussed later in this paper, refers to the idea of already-learned knowledge or skills. The basic premise is that education is more effective when new ideas are built upon the foundation of preexisting knowledge, which can be used to create new knowledge and understanding. Again regarding rhythm, relationships are a most effective way to teach the various note values. Using a quarter note as a foundation allows discussion of relationships to other notational values.

This type of teaching is innately linked to teaching rhythm. As a teacher, one could not imagine teaching each note value individually, separate from one another. Rather the quarter note is seen as a type of propositional knowledge and the concept of rhythm is then transferred through teaching various rhythms under which fall other notational values. This type of teaching builds on what a student has previously learned.

To support this idea, I would like to turn to another quote from David Jonassen, first providing a bit of background as context for understanding his thoughts about reasoning. He points out two of the main types of human reasoning. The first he calls "comparison-contrast." The idea here is that we learn from making connections by comparing things that are alike or different. In this type of learning, relationships between traits, such as seeing and comparing the different types of notational values, are how we form new knowledge. The second type of reasoning he refers to is "causal reasoning." Causal reasoning is built largely on the notion of cause and effect. If you press the piano keys, sound will result. Further, the harder and faster you press the keys, the louder the resultant sound. Both types of reasoning are built on the notion of relationships, either to similarities and differences, or to cause and effect. 
Jonassen says, "the process of linking two concepts by a descriptive relationship enables the two most basic forms of human reasoning: comparison-contrast and causal. Rather than teaching concepts as discrete learning outcomes, instructional designers might be better advised to teach propositions, including combinations of concepts and linking relationships. ${ }^{27}$ Here, Jonassen uses the term "concept" in two different ways, one based on comparison and contrast, and the second relating smaller details or components. Nevertheless, what Jonassen is saying is easy to grasp. In music, when symbols such as quarter notes, eighth notes, half notes, etc., are taught in isolation, the learning that may take place is not as effective as what would occur if these means of notation were taught in their relationship to one another. This is not to say we should bombard our students with every type of rhythm initially in order to see the connection. Rather, when a new rhythmic idea is taught, it should be taught within the framework of the concept of rhythm. By linking it to other rhythmic notations with which students are familiar, they can better comprehend the new material by making connections to previous lessons learned. Jonassen says,

"The most legitimate study of concepts should focus on changes in meaning of concepts with conceptual frameworks resulting from conceptual change, because concepts are the cognitive tools for representing ideas and testing relationships, not the object of instruction. Concepts learned in isolation will lack coherence and therefore be less useful than concepts-in-use in thought construction processes. In the processes of conceptual change, the meanings of concepts and their relationships with other concepts change in substantive, functional ways. ${ }^{28}$

By learning in terms of larger concepts, students are better able to understand by making connections to previously-learned material. Learning becomes successfully engaging by pushing a student forward and not simply tedious by learning mere trivia.

\footnotetext{
${ }^{27}$ Ibid., 190.

${ }^{28}$ Ibid., 193.
} 
To make learning these concepts even more effective through the course of a student's study, it is especially important for the teacher to pace the student's learning appropriately, to fit his or her level of understanding. Again, we can consider the example of rhythm: An initial presentation of the concept of rhythm might focus on learning the relationships between quarter notes, half notes, and whole notes. Selecting these note values allows a student to explore a limited selection of different notational values while playing a variety of easier pedagogical pieces. When a student has successfully mastered these notational values, then it would become appropriate to their understanding of rhythm to introduce other values such as dotted rhythms or eighth notes. Breaking a concept up in this way paces a student's progress to allow for growth, while at the same time not being burdened by an overabundance of new information. Pacing also gives a student several opportunities to explore a given concept when new information is added to their understanding, resulting in greater strength and confidence in their ability to tackle a particular musical challenge.

Now that we have established a definition of concepts for the purposes of this study, it is possible to look more closely at what is meant by conceptual learning. For a helpful explanation of conceptual learning, Effie Maclellan, a professor of education at the University of Strathclyde offers, "Conceptual learning is the acquisition and application of new knowledge to result in concepts and symbolic representations not previously in the individual's knowledge network, and would be exemplified in learning the meaning of a new idea, [or] making connections between two previously unrelated ideas. ${ }^{29}$ As this definition implies, the ability for students to engage with new ideas on their own is paramount. Our teaching should ultimately lead to assisting a student to develop ways to learn new material on their own, to be able to transfer what has

\footnotetext{
${ }^{29}$ Effie Maclellan, "Conceptual Learning: The Priority of Higher Education," British Journal of Educational Studies, Vol. 53, No. 2 (June 2005): 135.
} 
already been learned to new repertoire, based on interests of the student and not necessarily assigned by a teacher. Maclellan supports this thought, stating,

"...because the best resource we have for preparing students is our current knowledge, in its many varieties, propositional knowledge would appear to be the most potentially productive, to enable students to create further knowledge as and when new problems arise. In order that students may profit from this propositional knowledge, they must be required to engage in conceptual learning." 30

In the previous example relating to rhythm, propositional knowledge is the body of knowledge, the facts, with which a student is already familiar. By using the examples of a heartbeat, a marching band, and a ticking clock, we as teachers are able to take our students from this propositional knowledge (knowledge about something that exists) to create further knowledge (an understanding of the concept of rhythm). Students who are able to transfer concepts are better equipped to tackle challenges which arise in later study.

One of the major theorists who advocated for conceptual learning is Jerome Bruner. In his book, The Process of Education, he highlights some of the attributes of conceptual learning and why it is important. Bruner offers an excellent example of transferring concepts which relates to language. He says, "The often unconscious nature of learning structures is perhaps best illustrated in learning one's native language. Having grasped the subtle structure of a sentence, the child very rapidly learns to generate many other sentences based on this model though different in content from the original sentence learned." ${ }^{31}$ The same can be applied to music where once a specific concept of rhythm or pitch is learned, it can be applied to all pieces containing that particular concept.

One of Bruner's fundamental beliefs is the premise that learning ultimately must serve the future. This point is demonstrated or proven in a student's ability to transfer concepts. Bruner

\footnotetext{
${ }^{30}$ Ibid., 144.

${ }^{31}$ Jerome Bruner, The Process of Education (Cambridge: Harvard University Press, 1999), 8.
} 
gives two ways in which learning serves the future. The first way "is through its specific applicability to tasks that are highly similar to those we originally learned to perform." ${ }^{32}$ The second "is through what is conveniently called nonspecific transfer or, more accurately, the transfer of principles and attitudes. In essence it consists of learning initially not a skill but a general idea which can then be used as a basis for recognizing subsequent problems as special cases of the idea originally mastered." ${ }^{33}$ In music this can be seen by examining again the concept of rhythm. If quarter notes are taught, for example, without having explained rhythm, the skill seems rather abstract. Furthermore, there becomes no basis or point of comparison when teaching half notes, whole notes, and other rhythmic durations. When examined initially from the premise of rhythm, all of these different music durations can be seen as variants of one another, and the connectedness can be highlighted. The general concept is learned before the details.

For further evidence of the importance of learning the overarching concepts before the details, we need turn once again to Bruner. He offers, "Perhaps the most basic thing that can be said about human memory, after a century of intensive research, is that unless detail is placed into a structured pattern, it is rapidly forgotten. Detailed material is conserved in the memory by the use of simplified ways of representing it." ${ }^{34}$ In the case of our notational durations, the structured pattern is rhythm and the detailed material lies in the individual durations such as the eighth note, the quarter note, and the whole note. Further examples of these structures will be highlighted in the following chapter.

Bruner offers some guidelines which may help us as we design curricula for our students. He says, "Teaching specific topics or skills without making clear their context in the broader

\footnotetext{
${ }^{32}$ Ibid., 17.

${ }^{33}$ Ibid., 17.

${ }^{34}$ Ibid., 24.
} 
fundamental structure of a field of knowledge is uneconomical in several deep senses." He then goes on to provide examples of why this is true.
"In the first place, such teaching makes it exceedingly difficult for the student to generalize from what he has learned to what he will encounter later. In the second place, learning that has fallen short of a grasp of general principles has little reward in terms of intellectual excitement. Third, knowledge one has acquired without sufficient structure to tie it together is knowledge that is likely to be forgotten." 35

When students are able to make some of these connections themselves, there is an excitement related to a feeling of accomplishment. This excitement will likely transfer to more curiosity and deeper interest in the subject at hand.

Before discussing in depth how this works with musical concepts encountered in pieces by two composers from the United States, it should be demonstrated that conceptual learning and transfer is indeed a part of learning music. To help illustrate this point, two psychologists, Caroline Palmer and Rosalee K. Meyer, conducted a study which shows how details are transferred in music, specifically in piano playing. Their study assesses the differences in conceptual and motor learning. The study involved several different exercises that subjects were required to play, and the findings state, "transfer was greatest when the conceptual melodic relationships were retained across sequences, regardless of whether the hand and finger movements remained the same." ${ }^{36}$ Furthermore, their findings suggest, "Musicians' transfer of learning across novel melodies indicates that as skill increases, mental representations for performance become dissociated from the movements required to produce a musical sequence; advanced performers' mental plans are based on abstract, conceptual pitch relations." ${ }^{37}$ Because

\footnotetext{
35 Ibid., 31.

${ }^{36}$ Caroline Palmer and Rosalee K. Meyer, "Conceptual and Motor Learning in Music Performance," Psychological Science, Vol. 11, No. 1 (January 2000): 65.

${ }^{37}$ Ibid., 66-67.
} 
of the complex nature of music, pianists need to find ways to simplify all the material which they are performing. By breaking material into concepts, pianists are more able to digest the wealth of information and material presented to them.

As piano teachers, it is up to us to instruct our students as to the necessary concepts which are intrinsic to playing the instrument. Each of us likely has a particular curriculum which we use with our students. This might be in the form of a particular method or perhaps a combination of supplementary materials in addition to particular repertoire. However, the intentions are all likely the same —we desire that our students learn the skills necessary to play the piano. The following chapter takes many of the ideas presented here regarding conceptual learning and shows how they can be applied specifically to learning piano music. It also offers a discussion of reasons for why we should focus on conceptual learning, not only for transfer of skills, but also because this type of learning can reshape the way we as teachers teach our students. 


\section{Chapter Three}

\section{Bringing Educational Theory to the Piano Studio}

Because piano teachers have access to numerous method books that introduce many musical terms and symbols in a sequential fashion, we run the risk of being bound to a style of teaching that zeros in only on a specific new idea being introduced. For example, a method book might contain a unit which focuses on the sixteenth note. This method series might present several pieces, exercises, rhythmic activities, and theory sheets all relating to the idea of sixteenth notes. We as teachers help our students to understand how these notes are counted and later played. As soon as the unit is over, however, we move on with the next new lesson to be introduced. The disadvantage here is that students may become overwhelmed by the vast amount of material presented to them. Trying to recall a particular term from a previous lesson might be difficult for students, especially if there was a significant time lapse since the topic was discussed.

Pianist and educator Guy Duckworth highlighted in an article a different way of looking at teaching new material. This paradigm shift requires looking at how material is related and how ideas remain similar. Duckworth says, "There are probably more constants than variables in piano education; or more simply, in any kind of learning." ${ }^{38}$ As teachers, it becomes our responsibility to simplify material for our students by showing how things are not so different, but rather, how they are connected. Duckworth continues, "Our organization of materials determines to a great extent whether we teach trivia or concepts which are valid throughout a piano student's life, whether he is professional oriented or not." ${ }^{39}$ He goes on to suggest, "Without this overall, embracing viewpoint, the child by necessity learns one scale at a time, one

\footnotetext{
${ }^{38}$ Guy Duckworth, "What Are We Teaching - Concepts or Details?" Clavier 3, no. 3 (1964): 45.

${ }^{39}$ Ibid., 45.
} 
note at a time, one finger at a time, one note value at a time, even one chord at a time. Trivia, indeed." ${ }^{40}$ Pianist and teacher Sylvia Coats echoes this sentiment, stating, "The elements of music are too often taught as individual facts without regard for transfer to other music.

Presenting the elements to students in a conceptual manner will allow them to apply the concept to any music." ${ }^{41}$ In our method-book example, when these materials are presented simply in sequential order with students having to recall previous material learned in an earlier unit, the study of piano does seem to be more about recalling trivia than learning how to become musicians.

Fortunately, there are many ways to re-examine how we teach new material to our students. Coats gives teachers a way of dividing all the material required of piano students into large conceptual categories. Taught within such a framework, a student is able to learn about a given concept and how it relates to other learned material which relates to this concept. Once this is understood, a student is then able to take this knowledge and transfer it to the exploration of other pieces. Coats highlights eleven concepts that are learned in music study and fall into three main categories. These categories include: basic, aesthetic, and technique. Under the basic category fall the concepts of pitch, rhythm, texture, scale, form, and tension/release. In the aesthetic category lie dynamics, articulation, and tempo. Finally in the technique category fall the concepts of topography and technique - use of fingers, hands, arms. ${ }^{42}$ Seeing these concepts broken up into categories is more clearly illustrated in Table 3.1.

\footnotetext{
${ }^{40}$ Ibid., 45.

${ }^{41}$ Sylvia Coats, Thinking As You Play (Bloomington, IN: Indiana University Press, 2006), 30.

42 Ibid., 30.
} 


\begin{tabular}{lll}
\hline Basic & Aesthetic & Technique \\
\hline Pitch & Volume & Topography \\
Rhythm & Articulation & Use of fingers, hands, arms \\
Texture & Tempo & \\
Scale & & \\
Form & & \\
Tension/Release & \\
\hline
\end{tabular}

Table 3.1 Eleven Musical Concepts ${ }^{43}$

When these eleven concepts guide lesson planning for our piano students, it becomes easier to see how a student is better able to assimilate information and relate it to other similar ideas, rather than having to digest an overabundance of new material from week to week, presented within each unit of a particular method book. To further illustrate how this conceptual learning can play out in music, Coats presents the following example:

"Learning the facts of quarter notes and letter names on the staff is secondary to understanding the structure of a melody as it ascends and descends in even or uneven rhythm patterns. Structural awareness invokes an aural and emotional response to the music. For instance, if a student is listening to even rhythm patterns of a processional as he plays, he is more likely to respond to the noble character of the music. If the student is only concerned with the fact that each quarter note gets one beat, then he probably will have no emotional reaction to the rhythm." 44

To summarize, when a student is able to see the bigger picture of the music, of the concept, and of the relationships, more successful understanding is likely to result. When music is simply about regurgitating facts, it is more difficult for a student to understand their application.

\footnotetext{
${ }^{43}$ Ibid., 30

${ }^{44}$ Ibid., 29.
} 
Piano teacher and author Beth Gigante Klingenstein affirms this concept-based approach to teaching. She states, "Being a piano teacher involves more than teaching pieces; students need to be taught the many skills involved in becoming an independent, disciplined, and creative pianist." ${ }^{45}$ This requires much more thought on the teacher's part than simply guiding students through a method book. Klingenstein continues, "When less time is spent teaching individual pieces and more time is devoted to teaching important skills, students actually learn all pieces faster and better." ${ }^{46}$ Another way of looking at this statement is that, as teachers, we are giving our students a set of tools and concepts which enable them to construct the music largely on their own. Once students are able to understand a particular concept, they will be able to negotiate a recurrence of that concept which manifests itself in a wide array of repertoire. In this light, conceptual teaching is much more efficient and gives students the ability to overcome many more obstacles on their own.

Used appropriately, a concept-based style of teaching allows educators to be creative in designing curriculum. In understanding how concepts transfer between pieces, it is not necessary for a teacher to guide a student through a collage of Beethoven, Haydn, and Mozart sonatas. Rather, once a student understands the language presented in a given sonata, he or she will be able to transfer that knowledge to other similar sonatas. This gives teachers and students the freedom to explore a wider array of musical styles and composers. For example, attention can be given to contemporary pieces, to women composers, or perhaps to composers from a particular continent or country. The specific area explored is irrelevant, as skills learned in one piece can be transferred to another.

\footnotetext{
${ }^{45}$ Beth Gigante Klingenstein, The Independent Piano Teacher's Studio Handbook (Milwaukee, WI: Hal Leonard Corporation, 2009), 191.

${ }^{46}$ Ibid., 191.
} 
Scott McBride Smith offers a perceptive analysis of how we as teachers can find new and exciting repertoire for our students.

"Lovers of visual art know the excitement of the new: discovering a unique artist, a fresh viewpoint, and different media. They don't mind studying, either. It's our job as teachers to foment a revival of this spirit, especially in our piano students. The excitement of discovery, a perception of discouraging "strangeness" that yields to a thrilling insight, and performances reflecting individual intuition and creativity all need to be part of learning the piano. This experience does not necessarily have to be with exclusively "new" composers, an impossibility in a field of artistic endeavor like ours in which the "new" is often eighty years old, or more. Today's students know little of human character and imagination as reflected in art, and of the historical context in which this occurs. Many young students do not view artists of the past as being like themselves in any way. It's our job to change this." ${ }^{47}$

Smith charges us as teachers with instilling in our students not just the ability to play the standards, but rather to kindle in them a passion and love for music. He shows us the depth and breadth of the keyboard repertoire available to us as pianists and challenges us to look at it and explore it even further than we already do.

For me, this has meant engaging with the music of contemporary composers. Classical music is not something only of the past. It is not a relic which is to be preserved in museums. It is a body of music that is alive and organic. It continues to shape our world and our profession even today. Contemporary music did not cease with composers such as Bartók and Debussy. Wonderful music continues to be written, even at this very moment, by composers like Lowell Liebermann and William Bolcom, among many others. As teachers, it is our calling to find and explore this new literature. It is up to us to share it with our students. It is our mission to discover this new and engaging music with our students, to further the music being played today, and to keep the spirit of classical music alive and well in our world.

\footnotetext{
${ }^{47}$ Marienne Uszler, Scott McBride Smith, and Stewart Gordon, The Well-Tempered Keyboard Teacher (New York: Schirmer, 1999), 154.
} 
The following chapters will highlight three contemporary collections of works by Lowell Liebermann and William Bolcom. Examples will be drawn from these pieces showing how concepts can be analyzed. The analysis of these compositions will be followed by a brief summary of how these concepts can be transferred to other piano literature. The pieces contained in the Liebermann set, Album for the Young, present a variety of repertoire to students of different levels. Some of the first pieces of Album for the Young are definitely suitable for students who can play from Notenbuch der Anna Magdalena Bach by J.S. Bach or Bartók's third volume of Mikrokosmos. Later pieces from Liebermann's Album for the Young might better be suited for more-experienced students who are at an advancement level at which they can handle some of the Chopin waltzes or perhaps some of the preludes by Debussy. The difficulty range of these pieces is quite large; however, when selected appropriately, they offer students a collection of miniatures from which to draw during several years of piano study.

Bolcom's Monsterpieces have a slightly smaller range of difficulty. The brevity of many of the pieces, together with the frequent repetition of patterns, makes this collection of pieces suitable for students who are ready to play from Burgmüller's Op. 100 collection or the second volume of Bartók's Mikrokosmos. Similarly, the first pieces of Bolcom's Seven Easy Piano Pieces are suitable for students who can play from the Op. 100 set by Burgmuller or the first several volumes of Bartók's Mikrokosmos. Some of the later pieces in this collection are slightly more difficult and would provide a good bridge as preparatory works for some of the Chopin waltzes or the Bach inventions.

However, all three of these collections give students the opportunity to explore art music by American composers who are writing music today. These collections have the ability to 
inspire some students and to fill a niche for those who have the desire to connect to the classical music of today. 


\section{Chapter Four}

\section{Lowell Liebermann and Album for the Young}

One of the most well-known and well-published composers alive today is Lowell Liebermann. Liebermann was born in New York City in 1961. At a fairly young age, he took both piano and composition lessons. When he was only sixteen years old, he made his performing debut at Carnegie Hall. He holds three degrees from the Julliard School of Music and has had his works performed by other great artists including Sir James Galway and Stephen Hough. He has received numerous commissions and awards, one of the most prestigious being the American Composers' Invitational Award by the 11th Van Cliburn Piano Competition. He writes for a variety of mediums including opera, orchestra, chamber ensemble, voice, and solo instruments. Especially popular is his piano work Gargoyles, which has been recorded over fifteen times. ${ }^{48}$ Liebermann continues to compose works both for solo instruments and also for larger ensembles. Hints of Romanticism come out in his works with a tonality that is, although somewhat dissonant, captivating for both performers and audiences alike.

Within his compositional output for solo piano, works that that are frequently performed include Gargoyles, several of his nocturnes, his piano sonatas, and his set of impromptus, to name a few. Each of these works is highly demanding for the pianist.

However, Liebermann has written one collection of works which stands in contrast to the difficulty of those previously mentioned. His collection Album for the Young Op. 43, composed in 1993, represents a successful attempt at writing with an intermediate-level piano student in mind. This work comprises 18 short pieces ranging in difficulty, offering intermediate students a chance to experience contemporary-sounding music on a difficulty level which they can manage. Each of the 18 pieces includes a title; these range from the traditional ("Toccata," "Dance," etc.)

\footnotetext{
48"Lowell Liebermann::Biography," accessed Dec. 4, 2013, http://www.lowellliebermann.com/biography/index.html
} 
to the unconventional ("Funeral March for a Pet Rat"). Each of these pieces is sure both to delight and also to challenge students in their exploration of present-day literature while teaching those concepts which are universal to all piano works. The following analysis does not present a traditional theoretical breakdown of these individual works; rather, it discusses pedagogical concepts for how they can be used effectively in the piano studio.

\section{Analysis of Album for the Young}

The first piece of this set, "Dance," is a great introductory piece for students to develop an understanding of different sonorities, articulation, phrasing, and structure. On the surface it seems particularly easy; however, there is a lot of music packed into this eleven-measure work. The piece is largely based on the following figure:

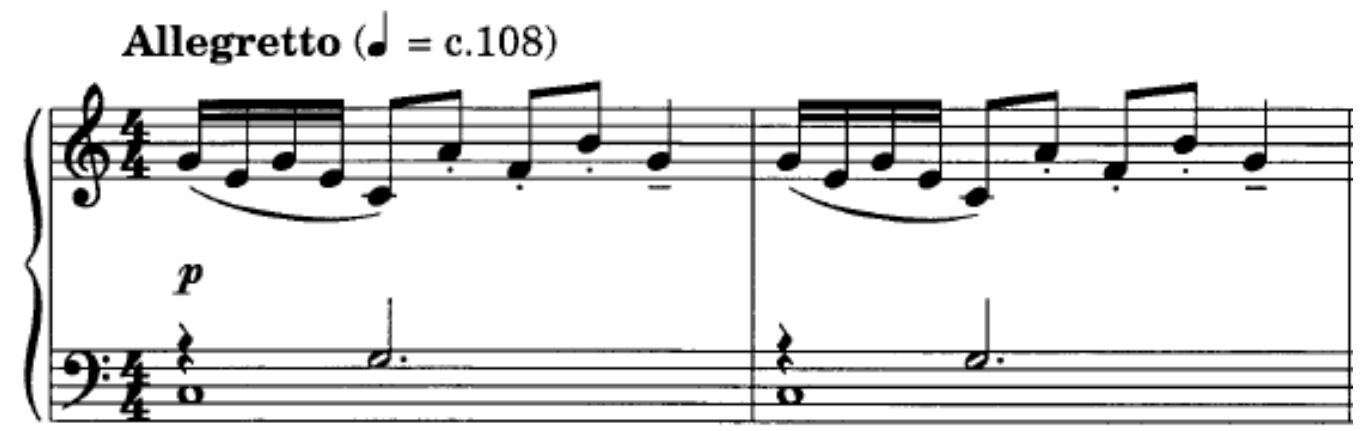

(C1994 by Theodore Presser Co., Used With Permission

Example 4.1. Lowell Liebermann, "Dance" from Album for the Young, mm. 1-2. ${ }^{49}$

The piece exposes students to varying sonorities in the key of $\mathrm{C}$ major. The left hand for the most part consists of the figure presented above. However, in mm. 3-4 the right hand presents its material in an F Major triad; this gives the student a mild taste of bitonality, which is a frequent style feature in Liebermann's works.

\footnotetext{
${ }^{49}$ Lowell Liebermann, Album for the Young (King of Prussia, PA: Theodore Presser Company, 1994), 3.
} 
As a whole this piece prepares a student for certain musical elements, especially those surrounding articulation, rhythm, dynamics, and technique, although more are obviously applicable. In looking at these first two measures, one thing that immediately stands out is the articulation marks. This piece forces a student to shift quickly from legato to staccato and then to a slightly accented beat four with the tenuto mark. M. 7 of the work requires the performer simultaneously to play a legato left hand while the right hand retains a staccato figure similar to the first half of mm. 1 and 2. Rhythmically, this piece poses a challenge as well for a student. He or she must be able to mark the alternation of sixteenth, eighth, and quarter notes precisely in order to retain the dance-like feeling of the piece.

Dynamically the piece contains only three markings: piano, poco forte, and a return to piano. Two diminuendo marks are also used. Although this appears almost simplistic, these dynamics are vital to the form of this piece and to the way the individual phrases work together as one cohesive unit. A student needs to understand the entire dynamic plan of the piece so that the dance is not fragmented. To assist a student in achieving the desired unity and dance quality of the piece, proper technique is required. The alternating skips up and down are especially important in that they present a great study for the student to practice the concept of technique through rotation.

The second work of this collection is entitled "Song." In this piece, a student is able to explore contemporary sonorities while learning elements of phrasing, form, dynamics, texture, and voicing. The melodic material of the first two measures presents a question which is answered in the next two measures of music. The first whole phrase then consists of the first four measures, followed by a second four-measure phrase of similar rhythm and melodic contour. The form of the piece can be considered a miniature ternary or ABA form. This form is not so much 
based on the rhythm, but rather on the dynamic shift and textural changes which occur at $\mathrm{m} .9$ and then return to the original presentation at $\mathrm{m}$. 17 . The piece challenges the student to be aware of the sound, especially on the softer side of the spectrum. There is no written dynamic level above piano in the whole piece, except for the result of a crescendo. This will give developing students an exercise focused on sounding each of the notes present in the composition.

The crux of "Song" lies in the texture. The work beings with a monophonic single melodic line. However, in mm. 3 and 4, a bass voice produces an interesting contrapuntal line. This texture marks what can be considered the A section of the piece.

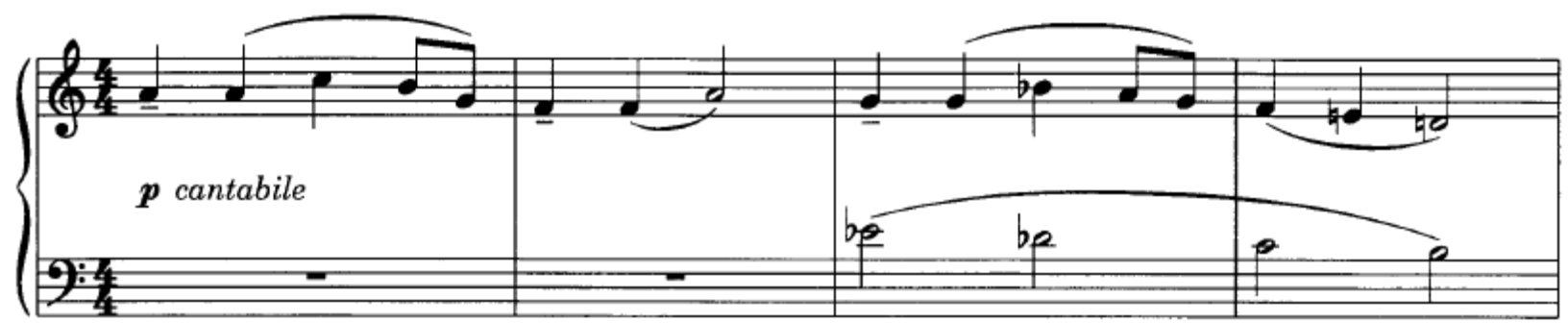

(C)1994 by Theodore Presser Co., Used With Permission

Example 4.2. Lowell Liebermann, "Song" from Album for the Young, mm. 1-4. ${ }^{50}$

The B section includes a similar rhythmic conception, but the texture reveals a three-part chorale.

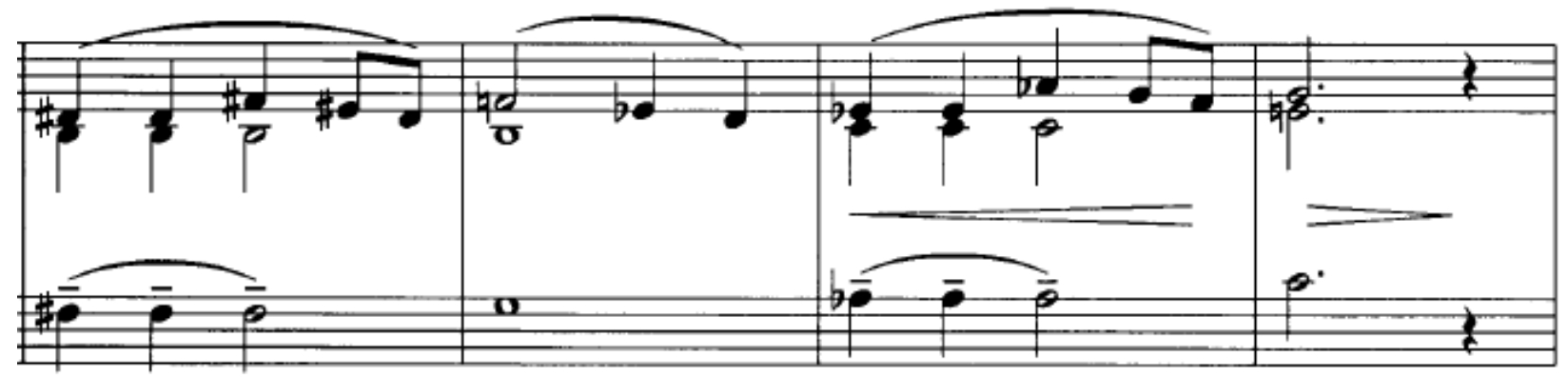

C1994 by Theodore Presser Co., Used With Permission

Example 4.3. Lowell Liebermann, "Song" from Album for the Young, mm. 11-14. ${ }^{51}$

\footnotetext{
${ }^{50}$ Ibid., 4.

${ }^{51}$ Ibid., 4.
} 
In this example, one can clearly see the similar rhythmic values, but with a thicker texture than the previous example. This really presents the student with a challenge in voicing, especially because, as the texture becomes thicker, the dynamic level becomes softer. Another challenge is to bring out the upper voice in the chorale section. However, in playing both the monophonic and contrapuntal sections, a student has already become familiar with the basic melodic shape of the piece and will likely know what the melody should sound like above the other voices.

"Endless Melody" is the title of the third piece of this set. The main challenges found in this composition include key/pitch and rhythm. However, the piece is relatively simple in texture and form. The left hand relies mostly on chromatic motion, with only a few deviations away from this pattern. The right hand provides the melodic material for the work and gathers complexity as the piece progresses, revealing more accidentals towards the end. In looking at the rhythmic breakdown of the piece, the dotted eighth notes followed by the sixteenth notes provide a challenge for the student, especially since the dotted eighths are almost always carried over from a previously tied note. The performer needs to keep the rhythmic pulse going. Adding to the rhythmic motion of this composition is the meter, $6 / 8$. Since $6 / 8$ is a compound meter, this piece should be counted in two pulses per measure, rather than six pulses, to propel the motion forward with a slight lilt. 


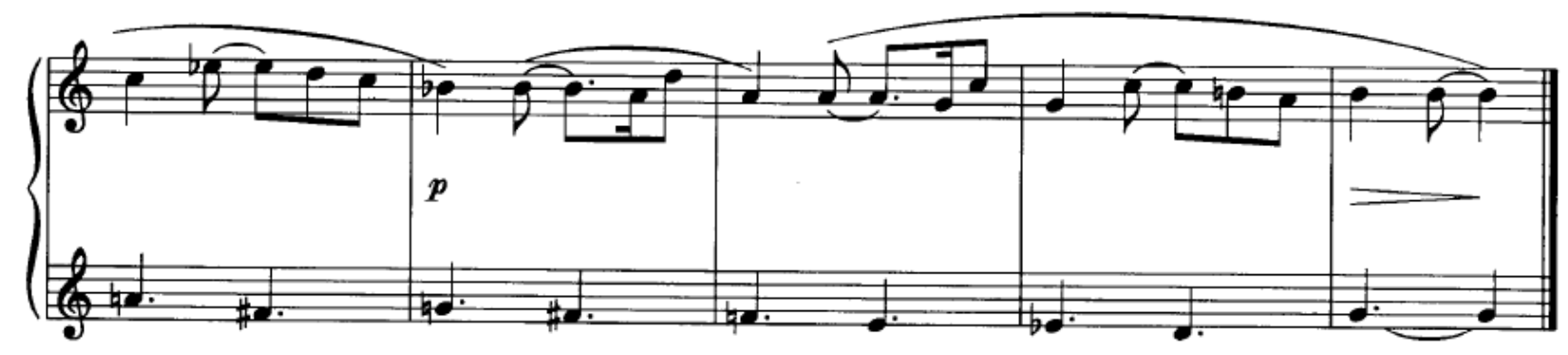

(C)1994 by Theodore Presser Co., Used With Permission

Example 4.4. Lowell Liebermann, "Endless Melody" from Album for the Young, mm. 13-17. ${ }^{52}$

The fourth selection from Album for the Young is a fun and exciting piece, sure to be popular for students. Entitled "Boogieman," it is slightly more difficult than the three previous pieces. Challenges encountered in this work include pitch, articulation, phrasing, and dynamics. The pitch content of the piece is loaded with various accidentals throughout. In contrast with the first piece of the set, which contained zero accidentals, "Boogieman" will definitely test a student's reading skills.

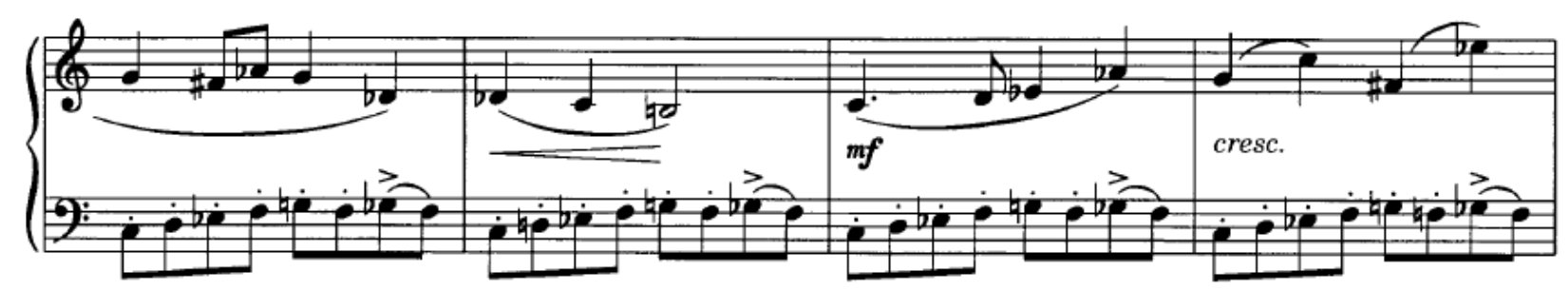

C191994 by Theodore Presser Co., Used With Permission

Example 4.5. Lowell Liebermann, "Boogieman" from Album for the Young, mm. 4-7..$^{53}$

The preceding excerpt not only shows the accidentals which may pose difficulty for a student's initial reading, but also highlights a variety of different articulations required for a successful performance of the piece. The two-note slurs, the accents, and the legato against the staccato present obstacles to be overcome by the student; fortunately, the left hand is fairly repetitive. The last half of the piece reverses the challenge, presenting the figures in opposite hands.

\footnotetext{
${ }^{52}$ Ibid., 5 .

${ }^{53}$ Ibid., 6.
} 


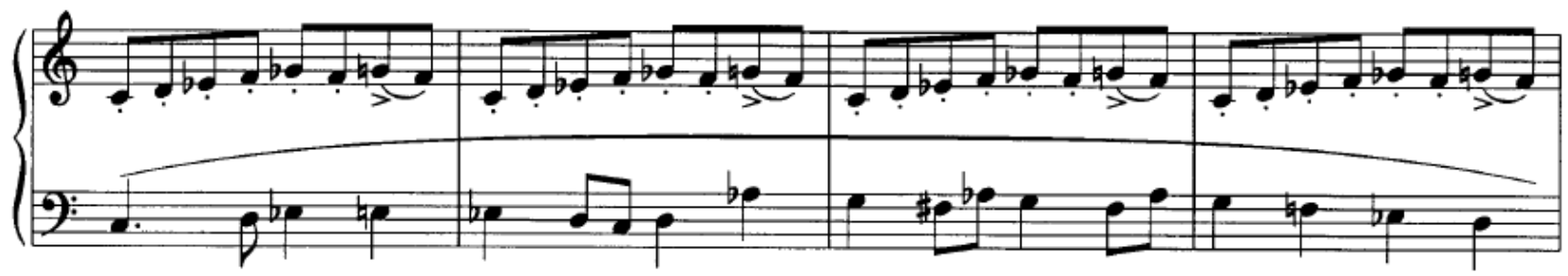

C1994 by Theodore Presser Co., Used With Permission

Example 4.6. Lowell Liebermann, "Boogieman" from Album for the Young, mm. 15-18. ${ }^{54}$

The other difficulty surrounding this shift is the slight change in beats three and four. The initial presentation of this material puts the $G$ natural on beat three and the $G$ flat on beat four. In the second half, this pattern is reversed and the performer needs to take special note of this shift in pitch.

Much of the phrasing of "Boogieman" is traditional, consisting mostly of four-measure units. The middle portion of this work differs slightly, but the regular four-bar phrasing returns at the end of the work. The difficulty lies not in how to find the phrases, but rather in how to shape them. Some phrases end with a written crescendo, as in m. 5, at the end of the first phrase.

Others reveal more obvious high and low points. However, the primary difficulty of this shaping lies in the fact that it appears with a pattern in the opposite hand that often demands contrasting articulation. Independence of the hands is a technique necessary to facilitate appropriate phrase shaping in this composition.

Finally, the dynamic content of this piece presents a broad spectrum ranging from pianissimo to forte and perhaps beyond, depending on the volume of the accents. To present a convincing picture of the idea of a scary boogieman, the performer must not be timid about exaggerating the range of dynamics, to depict the appropriate amount of dynamic color and drama demanded in this composition. "Boogieman" gives an instructor the opportunity to teach

\footnotetext{
${ }^{54}$ Ibid., 6.
} 
all of these musical elements within the framework of a piece bearing a name to which students are certainly able to connect. The idea of a boogieman offers students a more concrete image to portray musically than perhaps a bagatelle or a minuet; such titles are more abstract to today's piano students.

The fifth in this series of pieces is entitled "Ghost Waltz"; at least in title, it appropriately follows "Boogieman." Difficulties a student might encounter in this work lie mostly in the concepts of voicing, rhythm, dynamics, and articulation. Regarding other concepts such as pitch and texture, this piece is relatively simple, giving the student the ability to focus on the other technical demands of the piece. The first of these lies in the voicing. The following two passages show how the melody shifts between the hands in the beginning and ending sections of this composition.

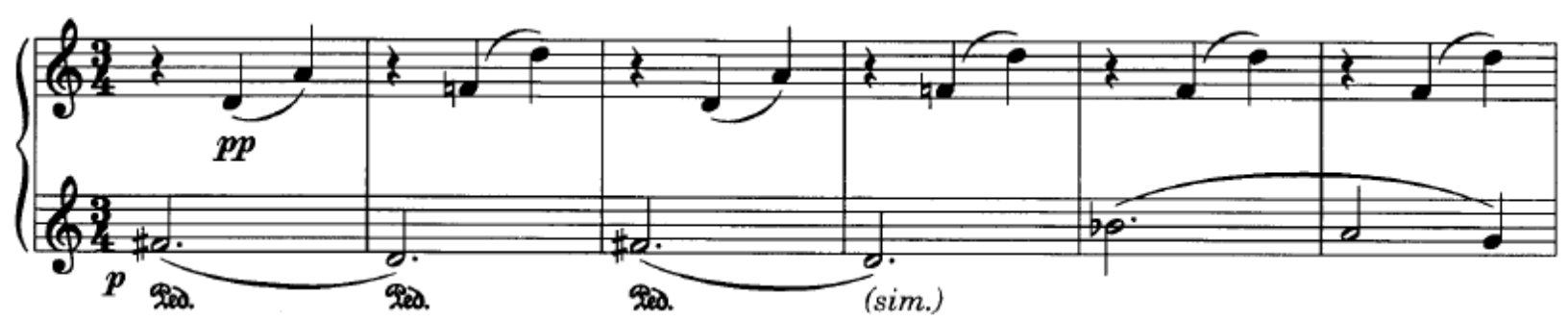

(C)1994 by Theodore Presser Co., Used With Permission

Example 4.7. Lowell Liebermann, "Ghost Waltz" from Album for the Young, mm. 1-6. ${ }^{55}$

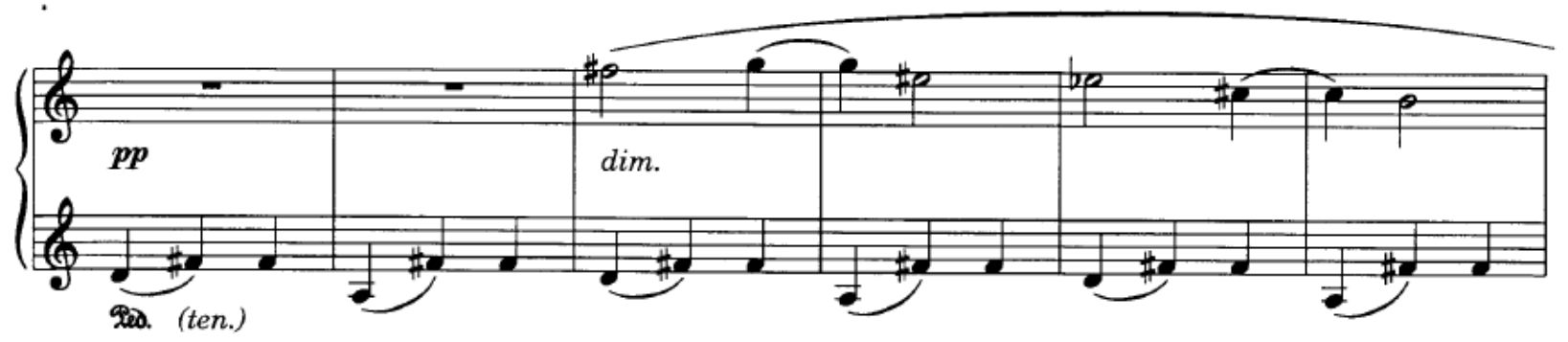

(C)1994 by Theodore Presser Co., Used With Permission

Example 4.8. Lowell Liebermann, "Ghost Waltz" from Album for the Young, mm. 25-30. ${ }^{56}$

${ }^{55}$ Ibid., 7. 
The voicing is not the only change that contrasts the beginning and the end of "Ghost Waltz." Rhythmically the feeling of the piece changes here in the second example as well. Although the left hand continuously retains the three-beat waltz pattern throughout, beginning in m. 27 the right hand shifts into a hemiola feeling, again necessitating hand independence in order to ensure the appropriate rhythmic character in the second half of the piece.

With the exception of m. 17, the entire piece contains no dynamic level above piano, requiring extreme control by the performer; the softest dynamic indication is pianississimo. Fortunately, the texture is thin enough that the performer can often concentrate on single notes, to produce a very soft and subtle sound that illustrates the phantasmal qualities of this waltz.

Finally, a student who engages with this piece must be able to feel the waltz pattern throughout the piece. Rather than playing each of the three beats equally, the student must feel the first beat of each measure more strongly, with the successive two beats being subordinate to the first. The articulation, as seen in the two excerpts above, helps to facilitate successful performance of this waltz pattern in its presentation of melodic material almost always on beat one, especially in the opening section. The two-note slurs, when appropriately performed, will give a lifting feeling and help to present the dancelike quality of the waltz.

The sixth piece in the set bears the title, "Ostinato." While neither melodic nor harmonic patterns are repetitious in this piece, the ostinato pattern could be considered a reference to the four-note figure in the left hand, which does indeed maintain a continuous pattern until the end of the work. Technical challenges in this work mostly appear in the concepts of rhythm and phrasing; other elements of the piece such as dynamics, articulation, and pitch are fairly straightforward.

\footnotetext{
${ }^{56}$ Ibid., 7.
} 
Under the concept of rhythm falls the use of meter. In "Ostinato," Liebermann chooses to present a study in 5/4, a meter not often encountered in the method books many students utilize. This gives the student a chance to explore an unfamiliar rhythmic feeling within the confines of an unchanging pattern. To further the rhythmic complexity of this piece, the student is usually unable to simplify the piece into either a three-plus-two or two-plus-three rhythmic formula, due to the fact that the left hand is divided into three plus two and the right hand melody is almost always in two plus three. Trying to simplify the meter, however much it might help the student, would disrupt the overall flow of the piece.

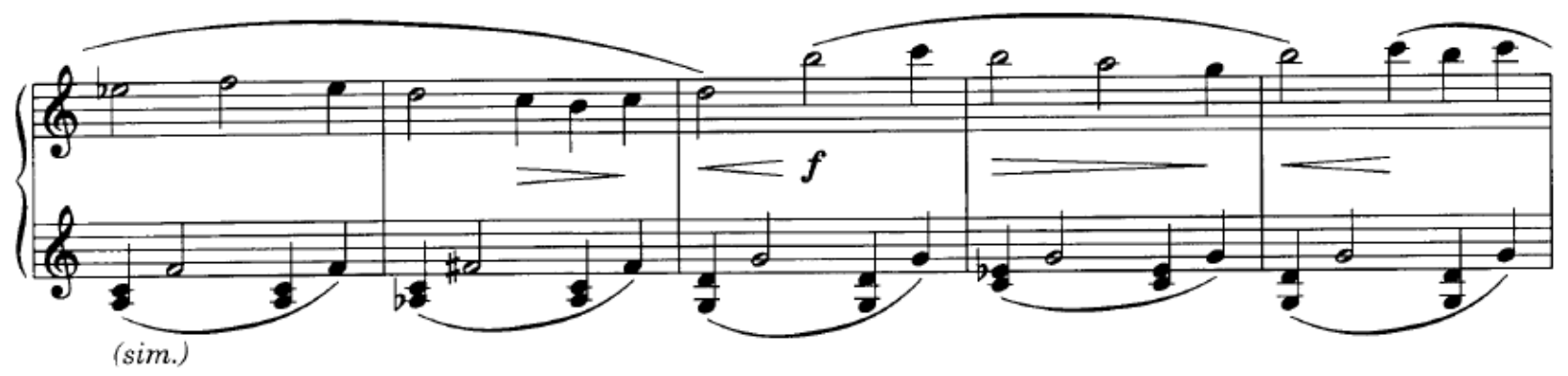

(C)1994 by Theodore Presser Co., Used With Permission

Example 4.9. Lowell Liebermann, "Ostinato" from Album for the Young, mm. 7-11. ${ }^{57}$

Although this work is largely a rhythmic study, the rhythmic pattern should not get in the way of the melodic line presented throughout. From the figure presented above, slurs, dynamic markings, expression markings like crescendos and diminuendos, and pedal all contribute to a very lyrical atmosphere in the piece. Because of these elements, it is important that a performance of this piece not be solely concentrated on rhythmic accuracy, but rather that the rhythmic motion be secondary to the lyrical nature of the melody.

Piece number seven, "Marching Off to War," is definitely a study and puzzle in rhythmic accuracy and precision. The march-like nature of the piece is marked by the initial directions

${ }^{57}$ Ibid., 8. 
sempre $\boldsymbol{f}$ e meccanico or "always loud and mechanical." With a marching tempo, this piece is certain to give students an exciting and challenging piece. Concepts which will likely pose obstacles for students include dynamics and technique, rhythm, and pitch.

I have included dynamics and technique together in this analysis because the two really go hand in hand. In many of the other pieces examined, dynamics leaned toward the softer side of the spectrum. However, this piece requires a very marked and pointed, almost percussive, sound. Dynamics range from forte to fortissimo with accents and sforzando marks abounding. In order to achieve such a loud and percussive sound (the staccato articulation also contributes to this) a student will need to understand how to play with a significant amount of arm weight. To portray the marching effect, a full sound with arm weight is necessary, and simply playing with fingers will probably cause the performance to sound shallow or thin.

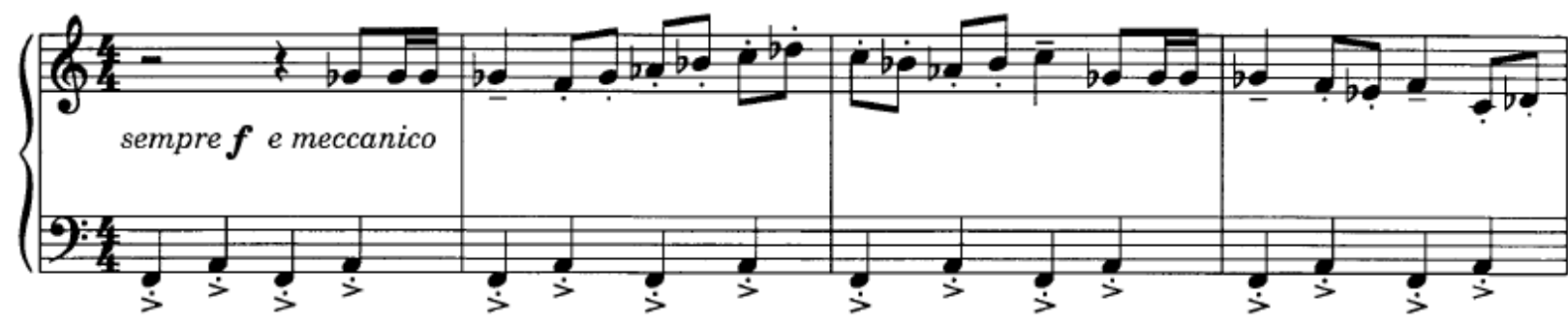

(C1994 by Theodore Presser Co., Used With Permission

Example 4.10. Lowell Liebermann, "Marching Off to War" from Album for the Young, mm. 1-4. ${ }^{58}$

As Example 4.10 shows, the piece appears relatively straightforward rhythmically, but Liebermann does present significant rhythmic challenges later in the piece. The following example presents a rhythmically complex portion of the piece which will likely require some additional attention on the part of the student.

${ }^{58}$ Ibid., 9 


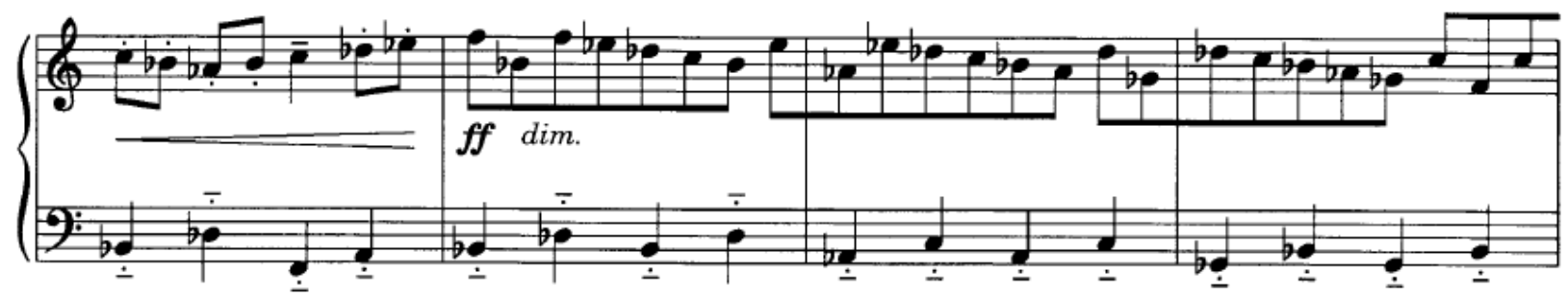

(C)1994 by Theodore Presser Co., Used With Permission

Example 4.11. Lowell Liebermann, "Marching Off to War" from Album for the Young, mm. 13-16.

Beginning in $\mathrm{m} .14$, the right hand initiates a seven-note sequence which continues through $\mathrm{m}$.

17. Because the pattern does not last the full measure, the beginnings of this sequential pattern occur on weak beats and do not always come together with the left hand, making the coordination of both hands together slightly more challenging than the previous material.

A final conceptual challenge of the piece surrounds the notion of pitch. From the two excerpts presented here, it is clear that a student will need to be aware of the abundance of flats throughout this composition. This will present an excellent study not only in awareness of accidentals but also in how the hand and fingers feel on the black and white keys together. This concept will definitely familiarize a student with the topography of the piano's keyboard.

The eighth piece, entitled "Rainy Day," presents a study in several concepts that are necessary for playing the piano musically. These concepts include phrasing, technique, texture, and articulation. Like several of the other pieces dynamically, "Rainy Day" falls on the softer side of the spectrum. However, the majority of technical difficulties of this piece can be seen in just a few lines. The phrases are mostly of traditional length, so shaping them is not extremely difficult. The problem occurs when the hands work together, especially since, compared to the melodic material, the accompaniment is often thicker in texture, higher in register, and faster in rhythmic motion. To shape the melody successfully within the phrases, the student should play just the melody in order to hear the sound and feel the shape for which he or she is striving. 


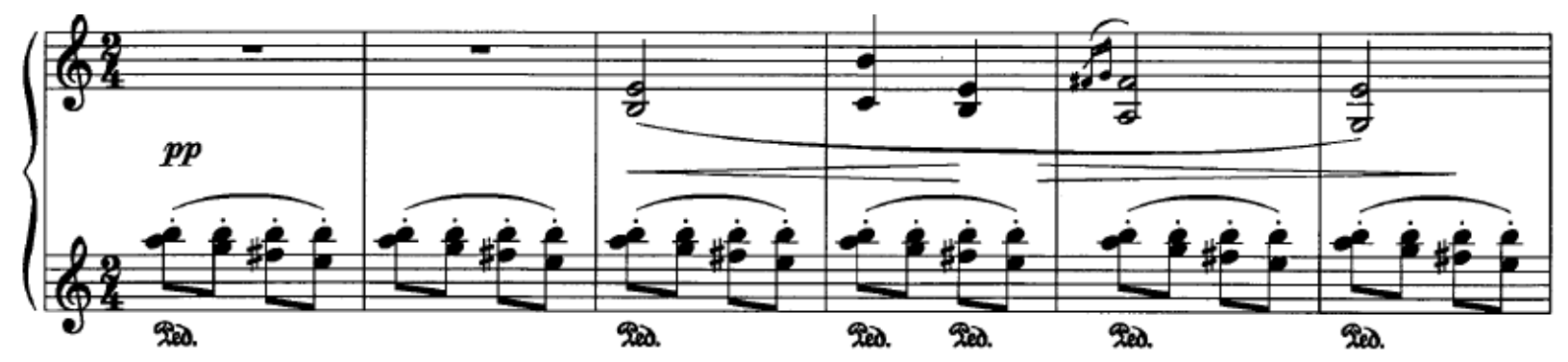

(C1994 by Theodore Presser Co., Used With Permission

Example 4.12. Lowell Liebermann, "Rainy Day" from Album for the Young, mm. 1-6. ${ }^{59}$

Also revealed in this excerpt is the technical difficulty that hand crossing presents for a student. To become comfortable with the arms on top of one another is a challenge a student will likely encounter throughout his or her playing career. The entire first half of the piece presents the left hand playing the accompaniment figure above the right hand's melodic line. This switches midway through the piece where the left hand takes over the melodic material and the right hand plays the accompaniment figure. This also poses a challenge for a student, not only technically, but also in terms of voicing. The follow excerpt shows this reversal.

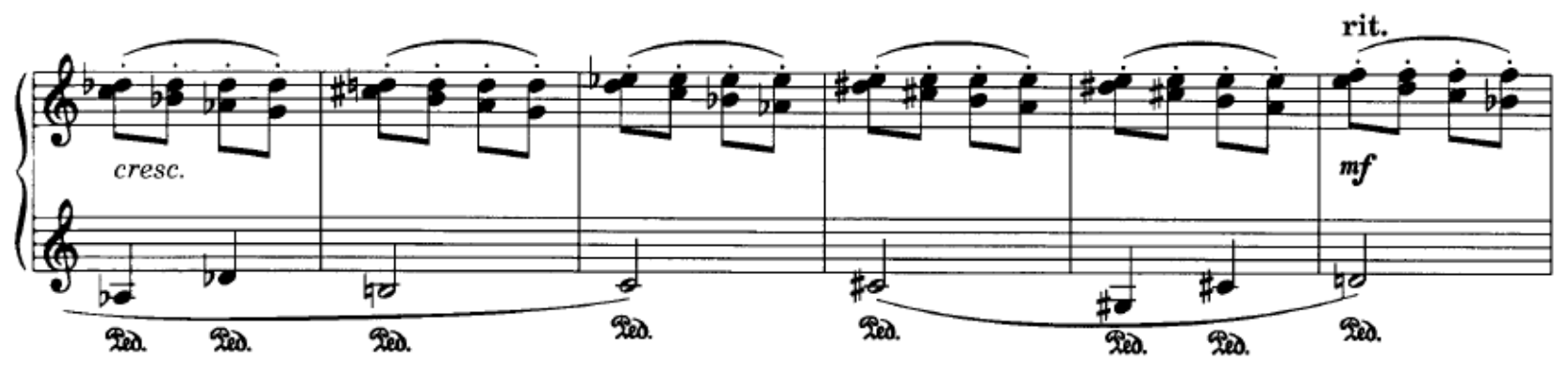

(C1994 by Theodore Presser Co., Used With Permission

Example 4.13. Lowell Liebermann, "Rainy Day" from Album for the Young, mm. 20-25. ${ }^{60}$

It is already evident from the discussion of this piece that many of the conceptual difficulties are woven together and build upon each other, resulting in a layering of challenges for the student. In this discussion lies texture as well. In these two excerpts, one quickly realizes

\footnotetext{
${ }^{59}$ Ibid., 10.

${ }^{60}$ Ibid., 10.
} 
that there is a slow-moving melodic figure which is harmonized with various intervals. In addition a new layer of moving eighth notes hovers above the melody. The texture presents the student with an obvious study in voicing. In order to play this piece successfully, a student must decide which voices are most important and which are simply there to create effect. Once these decisions are made, practice should be focused on simplifying the figures to make that voicing possible. This piece will challenge the student's listening skills.

A final obstacle for the student to deal with in "Rainy Day" is articulation. Pedal markings are numerous throughout the work. In addition, the directions for the accompaniment figure present a slur line over staccatos. It seems as though Liebermann is creating a type of atmosphere with this articulation above the accompaniment that is neither completely staccato nor legato. Rather, using one's imagination, the accompaniment figure should imitate a soft rain gently landing, neither harsh and pointed, nor smooth and connected.

Although there are many musical details in this piece, the title "Rainy Day" can certainly stimulate a student's imagination when performing it. A connection to the idea of rain can be made with the descending intervals. Challenging a student to imitate rain drops can help to promote the gentleness of the portato indication suggested in the notation. Furthermore, the grey and gloomy atmosphere of a rainy day can be connected to the somber ambiance called for in this composition. Again, the titles which Liebermann uses in this collection of works help to draw out the student's musicality through concrete ideas called for in the performance of these works.

The ninth piece of this collection is "Broken Heart." In this work, Lieberman challenges the student to explore the concepts of rhythm, phrasing, and dynamics. In this miniature, a student needs to incorporate all the nuances of these concepts in order to convey the emotional 
character of this piece. Romantic in nature, the piece requires an understanding not simply of the notes, but also of music as a language, in order to illustrate effectively the sadness and songlike nature of the work.

From the beginning of this short composition, the student is immediately challenged rhythmically. The following example instantly reveals this challenge.

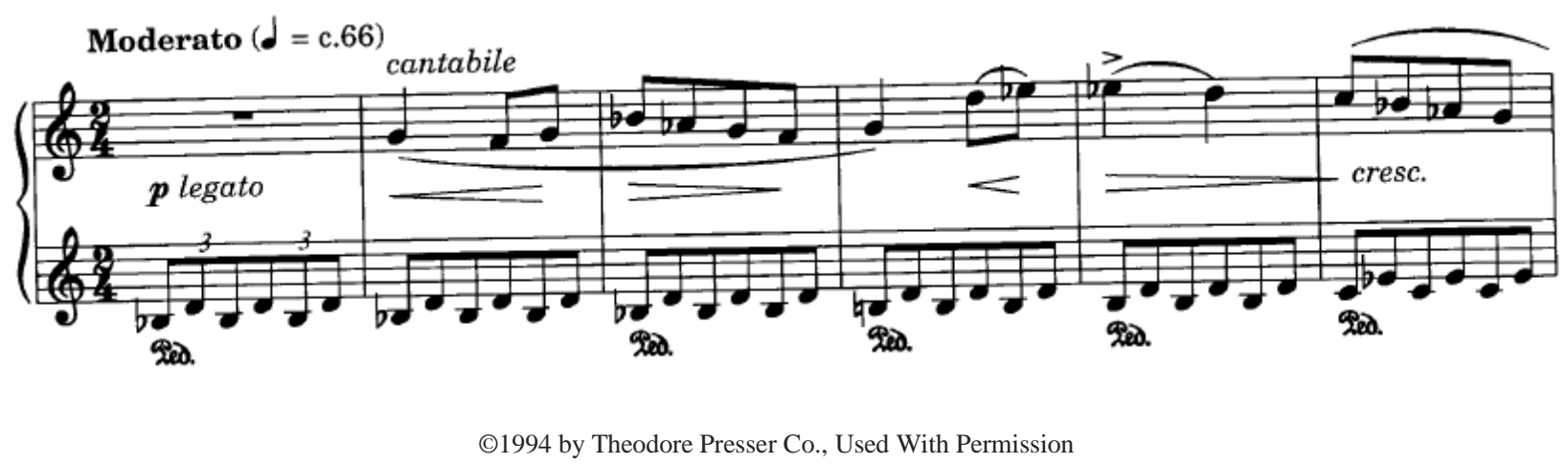

Example 4.14. Lowell Liebermann, "Broken Heart" from Album for the Young, mm. 1-6. ${ }^{61}$

The left hand comprises a constant triplet figure which persists throughout almost the entire work, while the right hand is divided in a duple formula. This gives student and teacher the opportunity to explore the concept of polyrhythm (in this case three against two) within a relatively slow meter with a simple melodic line. Because of this, the student has a chance to hear and feel how the notes fit and work together.

Once comfort in this technical challenge is established, additional attention should be given to the phrasing and voicing of the actual melody. The line is marked cantabile, requiring a lyrical and songlike simplicity. The other concept explored in this piece, dynamics, also contributes to the phrasing and voicing of the work. Within the first line of the piece, the dynamics and expression marks change six times. All of these expression and phrase marks serve to highlight the importance of the melody. This is especially critical so that a student's

\footnotetext{
${ }^{61}$ Ibid., 11.
} 
concentration on putting the polyrhythmic complexity together does not overshadow the main melody of the piece. Proper attention given to these details will prevent the piece from sounding mechanical and thought out, and can result in a lyrical and emotional performance.

Piece number ten, "Lullaby," represents a study primarily in the concepts of articulation, pitch, and phrasing. The first several measures of this slow and serene composition serve to set the ambiance of the work, especially its mood and sonorities. The challenges presented in the first several measures largely focus on articulation. Important for proper performance are an understanding of pedaling as well as a full grasp of the downward and upward motion of a twonote slur. These two concepts run throughout the entire composition and are vital in keeping the unhurried and lyrical mood of the lullaby.

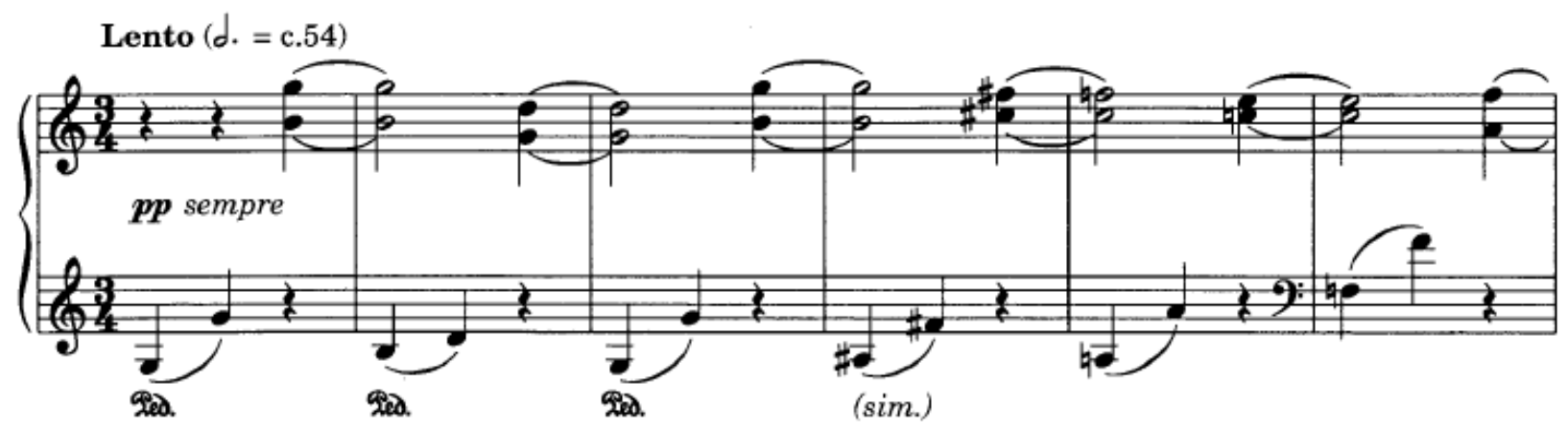

(C)1994 by Theodore Presser Co., Used With Permission

Example 4.15. Lowell Liebermann, "Lullaby" from Album for the Young, mm. 1-6. ${ }^{62}$

A second concept explored by this short work is the idea of pitch. An initial examination of this first excerpt shows the use of several accidentals which may or may not challenge a student. An additional challenge regarding pitch appears in the harmonic language of the piece. A harmonic analysis of the entire composition reveals a language unlike music of the eighteenth and nineteenth centuries, which relies heavily on the idea of tonic and dominant. The harmonic motion of this piece seems to meander without a definite destination in mind, with an almost

\footnotetext{
${ }^{62}$ Ibid., 12.
} 
dreamlike quality. The piece gently flows through and explores many different sonorities which reveal color changes and feelings rather than a specific harmonic direction. The following excerpt, in which an actual melody joins in the texture, further shows Liebermann's lack of concern with functional harmony in this piece.

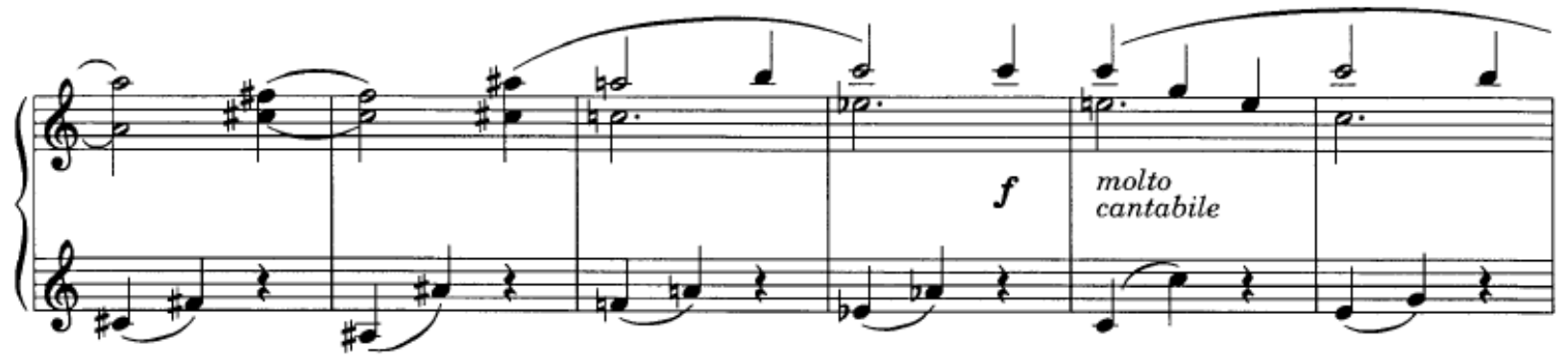

(C1994 by Theodore Presser Co., Used With Permission

Example 4.16. Lowell Liebermann, "Lullaby" from Album for the Young, mm. 19-24. ${ }^{63}$

Further examination of both these excerpts shows how the piece will challenge a student's understanding of phrasing. As already discussed, the articulation of the two-note slurs contrasts with the continuity presented in the longer phrases of the right hand. This is especially prevalent in mm. 20-24 and beyond. A student will be required to balance the lyrical phrases of the right hand against left-hand passagework which is much more separated. Hand independence will be critical so that the left hand can play the role of accompanist to the melodic material presented above. It is only when all of these concepts can be accomplished successfully that a polished performance of this piece can result.

The eleventh piece of the collection, "Starry Night," is one of the most interesting, especially in the rhythmic devices and contemporary sonorities it explores. Building upon concepts already explored in previous pieces, "Starry Night" reinforces and explores concepts of rhythm, pitch, phrasing, and dynamics. From the onset of the piece, a challenging polyrhythm is at play, featuring a duple-over-triple pattern which continues throughout the work, much like the ${ }^{63}$ Ibid., 12. 
previous piece, "Broken Heart." This polyrhythm is not an isolated challenge within the work, but rather includes elements of phrasing and dynamics all bound together. Whereas "Broken Heart" allowed a measure of triplets to establish the tempo and rhythmic pulse of the piece, "Starry Night" demands the simultaneous presentation of melody and accompaniment. The following example shows this complexity.

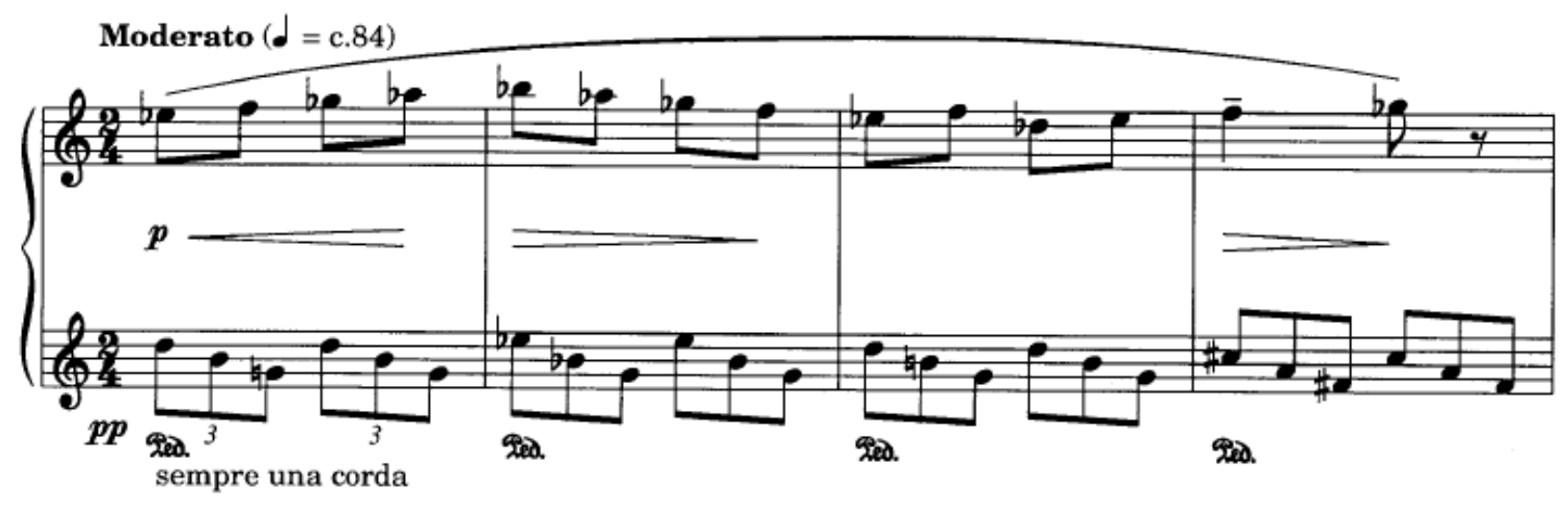

(C)1994 by Theodore Presser Co., Used With Permission

Example 4.17a. Lowell Liebermann, "Starry Night" from Album for the Young, mm. 1-4. ${ }^{64}$

Subdividing each beat into groupings of six pulses, the smallest common denominator of the right hand and left hand combined, will help to ensure that a student understands how these rhythms fit together accurately. The following figure shows how this can be done.

${ }^{64}$ Ibid., 14. 


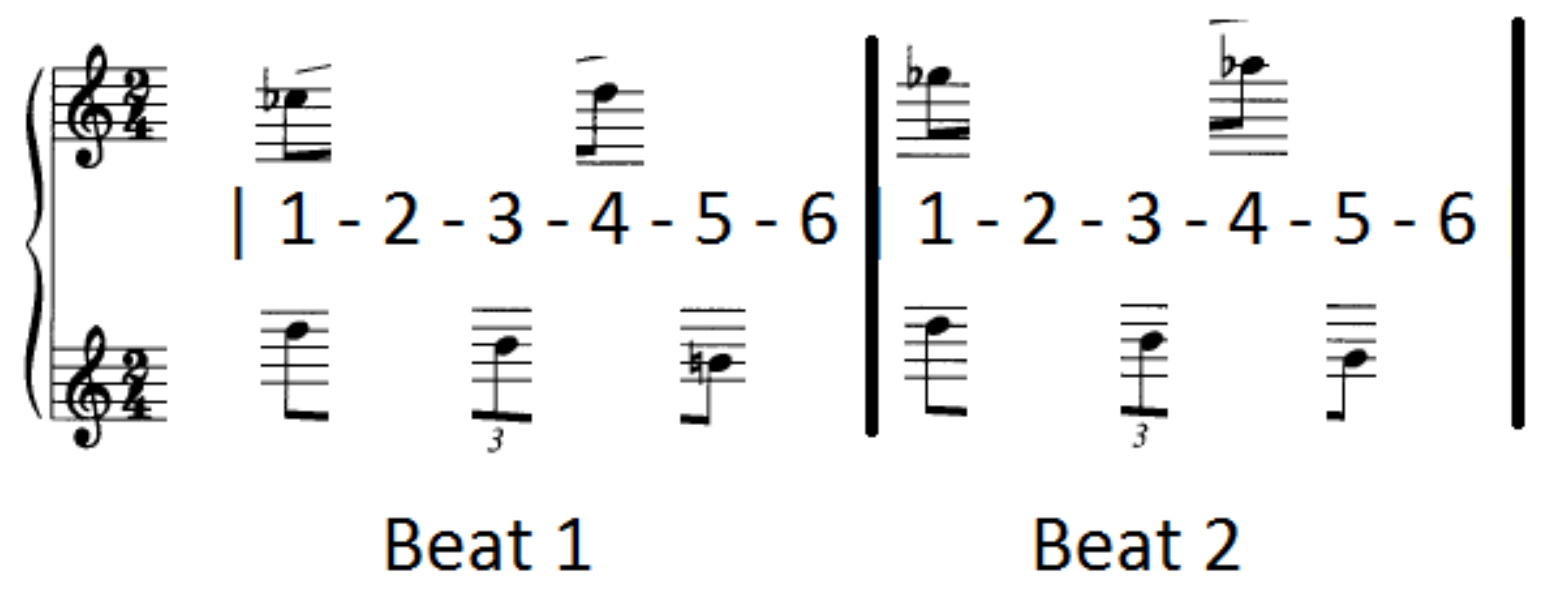

(C)1994 by Theodore Presser Co., Used With Permission

Example 4.17b. Lowell Liebermann, "Starry Night" from Album for the Young, m. 1 subdivided. ${ }^{65}$

By breaking the measure up in this way, a student's rhythmic understanding will be ensured as they will have experienced how each hand works together and the proper placement of the eighth note within the sixteenth-note accompaniment.

Regarding the pitches of this piece, the student will definitely be exposed to sounds which are likely to be unfamiliar and to harmonies which present the contemporary technique of bitonality. The first four measures help to illustrate this point. In looking at the left hand alone in mm. 1-4 for example, it becomes apparent that bar by bar the harmonic outline is as follows: G Major, E-flat Major, G Major, F\# minor. However, the melody of the right hand appears in E-flat minor, which presents some interesting sonorities that include several unique dissonances. $\mathrm{Mm}$. 5-8 continue to show this type of bitonality.

${ }^{65}$ Ibid., 14. 


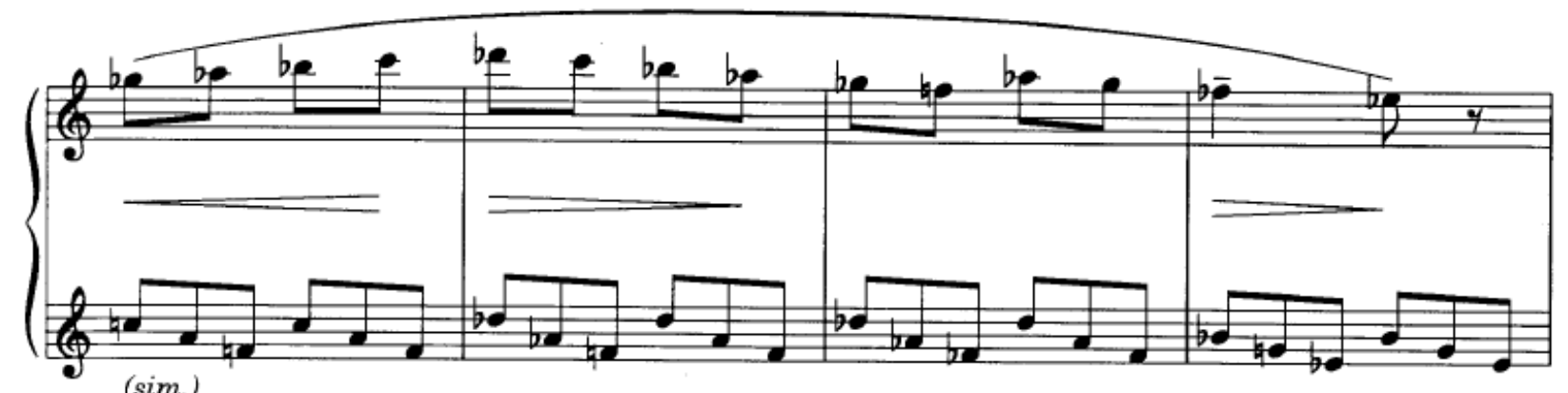

C1994 by Theodore Presser Co., Used With Permission

Example 4.18. Lowell Liebermann, "Starry Night" from Album for the Young, mm. 5-8. ${ }^{66}$

The left hand continues through the following progression: F Major, D-flat Major, D-flat minor, E-flat Major. The right hand here gives the student the opportunity to work with a G-flat Lydian mode, an exploration of the concept of scale, with some alterations at the end of the phrase. Similar figures continue throughout the piece, presenting a beautiful study in contemporary sonorities.

Going hand in hand with the pitch structure of this work is the concept of phrasing. The following two excerpts present traditional four-bar phrases. Moreover, these phrases complement one another, especially if one looks at how they end. The upward motion at the end of the first phrase is resolved by the downward motion at the end of the second. Subsequent phrases in this piece vary in length, but all contain similarities and connections that reveal a larger unity in the overall work. Phrasing presents another technical challenge related to the rhythmic motion of the piece. So that the piece does not just sound like a study in polyrhythm, a student must understand and be comfortable with the shaping of the phrases. Each phrase is to sound natural over the triplet accompaniment presented in the opposite hand. Only then can the sparkle of the melody be fully realized.

\footnotetext{
${ }^{66}$ Ibid., 14.
} 
A final conceptual challenge of "Starry Night" concerns the dynamics. The majority of this work falls into the soft end of the spectrum. The only dynamic marking on the first page of this work is piano; however, there are also twelve different crescendo or diminuendo markings, demanding that a student be in tune with the overall dynamic shape of this piece. Assisting a student in achieving the soft sound is Liebermann's directive sempre una corda at the beginning of the work, requiring the use of the soft pedal throughout the entire piece. Even in light of this, "Starry Night" will definitely challenge and increase a student's ability to work within the soft end of the dynamic spectrum.

"Hommage à Fauré" marks the twelfth piece of this set. This is the first of two compositions in Album for the Young which refer to other composers. The idea of referencing other composers (whether in title or in musical quotation) is something largely reflective of postmodern composers and is found in several works not only by Liebermann, but also in works by John Corigliano and George Crumb, among others. The piece contains a rhythmic pattern which repeats throughout the majority of the melodic figure. Rhythm and pitch are two concepts which will challenge a student who is learning this work.

The majority of the work reveals a relatively simple triple meter. The melody presents a dotted quarter note followed by three eighth notes which aim toward the next dotted quarter note. This rhythmic pattern forms most of the melody. 


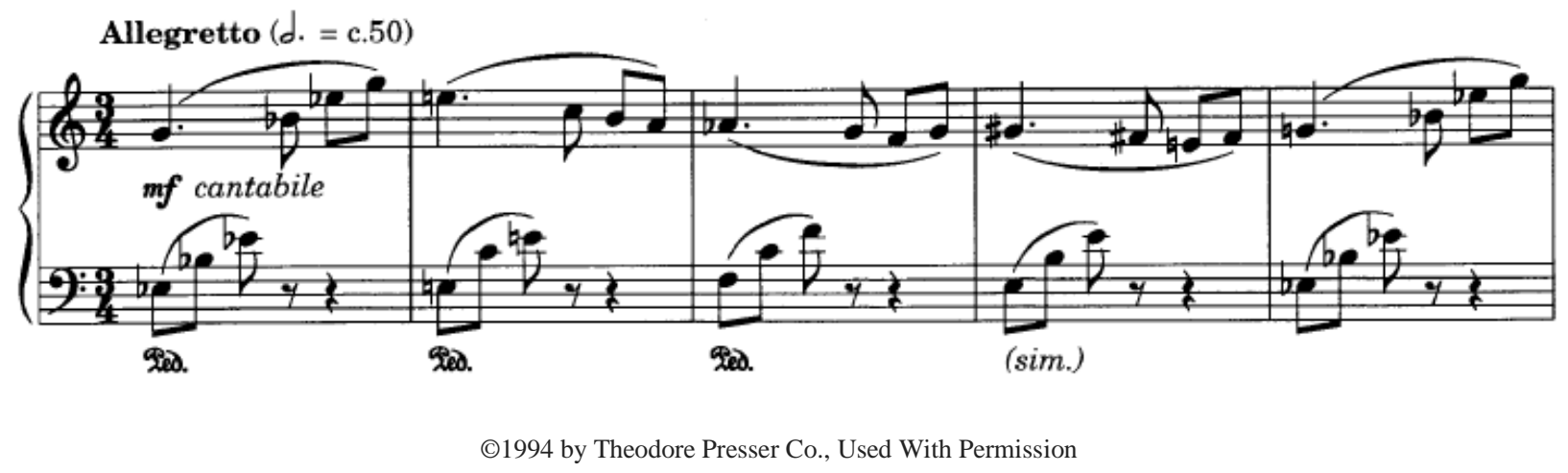

Example 4.19. Lowell Liebermann, "Hommage à Fauré" from Album for the Young, mm. 1-5. ${ }^{67}$

A complex rhythmic challenge to the student begins at $\mathrm{m} .13$, where the triple feeling gives way to a hemiola pattern, causing a sudden duple feeling for this portion of the piece.

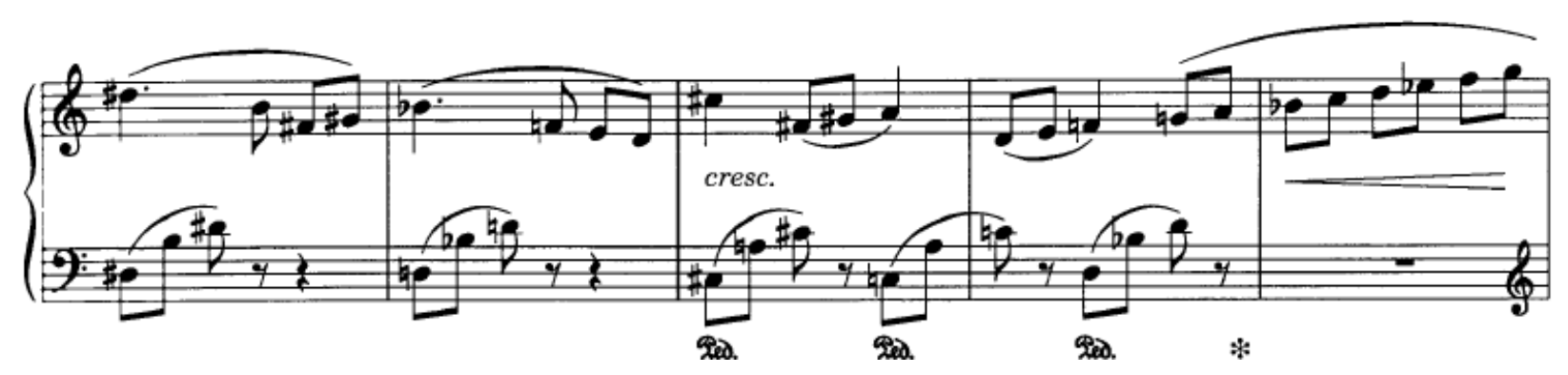

(C)1994 by Theodore Presser Co., Used With Permission

Example 4.20a. Lowell Liebermann, "Hommage à Fauré" from Album for the Young, mm. 11-15. ${ }^{68}$

This hemiola pattern is trumped by the return of the triple feeling as at the beginning, but then returns again in the last few bars of the piece. The approach to this technical challenge needs to be seamless and natural, so that the feeling of rhythmic change does not sound forced or abrupt.

Regarding pitch, multiple accidentals appear throughout the work, again presenting a particular challenge to a student's note-reading ability. Functional harmony is again a compositional element that is largely abandoned in favor of a harmonic language focused on effect rather than tonicity. The harmony is not inserted randomly, though. A brief examination of the initial pitches found in each measure of the left hand reveals a motion that may be helpful to

\footnotetext{
${ }^{67}$ Ibid., 16.

${ }^{68}$ Ibid., 16.
} 
a student's understanding of pitch. The following figure presents the initial notes of the harmony in the left hand for the first 14 measures, notated here in dotted half notes.

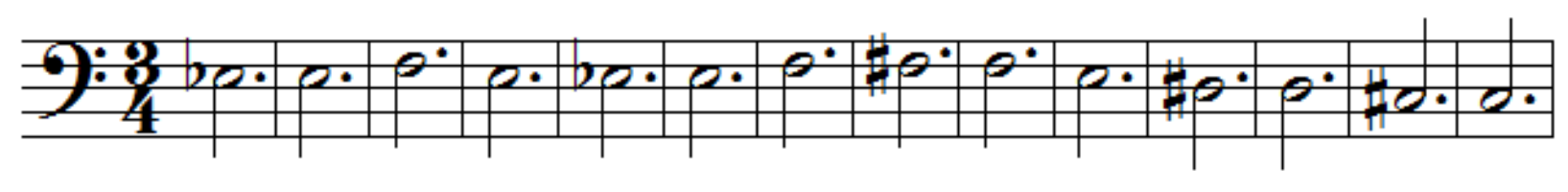

(C1994 by Theodore Presser Co., Used With Permission

Example 4.20b. Lowell Liebermann, "Hommage à Fauré" from Album for the Young, mm. 1-14 (bass notes). ${ }^{69}$

From this figure, what is apparent is the entirely chromatic nature of the line. In the second half of the piece, other chromatic motion is also prevalent, although it does not always occur in the bass voice. This small key holds the secret for unlocking the pattern behind the harmonic language. By seeing these relationships, a student becomes better able to understand that the harmony is not simply a series of random chords, but rather a process.

Piece number thirteen is entitled, "Funeral March for a Pet Rat." The imaginative title of this piece as well as the somber mood might resonate with students who have faced the loss of a pet. This connection may mark a point of departure for the teacher and student to discuss how to interpret this piece. Like almost every piece encountered in the collection thus far, this title again suggests an idea which can draw the student into the music. Many students will bring a vivid imagination to the task of portraying a funeral march for a beloved pet. This composition is one of only a few encountered so far with a three-voice texture. Concepts explored in this work include not only texture, but rhythm as well. The piece also explores the topography of the piano, placing before the performer a variety of intervals which alternate between black and white keys.

Regarding texture, Liebermann employs a primarily contrapuntal fabric, although disguised at times, throughout this piece. One might be tempted to examine the main melody and see how it is played out throughout the work, but a more fruitful approach to understanding

${ }^{69}$ Ibid., 16. 
Liebermann's voicing is to begin with the bass voice. The following excerpt shows how the contrapuntal lines are established in this work, shedding some light as to how this piece is constructed.

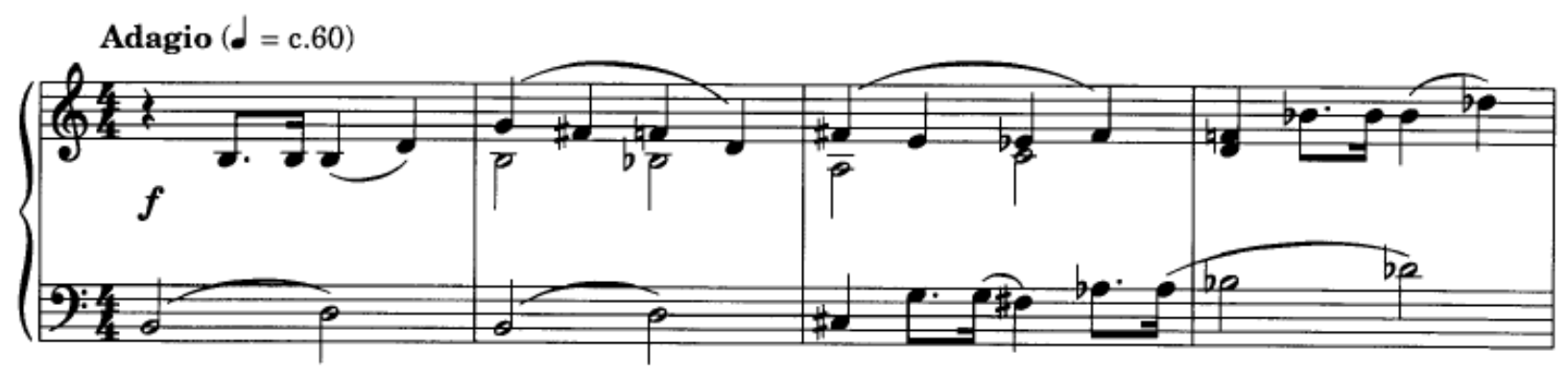

(C)1994 by Theodore Presser Co., Used With Permission

Example 4.21a. Lowell Liebermann, " Funeral March for a Pet Rat " from Album for the Young, mm. 1-4. ${ }^{70}$

In this example, the bass voice begins with a series of half notes and then continues with a quarter, followed by a dotted-eighth-and-sixteenth figure. Similar motion occurs in the alto voice, beginning in $\mathrm{m} .2$, and again in the tenor voice, in $\mathrm{m}$. 4 . The following example shows the same measures, but with these voices highlighted.

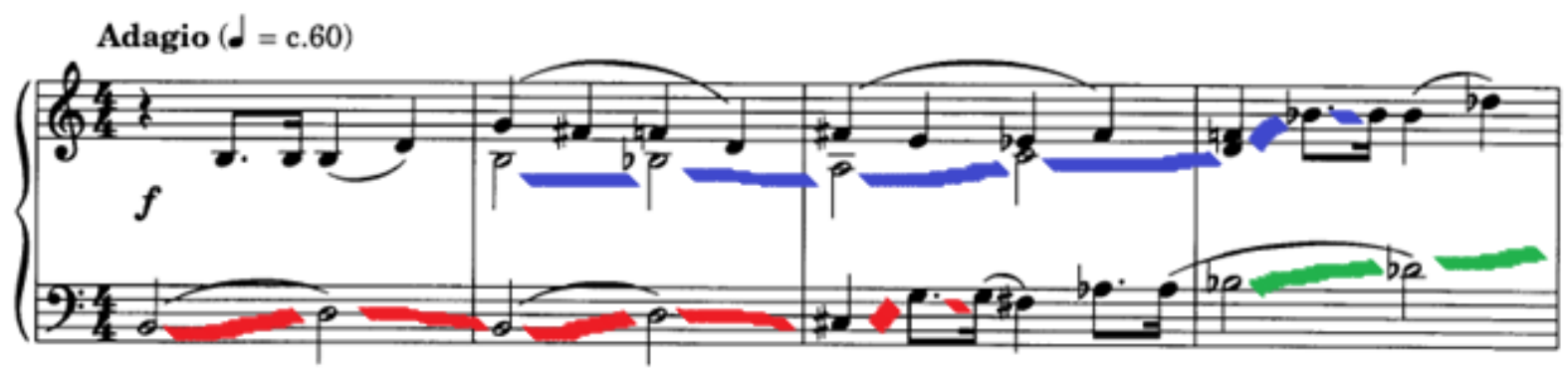

(C)1994 by Theodore Presser Co., Used With Permission

Example 4.21b. Lowell Liebermann, "Funeral March for a Pet Rat" from Album for the Young, mm. 1-4. ${ }^{71}$

The different colors show the direction of the individual voices. The bass voice (in red) spells out the main figure which is utilized throughout the piece, both in its entirety and in fragments. The

\footnotetext{
${ }^{70}$ Ibid., 17.

${ }^{71}$ Ibid., 17.
} 
alto voice (in blue) presents the same rhythm just heard in the bass, eventually continuing into the soprano voice. The tenor line, starting in $\mathrm{m} .4$, is picked up by the alto voice in $\mathrm{m} .5$; other portions of the rhythm enter as a previous voice stops. Seeing these individual voices will help a student both to hear and to play this work more accurately and musically.

The rhythmic challenge of the piece is fairly obvious from the example already given. It is critical that a student play the dotted eighth and sixteenth notes accurately. Especially within a slow tempo, if this rhythm is not played precisely, it can resemble a triplet, uncharacteristic of the march-like quality that this piece conveys. Exercises in counting and subdivision will help a student in his or her preparation of this piece.

The three-voice texture of "Funeral March for a Pet Rat" creates some harmonic and intervallic relationships which give the student an opportunity to explore the topography of the keyboard. Proper fingering will need to be worked out so that a student is comfortable with the technical challenges. Practicing the piece at a faster tempo can help a student with this fingering in that it forces a student to make the connections from one note or chord to the next more quickly than if they are practiced solely at the given tempo. If a student is able to make these connections at a faster tempo successfully, it will increase the likelihood that he or she will accomplish this at the given tempo of the piece. 


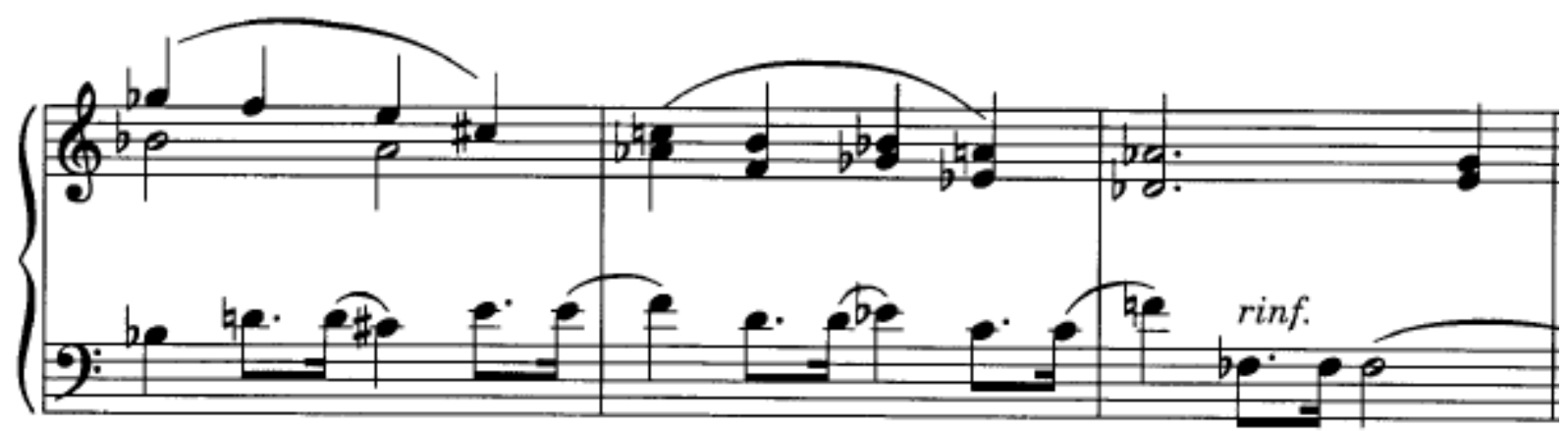

(C)1994 by Theodore Presser Co., Used With Permission

Example 4.22. Lowell Liebermann, "Funeral March for a Pet Rat" from Album for the Young, mm. 5-7. ${ }^{72}$

The right hand in this passage, especially m. 6, presents a series of intervals that require a legato touch, but also necessitate that the student move his or her hand to facilitate the entire span of this passage. There is a mix of black keys, white keys, and combinations of the two in the righthand material, giving the student an opportunity to have several different feelings under the hand for similar intervals. I have chosen not to give fingering suggestions here, but rather to allow a teacher and student to work on this individually. One reason for this choice is that each student, depending on his or her hand size, will require different fingerings, especially at an age typical of intermediate students.

The fourteenth piece of Liebermann's Album for the Young is designated "Hommage à Alkan." It is the second piece which bears a tribute to another composer. In looking at some of the compositional elements of this piece, one possibility for the tribute surrounds the repetition of particular motives or rhythms, and an ostinato-like repeating pattern in this piece. These are elements of some of Alkan's piano literature as well, frequently utilized in his 2 Petites pieces, Op. 60, 3 Petites fantaisies, Op. 41, and his Petits preludes sur les 8 gammes du plain-chant. All of these works by Alkan contain levels of symmetry and repetition similar to those elements

\footnotetext{
${ }^{72}$ Ibid., 17.
} 
found in Liebermann's "Hommage à Alkan." In Liebermann's work, concepts of pitch and phrasing are explored, but even more important are some of the technical challenges it poses to a student, such as repeated notes as well as larger leaps.

The beginning of the piece presents a simple melody over a repeated figure in the left hand. The simplicity and repetition of the accompaniment will allow a student to focus on note reading in the melody and do a better job with accidentals and other challenges. The following excerpt shows the initial presentation of the melody. In this example, the repeated figure of the left hand is the most obvious feature; however, the lyrical melody found in the right hand is a cornerstone on which the entire composition is based.

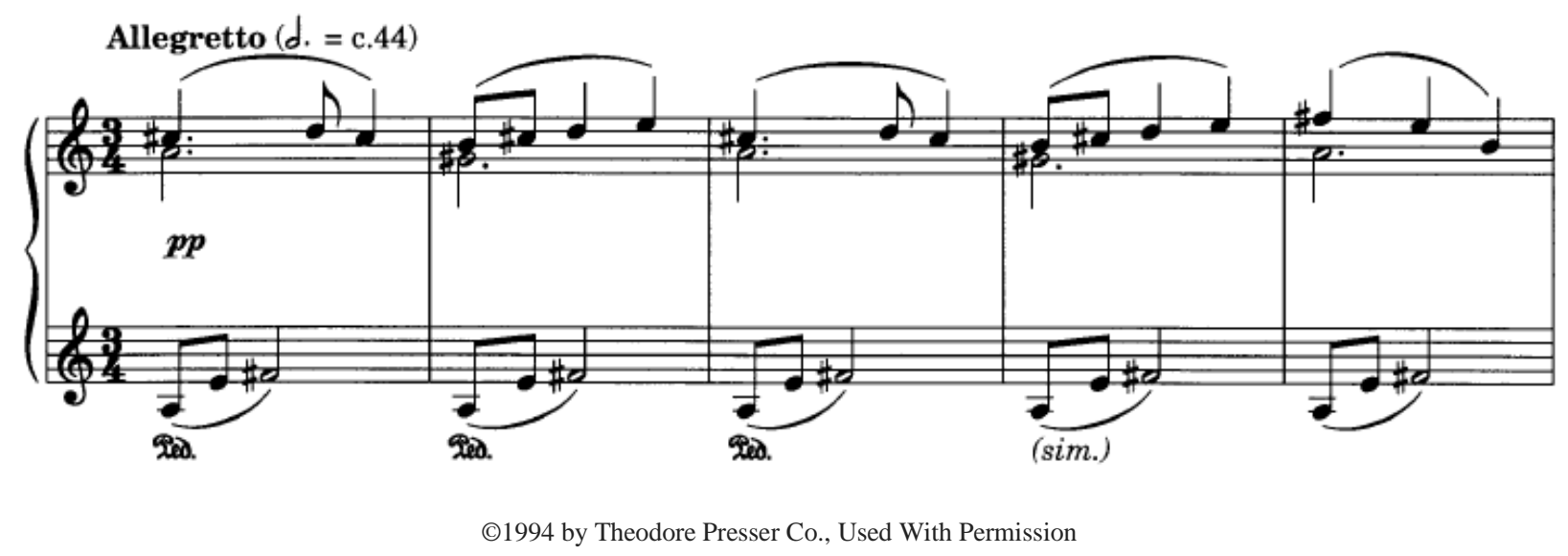

Example 4.23. Lowell Liebermann, "Hommage à Alkan" from Album for the Young, mm. 1-5. ${ }^{73}$

Later in "Hommage à Alkan," a student encounters this melody again, but transposed. What is unique about this second presentation is that the left hand retains its original pitch material.

\footnotetext{
${ }^{73}$ Ibid., 18.
} 


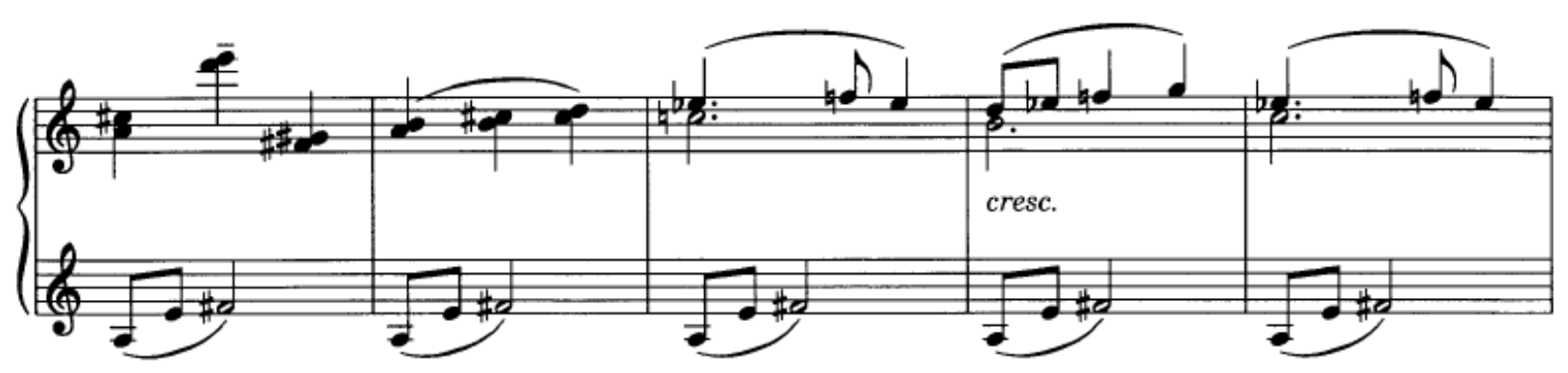

(C1994 by Theodore Presser Co., Used With Permission

Example 4.24. Lowell Liebermann, "Hommage à Alkan" from Album for the Young, mm. 23-27. ${ }^{74}$

At the beginning of $\mathrm{m}$. 25, this transposition is apparent and offers the student a study in contemporary sounds and devices.

A study of pitch in this particular work demands a study of phrasing as well. The first seven measures of the work are marked with only a single dynamic. Because of this, student and teacher must explore how best to shape this phrase. A discussion of elements such as the rise and fall of the melody, the tension of dissonance, as well as rhythm, are all considerations that should be taken into account when exploring phrase shape. In addition, the connection from one phrase to another as well as to the overall structure of the piece should all be factors in discussing how to interpret this work.

The majority of conceptual learning in this particular work lies in certain technical challenges it poses to the student. One such example is in repeated notes between hands seen in the following passage.

\footnotetext{
${ }^{74}$ Ibid., 19.
} 


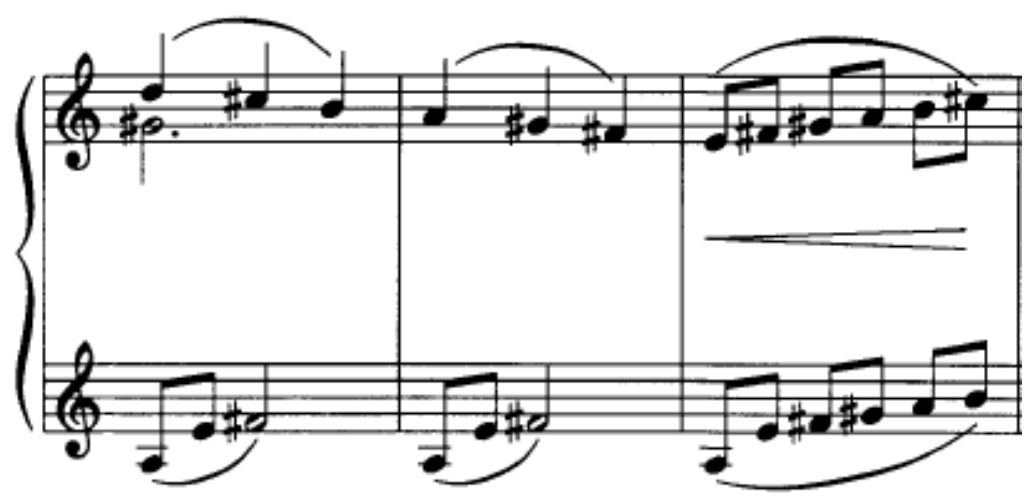

(C)1994 by Theodore Presser Co., Used With Permission

Example 4.25. Lowell Liebermann, "Hommage à Alkan" from Album for the Young, mm. 6-8. ${ }^{75}$

In $\mathrm{m} .8$, there are two scale passages in which the left hand repeats the right hand's notes a half beat afterwards. The student will be not only challenged with how the hands feel that close together, but also with timing the release and attack of each note to achieve the sounding of each note of the scale successfully. A second major technical challenge of the piece occurs with the wide leaps presented halfway through the composition.

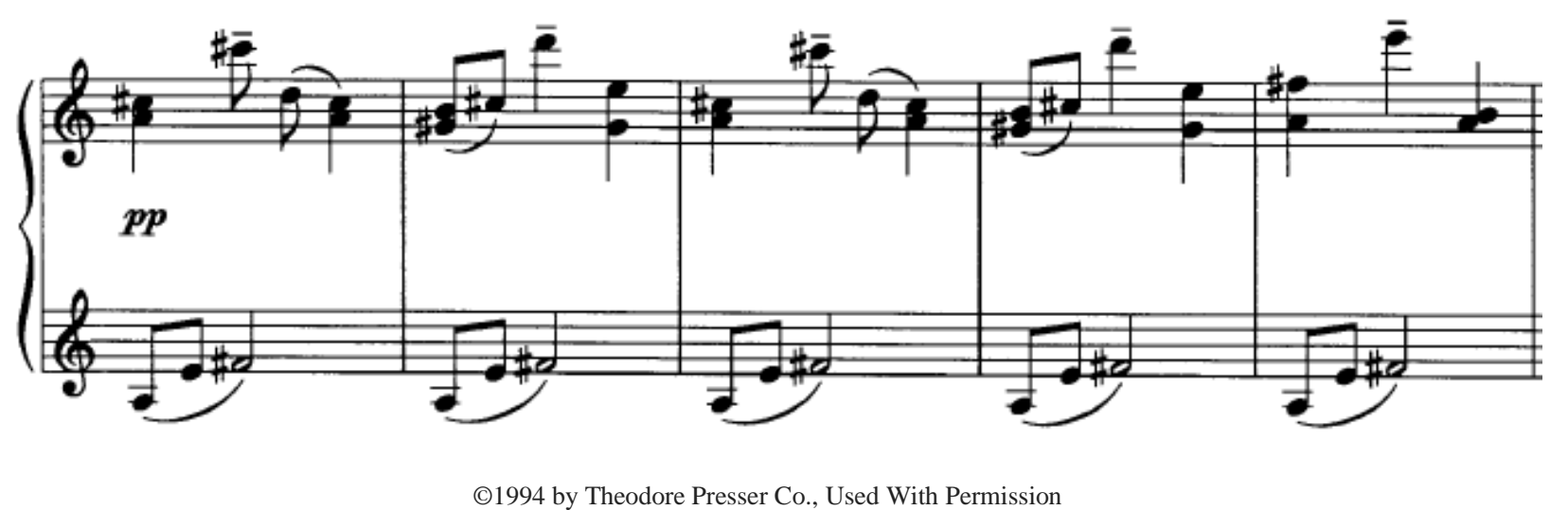

Example 4.26. Lowell Liebermann, "Hommage à Alkan" from Album for the Young, mm. 17-21. ${ }^{76}$

The second beat of each measure demands a large jump in the right hand. A student must develop comfort not only with the ascent but also with the descent of the melodic figure.

\footnotetext{
${ }^{75}$ Ibid., 18.

${ }^{76}$ Ibid., 18.
} 
Fortunately, a student will be able to concentrate on the motion of the right hand passage as the left hand retains the repeated figure it has used for the majority of this composition.

The fifteenth piece, "Melancholy," contains some unique conceptual challenges to be explored by teacher and student. These relate to pitch, rhythm, texture, and articulation. A look at the opening measures of this piece reveals the complexity of these concepts.

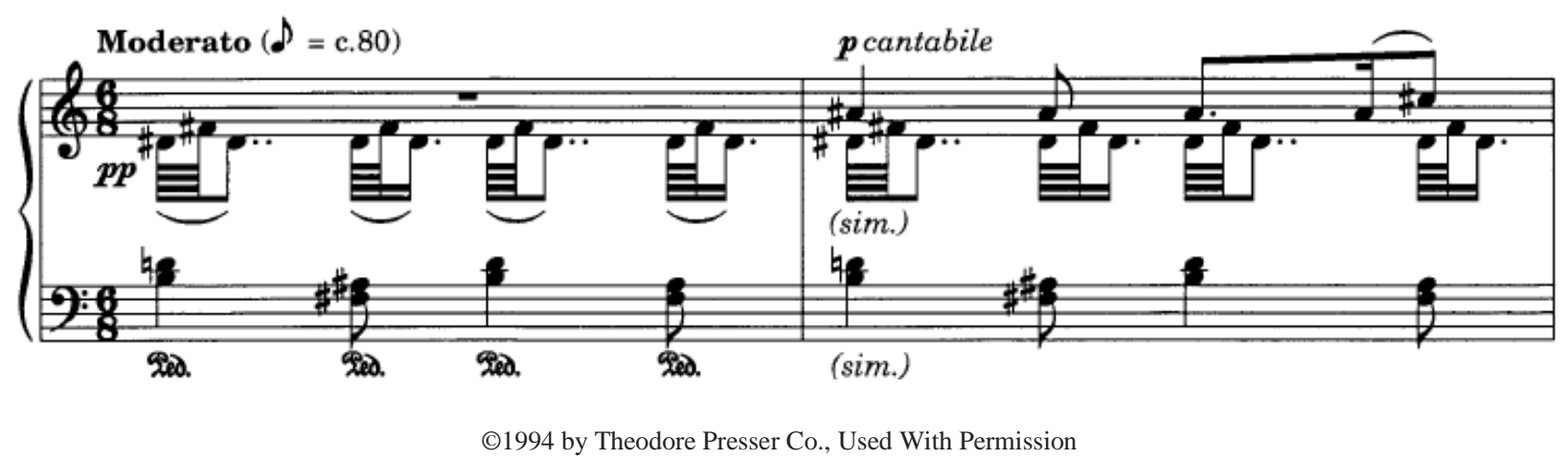

Example 4.27. Lowell Liebermann, "Melancholy" from Album for the Young, mm. 1-2. ${ }^{77}$

Most of these conceptual challenges appear clearly within the first two measures. However, when we investigate each of these concepts individually, a simplification takes place; as a result, a student is able to grasp more easily the musical elements discovered in this piece.

Because of the density of the texture, pitch creates the first conceptual challenge for a student. The frequent accidentals in this piece contribute to the possible reading difficulties found throughout. Sharps, flats, and accidentals permeate the majority of the work; keeping track of them, given the quantity of material packed into this composition, is certain to challenge students. However, a closer examination of the left hand's material reveals an accompaniment pattern based largely on the interval of a third. Allowing a student to make this discovery would assist in simplifying the events happening in this work.

Rhythmically, "Melancholy" also presents several challenges to the student. The use of sixty-fourth notes in this work may be the first encounter with note durations smaller than a ${ }^{77}$ Ibid., 20. 
sixteenth note for a student at this level. This element would facilitate a good discussion about notes of smaller durations and how they play out in music. There is also another solution to the problem posed by this rhythmic complexity. Although not as precise, treating the three note figures of the right hand as written out ornaments occurring on the beat while maintaining the lilt of the $6 / 8$ time is another possible way to remedy this problem.

Texturally, this one of the most complex pieces of the entire set. The following example helps to illustrate this point.

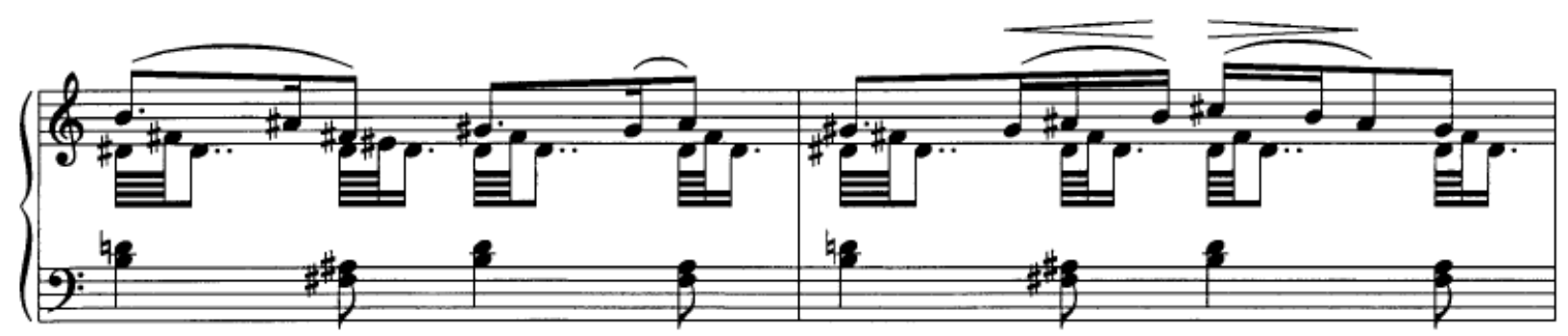

(C1994 by Theodore Presser Co., Used With Permission

Example 4.28. Lowell Liebermann, "Melancholy" from Album for the Young, mm. 3-4. ${ }^{78}$

There are really three voices at play here, the first being the bass line which, as previously stated, consists mostly of blocked intervals, primarily thirds. The voice immediately above that contains the decorative sixty-fourth notes, and above that lies the melody voice. The two voices in the right hand present difficult textural challenges related to voicing, articulation, and dynamics. It is essential that a student be able to voice the melody properly so that certain notes do not unexpectedly stand out. This is especially important when the ornamental figures enter simultaneously with the melody. In order to accomplish this, it is advisable that a student practice the notes in the treble clef between the two hands to ensure proper voicing and the shaping of phrases and dynamics.

\footnotetext{
${ }^{78}$ Ibid., 20.
} 
The sixteenth piece of the set is called "Barcarolle." It contains many of the traits associated with traditional barcarolles, including the rocking $6 / 8$ meter as well as a moderate tempo and a smooth, legato feeling, reminiscent of a boat floating through gentle water. Liebermann primarily explores concepts of pitch and rhythm or meter in this short piece. These both contribute to the quasi-romantic nature of this composition.

In looking at the conceptual elements of pitch, and perhaps scale, in this piece, the right and left hands take on entirely different characters. The left hand is primarily tonal in nature, utilizing broken octaves and fifths the entire way through the composition. The right hand takes on a radically different character.

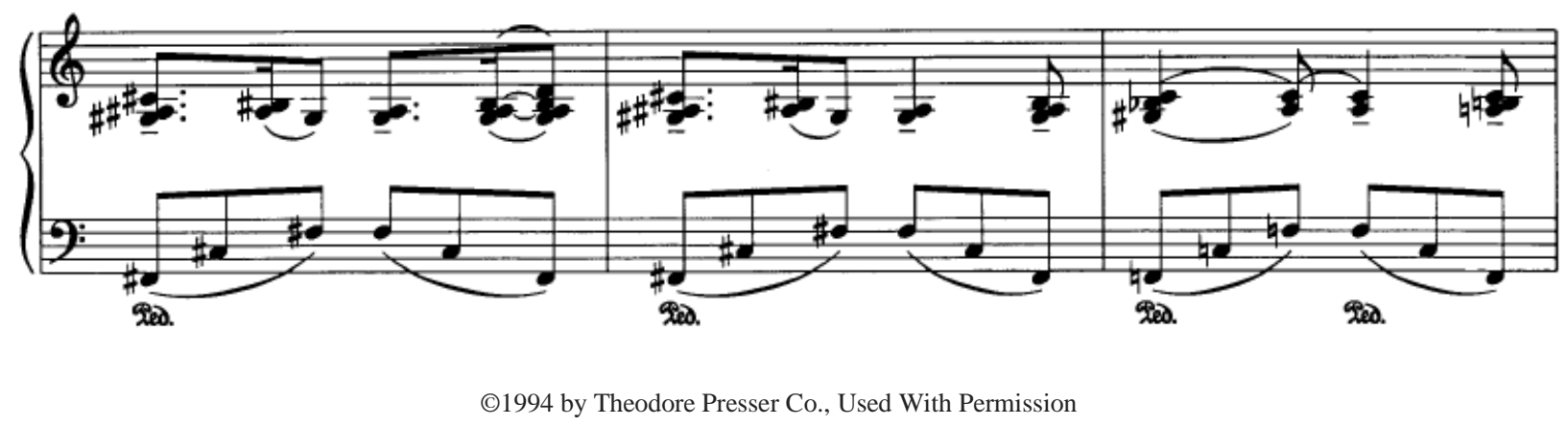

Example 4.29. Lowell Liebermann, "Barcarolle" from Album for the Young, mm. 4-6. ${ }^{79}$

This segment of the piece shows the dissonant clusters of the right hand superimposed atop the tonal material of the left hand. As the piece progresses, more pitches are added to the dissonances of the right hand. By the middle of the piece, as many as five pitches are sounded simultaneously in the right hand, as seen in the following example.

\footnotetext{
${ }^{79}$ Ibid., 21.
} 


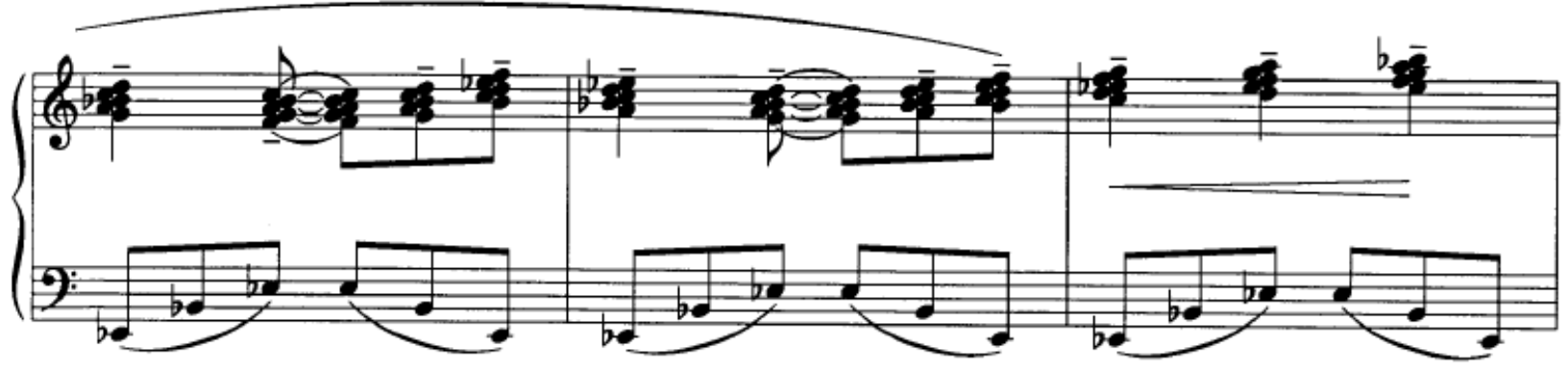

(C1994 by Theodore Presser Co., Used With Permission

Example 4.30. Lowell Liebermann, "Barcarolle" from Album for the Young, mm. 16-18. ${ }^{80}$

The final measure of "Barcarolle" shows an even greater saturation in pitch where ten pitches are sounded at once in the right hand. This compositional technique is commonly referred to as a tone cluster and can be found in the music of several composers of the twentieth and twenty-first centuries.

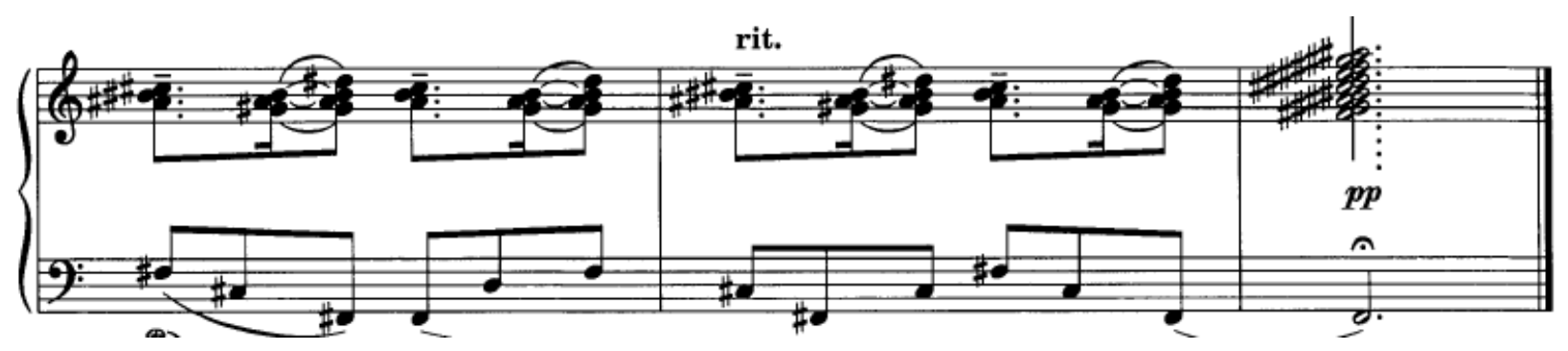

(C)1994 by Theodore Presser Co., Used With Permission

Example 4.31. Lowell Liebermann, "Barcarolle" from Album for the Young, mm. 36-38. ${ }^{81}$

From all of these examples, the rhythmic pulse of this piece is fairly obvious. The meter is compound in $6 / 8$ time. That being said, the rhythmic motion or pulse should not reflect all six beats as being equal in emphasis. Rather, as the piece is written in a compound meter, two pulses per measure should be an objective - or perhaps even one large pulse per bar-in order to achieve a rhythmic momentum which keeps the piece moving forward. However, this should only be done once a student has successfully become comfortable with the rhythmic material of

\footnotetext{
${ }^{80}$ Ibid., 22.

${ }^{81}$ Ibid., 23.
} 
this work. The following example illustrates a progressive system of counting which shows each of the three ways of counting described.

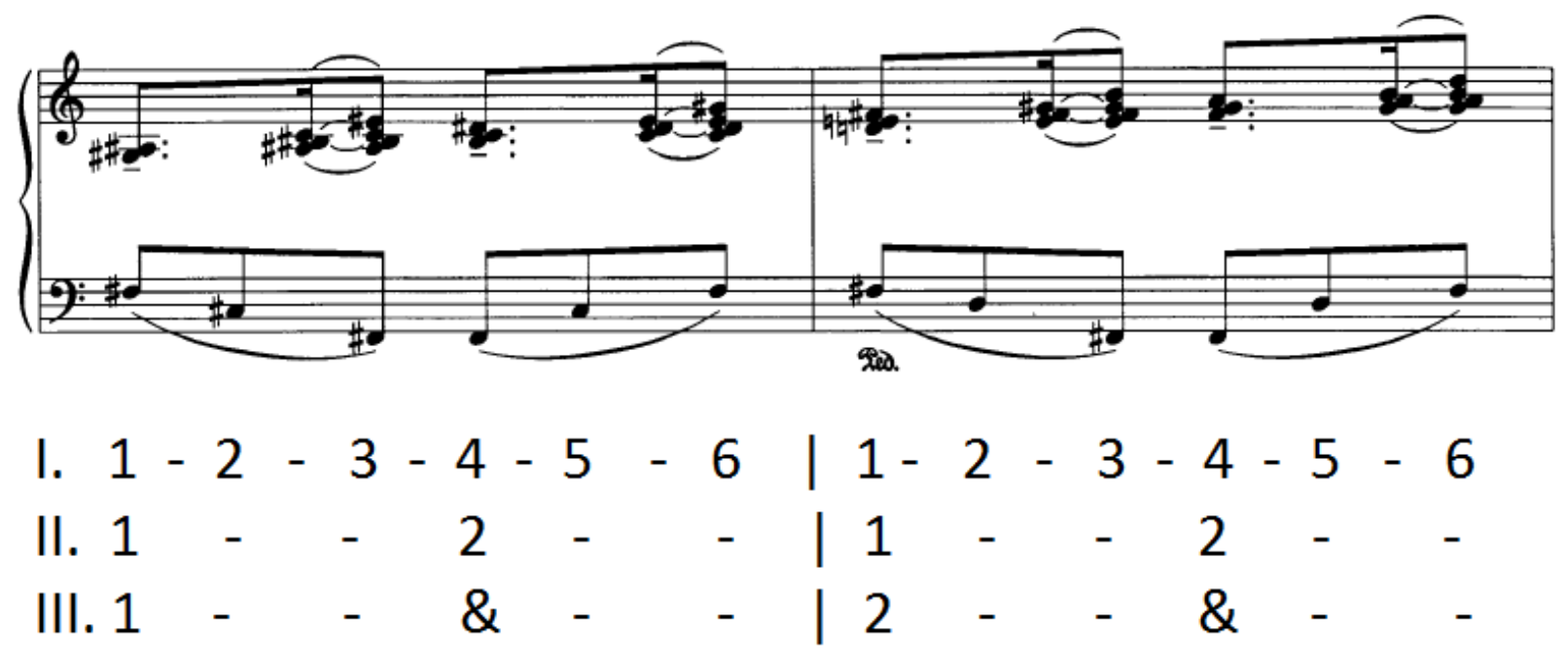

C1994 by Theodore Presser Co., Used With Permission

Example 4.32. Lowell Liebermann, "Barcarolle" from Album for the Young, mm. 34-35. ${ }^{82}$

A final concept that could be explored in this piece is that of voicing. Having a student simply play the clusters for tonal accuracy does not reflect the overall lyricism of the piece. Rather, uncovering the main melody within the complexity of the tone clusters by experimenting with playing single notes or dividing the clusters between both hands will result in a particular direction and shaping of the melody which would otherwise be lost in the mass of sound produced by the clusters.

Liebermann's penultimate piece in this set is entitled, "The Little Baby Rhino." The material of this work is primarily tonal, mostly reflecting the key of G Major, although there are definitely chord structures and passages which allude to other key areas as well. Concepts explored in this piece are abundant, but the major ones include articulation, technique and tempo, and pitch.

${ }^{82}$ Ibid., 23. 
The first line of this composition shows the variety of articulation devices drawn upon by

\section{Liebermann.}

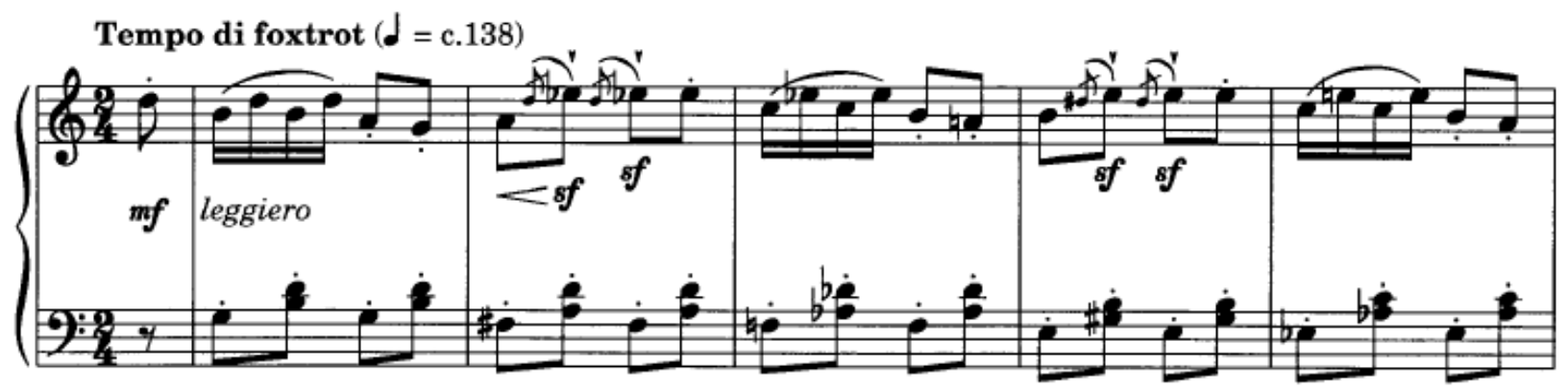

(C)1994 by Theodore Presser Co., Used With Permission

Example 4.33. Lowell Liebermann, "The Little Baby Rhino" from Album for the Young, mm. 1-5. ${ }^{83}$

We see an assortment of articulation markings in this example. These marks include, slurs, staccato marks, spiccato marks, sforzando marks, and grace notes. All of these contribute to a very marked and pointed character of the work. Together they give a particular lightness (also indicated by the leggiero) and playfulness, as suggested by the title of the piece.

The idea of tempo is inseparable from a discussion of the technical concepts of this piece. Because a fast tempo is demanded in this work, extra attention to technical requirements will be required in order to perform this work effectively. For example, in the opening measures of the piece, rotation is demanded of the arm in both the right and left hand to play the notes with relaxation. Using just finger movement may result in unnecessary tension and unevenness in the rhythm. Another example of the technical demands of this work occurs in the crossing of hands. This is seen in the following passage.

\footnotetext{
${ }^{83}$ Ibid., 24.
} 


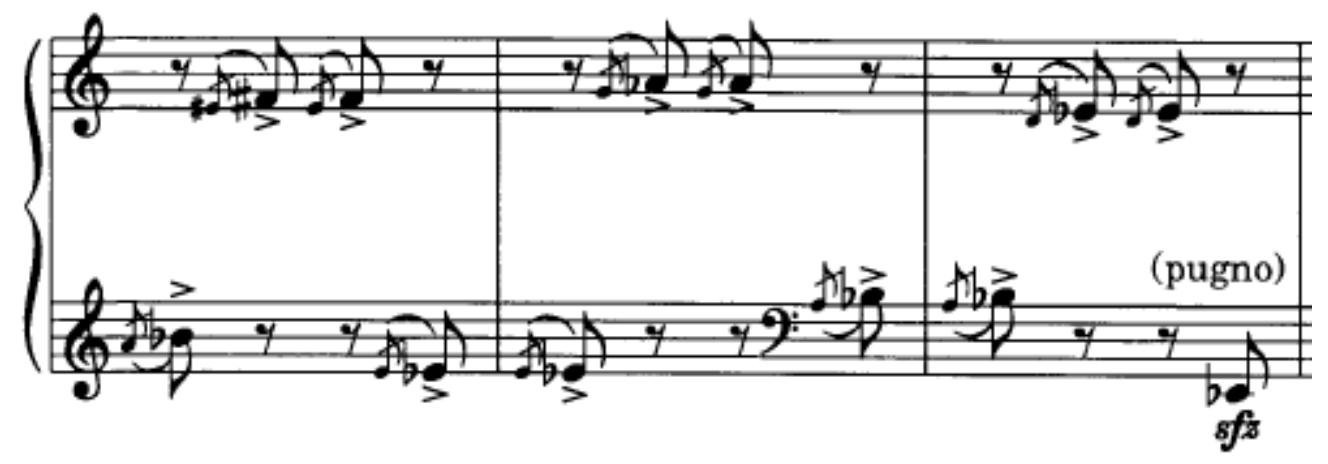

(C)1994 by Theodore Presser Co., Used With Permission

Example 4.34. Lowell Liebermann, "The Little Baby Rhino" from Album for the Young, mm. 17-19. ${ }^{84}$ Leaning the body in the direction of the pitches will help to facilitate easier movement of the arms. This will result in better alignment when attacking the appropriate pitches. A final example where proper technique is required is the scalar passagework of this composition. A relaxed hand makes it easier to play these passages with evenness and forward motion. Weight transfer and using the arm, rather than the fingers, for the directional motion of the scales, facilitates playing these segments accurately.

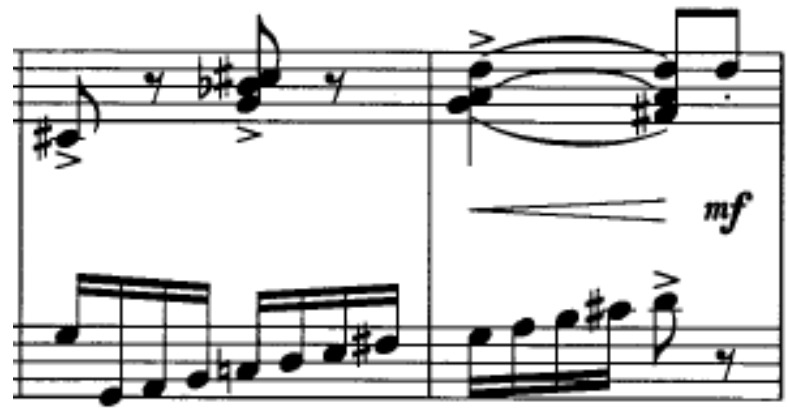

C1994 by Theodore Presser Co., Used With Permission

Example 4.35. Lowell Liebermann, "The Little Baby Rhino" from Album for the Young, mm. 9-10. ${ }^{85}$

The final piece in the discussion of Liebermann's, Album for the Young, is "Toccata."

This work is the most virtuosic of the collection and arguably the most difficult of the set.

\footnotetext{
${ }^{84}$ Ibid., 24.

${ }^{85}$ Ibid., 24.
} 
Concepts that can be explored by the student include rhythm, pitch/scale, and technique (in a variety of ways). The rhythmic challenges contained within this composition can be used to teach a student about thirty-second notes. Similar to "Melancholy," this will likely be one of the first times a student is exposed to such small note durations. The following example contains several passages which illustrate the use of thirty-second notes.

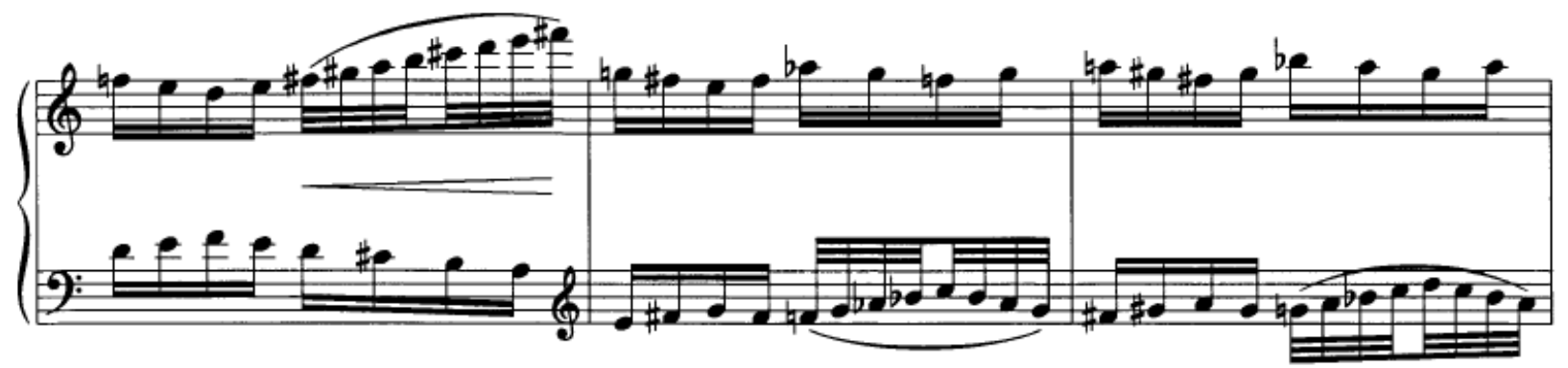

Example 4.36. Lowell Liebermann, "Toccata" from Album for the Young, mm. 13-15. ${ }^{86}$

In these measures, as well as the other places in which thirty-second notes occur, they are always presented in conjunction with sixteenth notes, giving the student a point of reference on which to base the duration and timing of the thirty-second notes.

As with several of the other pieces in this set, pitch plays a significant role in the conceptual value of this work. Again, several accidentals will challenge a student's reading ability. In the opening of this work, a simplification of the initial measures into blocked chords will give a student the feeling of how the composition lies beneath the hands. It will also allow a student to hear the changes in sonority when moving from chord to chord.

\footnotetext{
${ }^{86}$ Ibid., 26.
} 


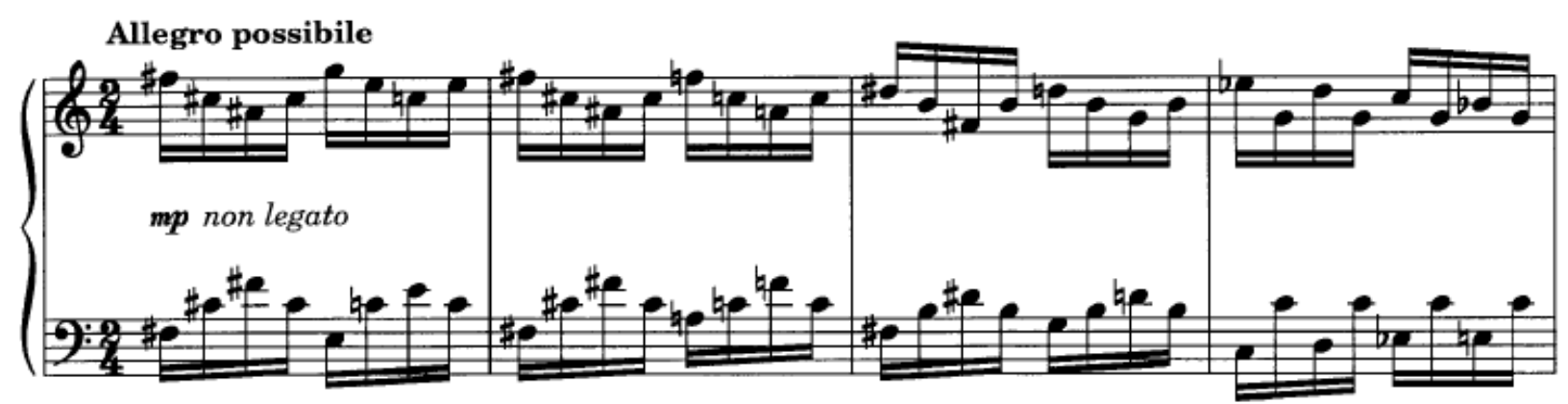

C1994 by Theodore Presser Co., Used With Permission

Example 4.37. Lowell Liebermann, "Toccata" from Album for the Young, mm. 1-4. ${ }^{87}$

From the excerpts of "Toccata" shown, the majority of the technical challenges become apparent. Especially given the tempo, Allegro possibile, a thorough understanding of technique is demanded in order to get past the difficulties presented in this work. The piece is etude-like in this regard. For example, m. 13 requires an understanding of weight transfer and lightness of the fingers in order to play the scale with clarity and speed. The broken chords in mm. 1-3 call for a circular motion of the arms, much like Chopin's Etude Op. 25, No. 1, rather than simply relying on the fingers. Finally, the broken intervals in $\mathrm{m} .4$ demand a rotation of the arm to move back and forth between the upper and lower notes. All these are necessary in order to play the piece at a fast tempo with ease.

From this discussion, it becomes clear that Liebermann's Album for the Young presents a compendium of pieces relating to a wide variety of musical and technical concepts which a student may encounter throughout his or her years of piano study. Moreover, these concepts are not specific to solely this work, but can be transferred to a student's learning of other repertoire. This is especially evident in the use of polyrhythm. A student can explore the concept of three pulses against two; once learned, this skill can be transferred to other works which also use similar rhythmic patterns, such as the first of Debussy's "Deux Arabesques."

\footnotetext{
${ }^{87}$ Ibid., 26.
} 


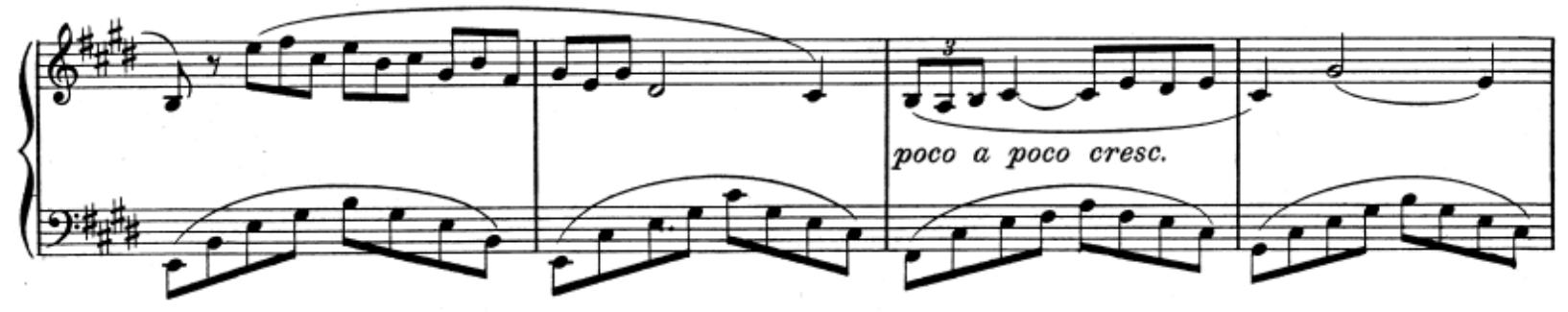

Example 4.38. Claude Debussy, "Deux Arabesques, No. 1" mm. 8-11.

Similarly, pieces which focus on the simultaneous use of different articulations, such as legato and staccato, are especially useful when working on a multitude of repertoire, especially the works of Johann Sebastian Bach, where a detached left-hand accompaniment fairly often occurs underneath a legato right-hand melody. Other connections between Liebermann's work and works of other composers can be found as well. Additional information regarding fingering suggestions, the formal structure, and theoretical analysis of the individual pieces in Liebermann's Album for the Young appears in a DMA dissertation by Adam Clark entitled "'Modern Marvels:' A Pedagogical Guide to Lowell Liebermann's Album for the Young, Op. 43." 188

It is obvious from this discussion that these pieces, when looked at in terms of their conceptual value, contain a rich and wide variety of elements which are sure to challenge and appeal to students of varying levels of study. In addition to their technical and musical merit, the pieces help to show that classical music is kept alive and well in the present culture by composers who are active in the world today. Moreover, the imaginative titles are sure to inspire students who attempt these works to develop ways of musical performance. Liebermann's imagination in this area gives students something to grasp when they are learning and performing

\footnotetext{
${ }^{88}$ Adam Clark, "'Modern Marvels:" A Pedagogical Guide to Lowell Liebermann's Album for the Young, Op. 43" (D.M.A. diss., University of Cincinnati, 2008).
} 
these attractive works. This collection is undeniably deserving of further study by performers, teachers, and students alike. 


\section{Chapter Five}

\section{William Bolcom and Monsterpieces}

The year 1938 marks the birth of several notable composers, some of whom are still writing today. This list includes such well-known composers as Joan Tower, John Corigliano, Frederic Rzewski, Philip Glass, and William Bolcom, to name only a few. From this catalog of composers, William Bolcom is one who has not only written for the concert stage, but has also shown his ability at creating didactic pieces for younger students. To understand these pieces, we first need to know a bit about the composer himself.

Bolcom was born in Seattle, Washington, and studied both piano and composition at a young age. Notable teachers throughout his formative years included Darius Milhaud and Olivier Messiaen. He received training both in the United States and abroad, including study at the Paris Conservatoire. He has received numerous commissions for his compositions as well as several significant awards, including the National Medal of Arts, a Pulitzer Prize, and a Grammy Award. ${ }^{89}$

As a whole, his works present an eclectic collection ranging from tonal to serial. Some of his most famous works for solo piano come from the 1970s, when he and American composer William Albright became well known for their work in a revival of ragtime music. One piece from this decade, "The Graceful Ghost Rag," appears on several competition lists for high school students. Other works are more virtuosic in nature, such as his two collections of etudes; still others are post-modern in nature, quoting or referencing other composers and pieces, as in his collections of bagatelles.

\footnotetext{
${ }^{89}$ "William Bolcom: Meet the Composer," accessed Dec. 4, 2013, http://williambolcom.com/index.php?contentID=1011
} 
Two collections of pieces by Bolcom stand out for their pedagogical significance. These include his Monsterpieces (and Others): for Older Children for Piano and the more recent Seven Easy Piano Pieces. Each of these collections presents students with an opportunity to play solo literature by a living American composer and to explore idioms of contemporary music. Most of these pieces are slightly easier than those in Liebermann's Album for the Young; however, they do pose specific difficulties which are certain to engage and challenge students who are looking to explore uncharted territory in the piano literature.

\section{Analysis of Monsterpieces (and Others)}

The first Bolcom collection explored in this study will be his Monsterpieces. This collection is a set of ten short works. Each of these has a unique name, some being named after different types of monsters, others referring to objects or ideas. Like Liebermann's Album for the Young, this collection becomes progressively more difficult technically. Various contemporary compositional devices are explored as well, including tone clusters and the absence of time signatures. This collection offers the student a chance to see these devices in real musical situations, in pieces that are both accessible and interesting. Monsterpieces begins with a piece called "The Mad Monster." Perhaps to show the pedagogical nature of this piece, Bolcom includes a footnote which states, "In musical scores, you will often find Italian words for qualities of music. We've used them universally since the 17 th century. They allow us to be able to read music with more understanding." ${ }^{90}$ He goes on to provide explanation of particular musical elements included in this composition. It is evident that Bolcom does this in order to teach students, to connect with them on a pedagogical level. Other pedagogical values in this

\footnotetext{
${ }^{90}$ William Bolcom Monsterpieces, p. 2
} 
composition include its presentation of particular concepts, most notably rhythm, tempo, and articulation.

Although the piece is only sixteen measures long, it offers a good introduction to a particular rhythm. From the beginning, the student is exposed to triplets throughout the majority of this work. Many of these are presented in succession, requiring a clear understanding of technique and rhythmic clarity.

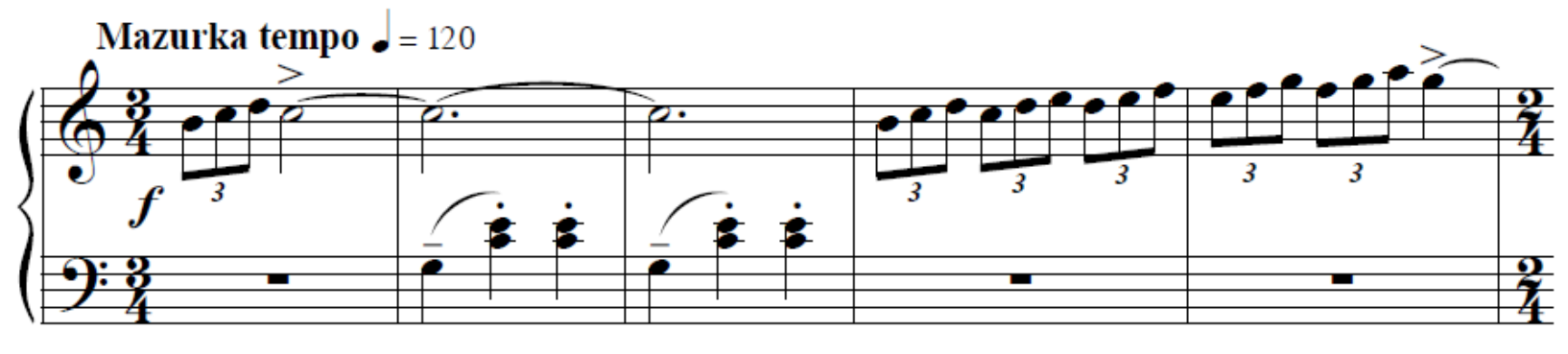

Example 5.1. William Bolcom, "The Mad Monster" from Monsterpieces, mm. 1-5. ${ }^{11}$

In these initial bars, continuous triplets appear in $\mathrm{mm}$. $4-5$. The meter changes to $2 / 4 \mathrm{in} \mathrm{m} .6$, and back to the original meter in the next bar, producing interesting challenges for a student. First, the student needs to be aware of the triplet figure; in addition, the student is faced with two sudden changes in meter. A slow practice tempo can help a student surmount both these challenges.

Tempo is another conceptual challenge presented in this composition. The marking indicates that the piece should be played in the tempo of a mazurka. It is unlikely, however, from the difficulty of this piece, that a student would have been exposed to the definition of a mazurka. This creates a teachable moment, in which the teacher can guide the student to explore what a mazurka is through listening, through reading, through playing, and perhaps even through dancing. Connections can be drawn between this composition and Chopin as well, creating

${ }^{91}$ Ibid., 2. 
another bridge which a student may choose to explore. The metronome marking also presents a challenge for a student, calling for 120 beats per minute. A slower practice tempo is effective here to allow a student to focus on proper technique and relaxation in order ultimately to play the work at a faster tempo.

Finally, articulation is of great importance in this work. Although specifics as to the articulation are not always called for, the second measure of the left hand gives clear directions for proper performance of the accompaniment figure. Showing not only the legato and staccato, but also the slight emphasis on beat one, followed by a lightness on the subsequent beats, are all ideas the student can explore. The final measure of the piece is also of particular interest. Bolcom indicates an entire measure of rest in the final measure of the work, but this rest is further emphasized with a fermata. One possible reason for this is to help a student develop an understanding that a piece does not end when the last note is played. This fermata requires a student to stay in character at least three full beats beyond the final note, allowing the sound to decay. This creates an interesting and startling effect, and one that should be rehearsed with the student.

The second work of Monsterpieces is called "The Sad Monster." Like the first piece, "The Sad Monster" weighs in at just sixteen measures also. Similarly, the piece is to be played in the tempo of a mazurka as well. These two pieces complement each other quite well not only for these reasons, but also because of the similar melodic contour, relative key area, and comparable accompaniment figure. Notable concepts explored in "The Sad Monster" include articulation and dynamics.

Regarding articulation, the following passage illustrates how this concept is presented throughout the piece. 


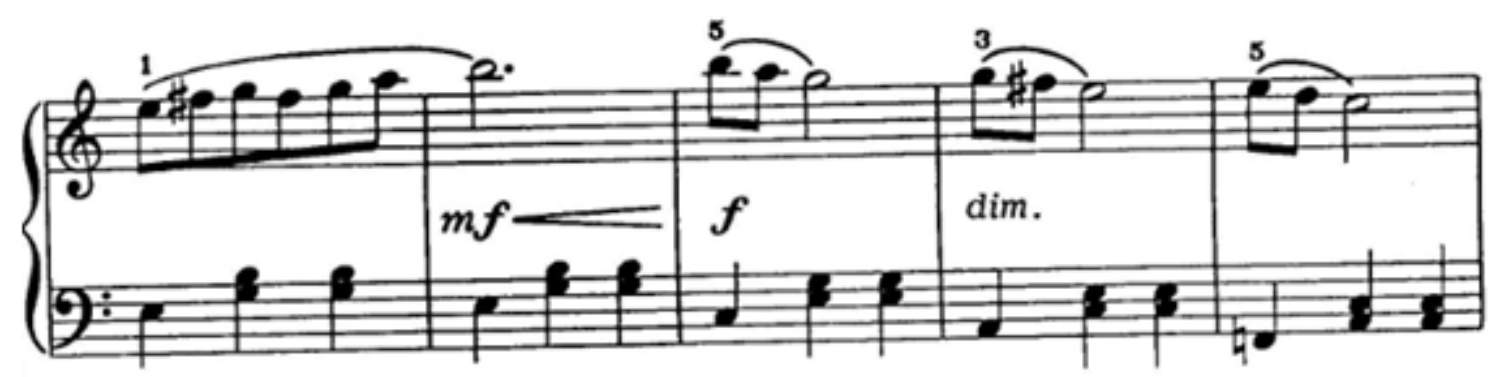

Example 5.2. William Bolcom, "The Sad Monster" from Monsterpieces, mm. 7-11. ${ }^{92}$

There is a wide display of slurs indicating a smooth, legato feeling throughout; however, the lefthand passage bears no specific markings. An examination of the similarities between this composition and the previous one hints at a similar articulation for each of the accompaniment figures. Given this information, a student will be required to perform contrasting articulations in opposite hands. Practicing the hands separately as well as together at a very slow tempo will help a student to become comfortable with this hand independence.

The second major concept a student will discover when playing "The Sad Monster" is the wide variety of dynamics. From the above example, there are two different markings as well as a crescendo and diminuendo within three measures. The other portions of this work require a student to begin the piece at piano and by the end of the composition bring the dynamic down to pianissimo (a dynamic shape similar to that of the first piece of Monsterpieces). This presents not only another parallel, but also a way that a learned concept can be transferred from one piece to another.

"The Bad Mister" marks the third piece of this collection. Again, two major concepts are explored in this work which help to build a student's musical foundation. These are scale and articulation. In this piece, Bolcom uses the concept of scale first to explore the key of $\mathrm{d}$ minor. A sudden shift to $f$ minor occurs in $\mathrm{m}$. 5. Bolcom then shifts from the minor to the parallel major of

${ }^{92}$ Ibid., 3. 
$\mathrm{F}$, and through a series of modulations brings the piece back to $\mathrm{d}$ minor. This modulation appears in the following passage.

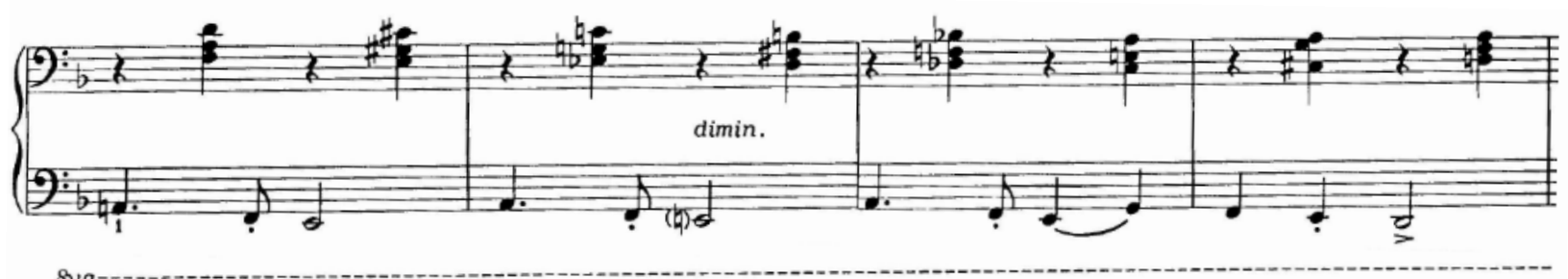

Example 5.3. William Bolcom, "The Bad Mister" from Monsterpieces, mm. 9-12.93

Bolcom then repeats the same right-hand harmonic pattern in the next four measures with an altered left-hand melody. This excerpt provides a student with an excellent example of how modulations work, especially in such a chromatic fashion.

Articulation presents another significant conceptual challenge to younger students in this composition. The first two measures give a full catalogue of the majority of musical events relating to articulation found in this work.

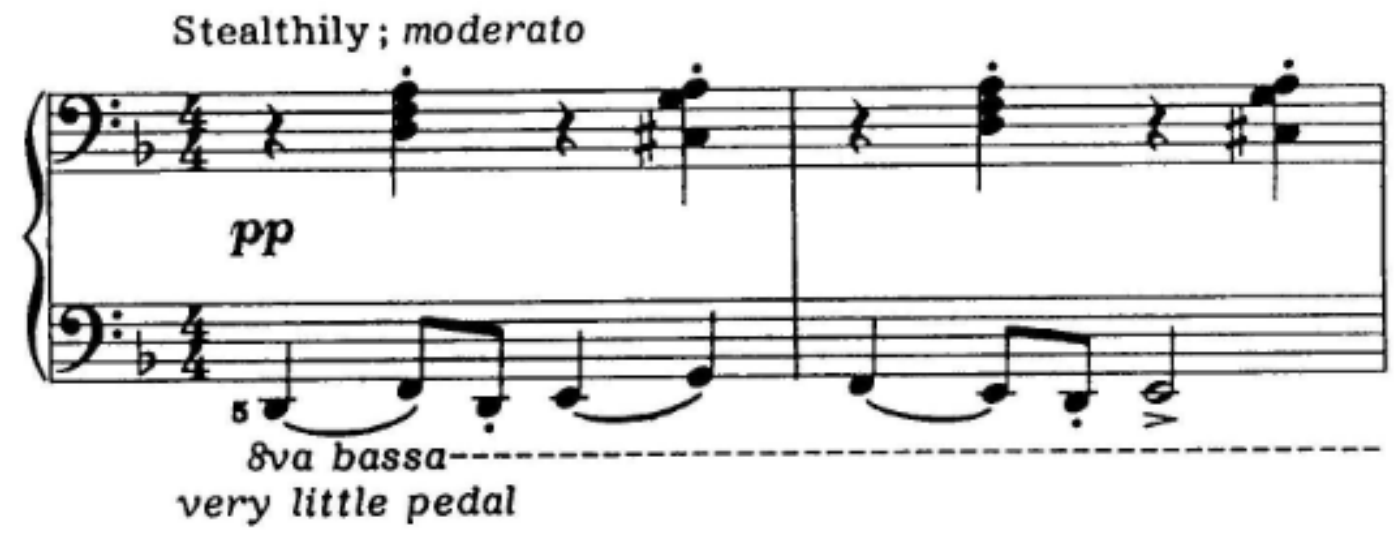

Example 5.4. William Bolcom, "The Bad Mister" from Monsterpieces, mm. 1-2. ${ }^{94}$

In this passage the student is required to play both legato and staccato. A challenge involved in this articulation is not to accent the second note of the left hand slurs during the attack of the

\footnotetext{
${ }^{93}$ Ibid., 5.

${ }^{94}$ Ibid., 4.
} 
right hand. This an important skill for a student to develop. Additionally, longer slurs are presented later in the piece, giving the student the opportunity to discover differences between staccato and legato, and how these can work together within the same piece.

The fourth piece of this collection, entitled "The Glad Minister," presents two concepts within the framework of a short fifteen-bar composition. These concepts are rhythm and articulation. An initial look at this short composition reveals the inclusion of sixteenth notes. Given the elementary level of these pieces, this may be a student's first experience of such a note value. However, the context for its presentation creates an easy exploration of how the sixteenthnote values are to be counted, as they are mostly surrounded by eighth notes. Much like Dmitri Kabalevsky's Scherzo Op. 39, No. 12, from 24 Pieces for Children, this work by Bolcom presents a similar rhythmic figure which includes sixteenth notes throughout. Because of this, it would be easy if necessary to teach this work to a student by rote. However, simple counting devices and exercises can be devised which can effectively help a student in learning sixteenth notes and can play into a concept that will undoubtedly be used throughout his or her playing career.

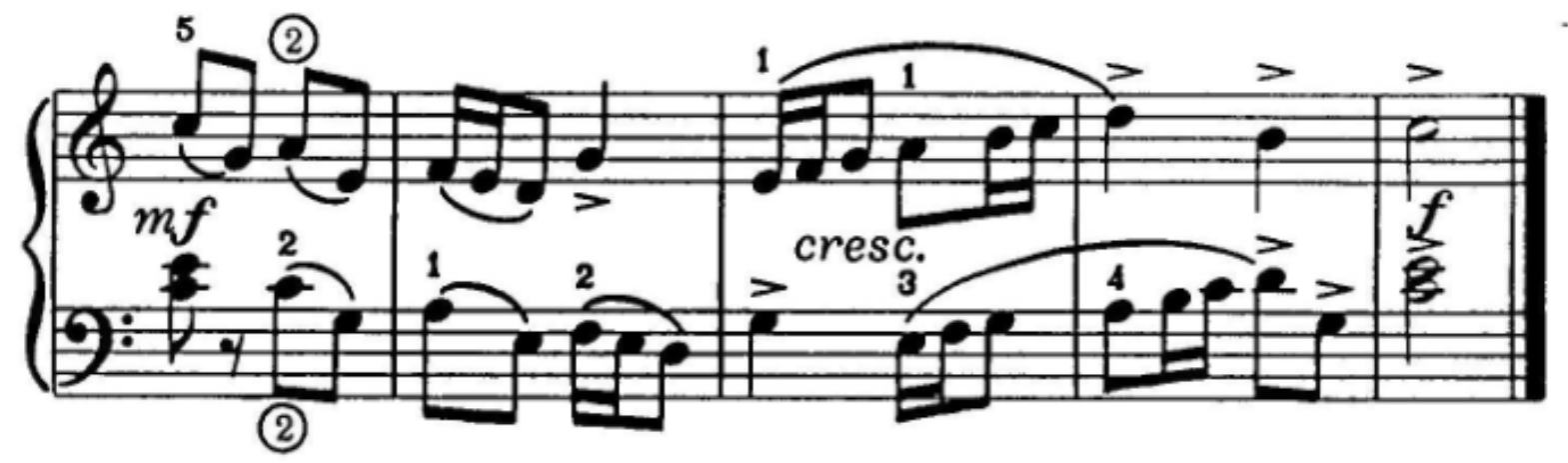

Example 5.5. William Bolcom, "The Glad Minister" from Monsterpieces, mm. 13-17. ${ }^{95}$

\footnotetext{
${ }^{95}$ Ibid., 6.
} 
Not only does this passage show the rhythmic hurdles a student must overcome for successful performance of this piece, but it also highlights the articulation challenges that this composition presents. The two-note slurs at the beginning require a down-and-up arm motion to convey a lightness on the second note of each pair. Legato passagework is required again in mm. 15-16, followed by accents which necessitate the use of significant arm weight, especially for younger students who may not have a lot of strength, to produce the desired volume from these notes.

"The Glad Minister" is followed by a piece called "The Plaid Miss." Here, a student is given the opportunity to explore concepts of pitch and dynamics, given a large quantity of accidentals as well as frequently changing dynamic markings. The concept of pitch is especially prevalent in this specific piece in that it requires comfort with note reading in its presentation of a significant number of sharps throughout. In addition, many different intervals are used, giving a student a chance to feel, see, and hear the various traits of each interval in a variety of combinations.

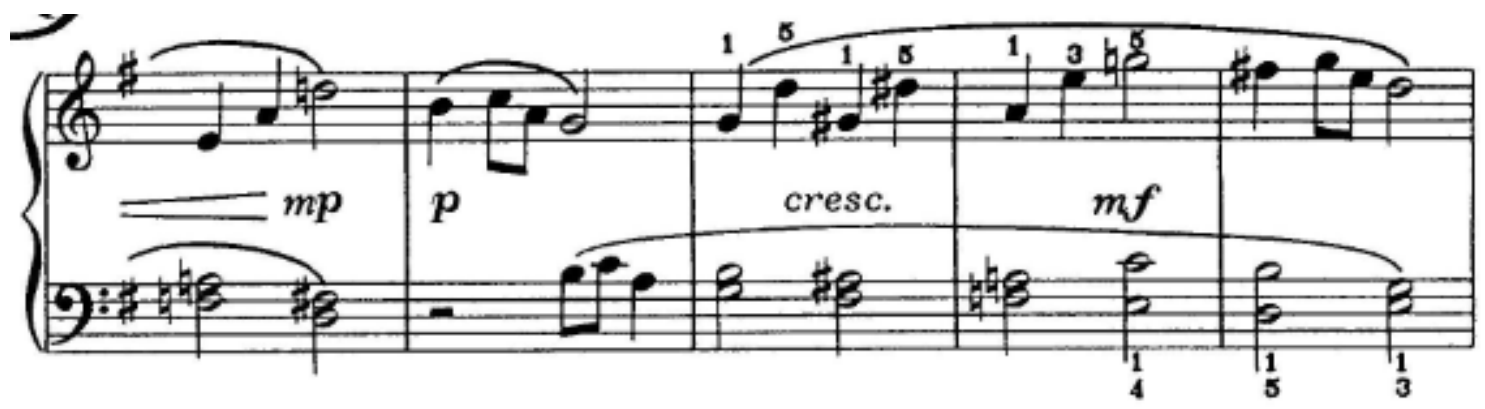

Example 5.6. William Bolcom, "The Plaid Miss" from Monsterpieces, mm. 5-9. ${ }^{96}$

In this passage the left hand presents mostly blocked intervals, almost all of which are either thirds or sixths. An exception to this occurs in $\mathrm{m}$. 6, where single notes form a second and a third in succession. Similar intervallic structures appear throughout the work. However, the

\footnotetext{
${ }^{96}$ Ibid., 7 .
} 
right hand presents a more varied set of intervals, including sequential (non-block) seconds, thirds, fourths, and fifths. If we expand this observation to consider the intervals more contextually, the right-hand notes in $\mathrm{m} .5$ are not isolated, but their motion is continuous and their interval span as a whole extends over the distance of a seventh. Intervals in the right hand are all broken, as the entire right-hand part is made up of single notes. Because of that, this piece provides a great exercise for students in naming the intervals they encounter.

This passage also highlights the highest point of the piece within its dynamic structure. The first several measures of this piece have a similar dynamic shape, beginning softly at piano, which is followed by a crescendo to mezzo piano. This expansion is interrupted by a sudden drop to piano, followed by a similar increase. The climax of this work occurs at the end of $\mathrm{m} .8$ with the mezzo forte mark. The piece ends with a softer dynamic, including pianissimo in its last several measures. Because of this variety, a student is able to project a wide variety of dynamics within the confines of a shorter piece. This will help a student to focus on the dynamic shape without the complexity of a longer form.

The sixth piece is the first of the set which does not bear a title referring to a particular character. Rather, this work is entitled, "Badminton." This work gives a student exposure to a wide variety of concepts in small portions. These include dynamics, pitch, articulation, and rhythm — primarily as it pertains to meter. The written dynamics include either pianissimo or pianississimo but are occasionally broken up by the inclusion of a sforzando marking. To see how this works, please consider the following passage in more detail. 


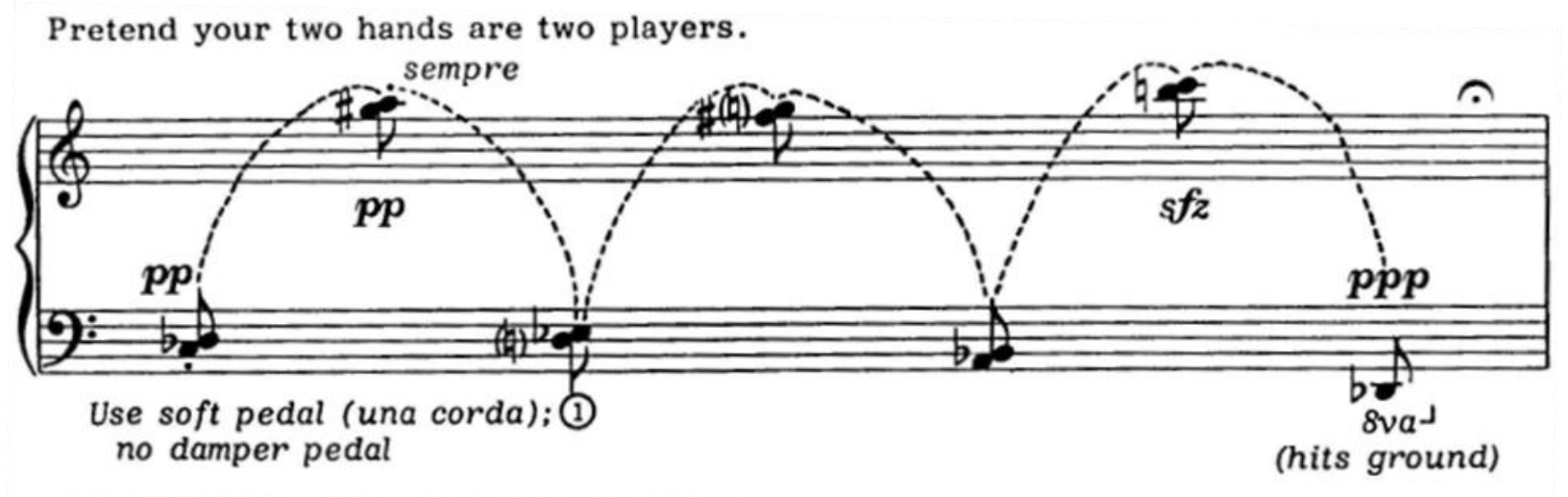

Example 5.7. William Bolcom, "Badminton" from Monsterpieces, m. $1 .^{97}$

To understand the performance directions and compositional marks included in this piece, the student needs an overview of the game of badminton. If a student approaches this piece with that understanding, he or she will see that each measure of the piece represents a volley. Because the object being struck is a birdie and not a ball, there is more of a delicate aura to the piece, to emulate the lightness of a birdie in flight. The notes marked pianissimo represent the hitting back and forth of the birdie between players with the sforzando notes representing a more aggressive or forceful strike of the birdie. The notes marked pianississimo signal that a volley has ended and show the birdie has fallen to the ground, as indicated by the text in the score. The subsequent fermata represents breaks between volleys as the players set up for the next one. These performance directions give the student something visual to imagine while performing the piece, so that the dynamics become something tangible to relate to, rather than just an abstract idea.

The concept of pitch is seen as a series of alternating intervals of seconds between the two hands. The pitches are all presented in half steps and contain several accidentals which will pose a challenge for the student. The movement of the hands to different pitches correlates to the movement of the players during each round of the game. In addition, the alternation of the ${ }^{97}$ Ibid., 8. 
seconds between the hands represents the passing of the birdie back and forth between the two players.

Proper and effective performance of the articulation again requires that a student have the image of badminton players in mind. The staccatos between the hands need to reflect the impact of a racket with the birdie. This does not mean each staccato needs to be exactly like the rest. Rather, the staccato needs to mirror the variety of hits in an actual game of badminton with the largest and most forceful impacts occurring on the pitches marked sforzando, and the least forceful when the pitches are marked pianississimo.

The final concept explored deals with the concept of rhythm. The rhythm itself is not difficult, as each note value is the same. However, the student might be quick to notice the lack of a time signature at the onset of the piece. Variety of meter is explored by several contemporary composers, notably in the works of Bela Bartók. In this miniature by Bolcom, the lack of a precise meter is due to the fact that the length of each volley is likely to be different. A different amount of hits each time reflect the variety encountered in the actual volleys in a real game of badminton. Each measure symbolizes a volley; thus, the lack of meter shows the unpredictability found in a game of badminton. All these concepts together present the student with an interesting piece that explores abstract concepts and makes them accessible to a student. Using this type of analogy, a teacher can present other pieces to a student in this way if it seems to be an effective way of teaching and learning.

Piece number seven is called "Big Mountain." In this work, Bolcom utilizes certain compositional elements and devices which pertain to the concepts of texture and rhythm. The first two measures of the piece may, at first glance, appear intimidating. This is due to the use of tone clusters, which create a texturally-saturated effect. A student is also given the instruction to 
play these clusters with either the arm or the palm of the hand. A teacher may need to demonstrate this concept, as it is likely to be a student's first exposure to such an idea.

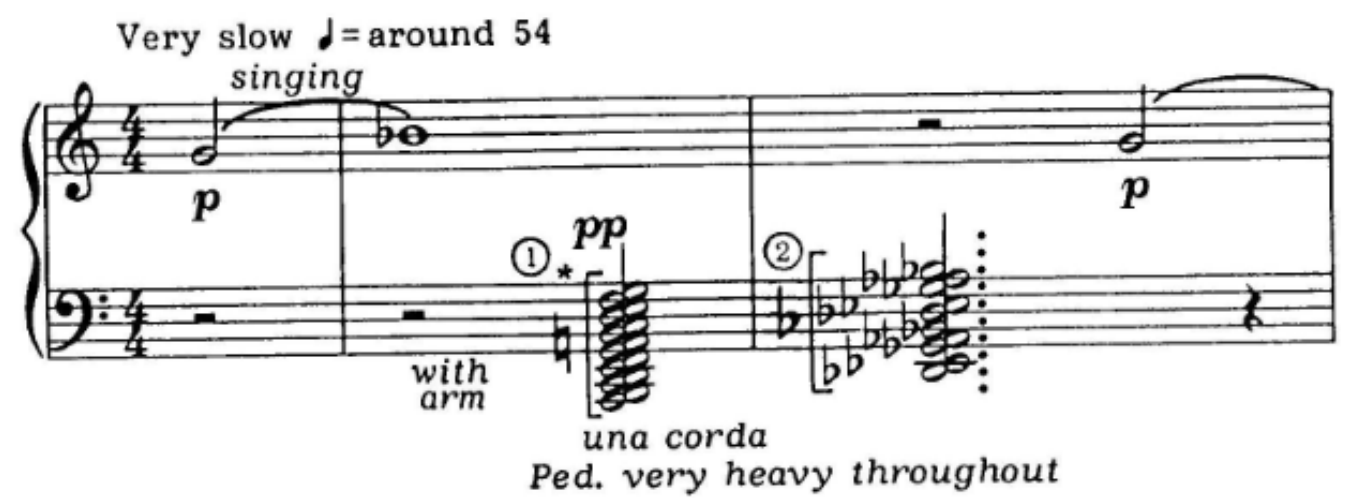

Example 5.8. William Bolcom, "Big Mountain" from Monsterpieces, mm. 1-2. ${ }^{98}$

In this passage, the clusters are very apparent, but require a soft sound, adding to the challenge of their presentation.

The second concept which might pose difficulty in this piece for a student is the rhythm. The note values presented here are not unlike others a student has likely encountered in their study of the piano thus far, but Bolcom creates a rhythmic challenge in his use of ornaments. The following excerpt shows several instances of these.

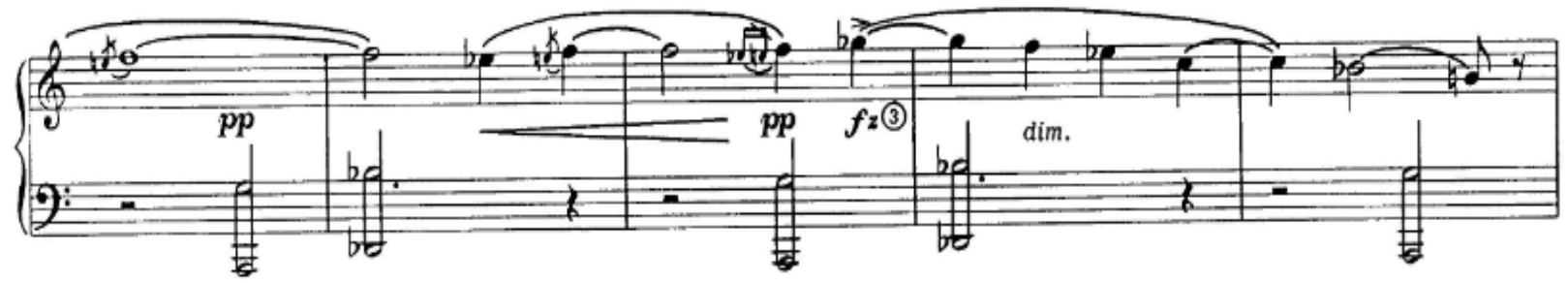

Example 5.9. William Bolcom, "Big Mountain" from Monsterpieces, mm. 9-13.99

In this line alone, we find three different occurrences of ornaments in the form of grace notes. Again, because of when students might be given this piece in their course of study, this might be their first time seeing grace notes and other types of ornaments. Because of this, specific

\footnotetext{
98 Ibid., 10.

${ }^{99}$ Ibid., 11.
} 
attention deserves to be given these ornaments. Proper understanding now will prove useful later in studying a multitude of other pieces. The notation in the left hand of Example 5.9 requires the student to use their arm to play a span of notes in the given range. This is not necessarily a technique that is prevalent in piano literature; however, it does expose a student to a contemporary performance technique and it prepares them for harder literature, such as Rzewski's "Winnsboro Cotton Mill Blues," if they develop their skill to that point.

The eighth piece in this collection, "A Boating Tune," presents several unique ideas not previously encountered in this set. These fall into the conceptual categories of rhythm-meter, pitch, and phrasing. Rhythmic difficulty is evident from the very beginning of this piece. The following passage shows exactly how this difficulty plays out.

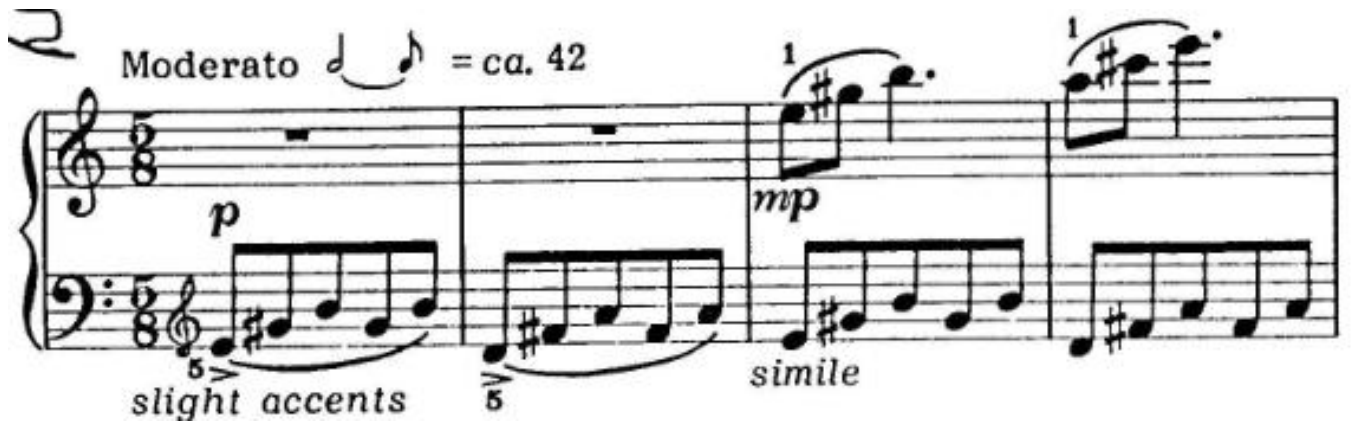

Example 5.10. William Bolcom, "A Boating Tune" from Monsterpieces, mm. 1-4. ${ }^{100}$

The meter Bolcom uses, 5/8, is rather uncommon in classical literature. Because of this, "A Boating Tune" offers a great opportunity to explore the feeling of a rather unusual time signature at a fairly early point in one's study at the piano. Another rhythmic complexity in this piece is a sole instance of polyrhythm. The following example shows this challenge.

\footnotetext{
${ }^{100}$ Ibid., 12.
} 


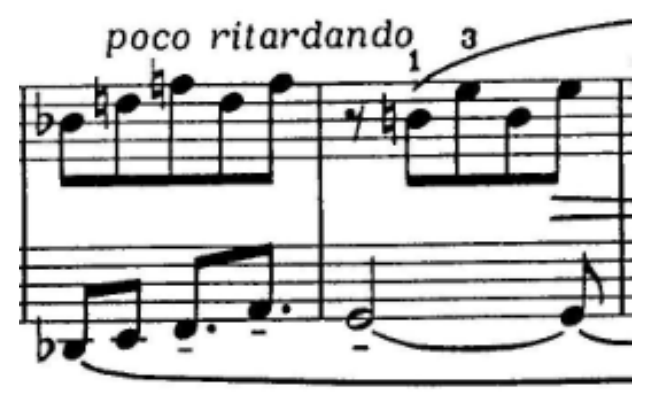

Example 5.11. William Bolcom, "A Boating Tune" from Monsterpieces, mm. 17-18. ${ }^{101}$

The last three beats of $\mathrm{m} .17$ show Bolcom's use of three beats in the right hand against two beats in the left hand. Like Example 4.17b above, from the Liebermann work, these beats should be subdivided into their smallest common denominator to show how they appropriately fit together.

The second concept present throughout this piece is pitch. This concept plays out primarily by challenging a student's ability in note reading. Seeing a multitude of sharps and flats, the student must cultivate an awareness of accidentals. The following passage shows the presence of many accidentals.

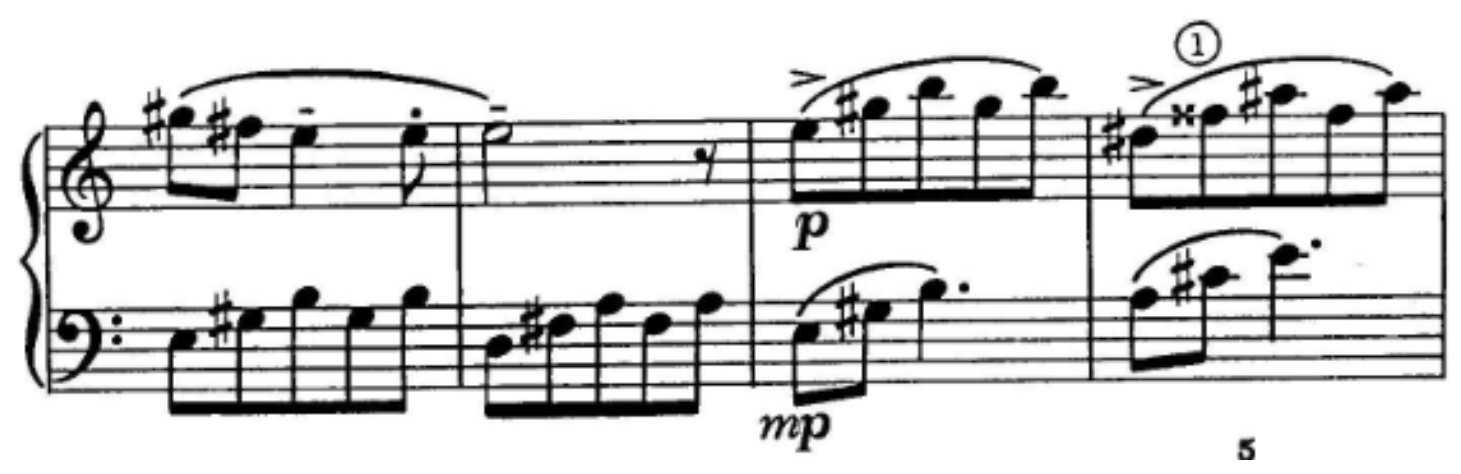

Example 5.12. William Bolcom, "A Boating Tune" from Monsterpieces, mm. 9-12. ${ }^{102}$

M. 12 may warrant additional discussion of accidentals between the teacher and the student. The presence of a double sharp, being such an infrequently used symbol, is likely to be novel to a student. The inclusion of a double sharp in this instance presents an excellent teaching moment for the educator.

\footnotetext{
${ }^{101}$ Ibid., 12.

${ }^{102}$ Ibid., 12.
} 
Finally, in looking at the concepts presented in "A Boating Tune," one should be aware of Bolcom's use of phrasing. The initial melody is played by the right hand in the first ten bars of the piece. A similar melody is presented in the left hand beginning at $\mathrm{m} .11$ with an accompaniment in the right hand, again similar to what was initially present in the opposite hand. This switching of the melody between the hands requires hand independence in order to shape the phrases appropriately. Attention should be given to this concept in order that the phrasing sound natural, rather than a being struggle to bring out the melodic material where necessary.

The ninth piece of this collection presents a variety of concepts to the student within the course of a single short composition; it bears the title "The Bitty Town." Because of the wide variety of compositional elements presented, the piece sounds quite interesting, even in light of its brevity. In this work, students will be challenged to explore rhythm, articulation, and dynamics, to name the most significant. Challenges related to pitch may also occur, especially with the accidentals, but will require less discussion than the other concepts mentioned here.

The opening passage of this work displays several rhythmic challenges presented to the student at the onset of the piece. The first feature of the rhythmic elements of this work is the lack of a time signature. There is not a consistent number of pulses throughout each measure; rather, the beats vary from bar to bar.

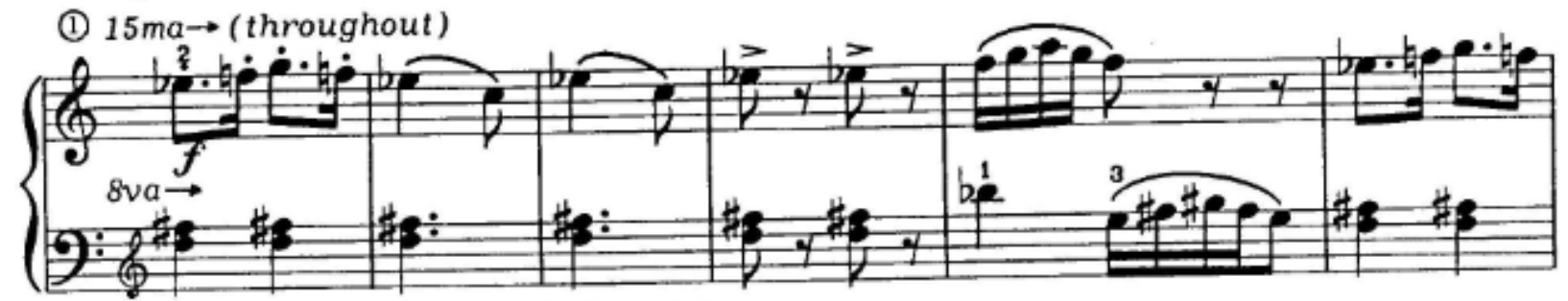

No pedal (move up on the bench!)

Example 5.13. William Bolcom, "The Bitty Town" from Monsterpieces, mm. 1-6. ${ }^{103}$

\footnotetext{
${ }^{103}$ Ibid., 13.
} 
In order to count the piece successfully, a student must feel the pulse in eighth notes; Bolcom suggests this in a text note to assist the performer saying, "Note: There is no time signature, so you will have to count out every bar. Count eighth notes." ${ }^{104}$ A variety of note durations appears here: Quarter notes, dotted quarter notes, eighth notes, dotted eighth notes, and sixteenth notes fill out the rhythmic patterns, in addition to several rests. It is exactly this variety that offers the student a challenge in the concept of rhythm.

A second concept explored in "The Bitty Town" is articulation. In the opening line, one finds again quite a variety of ways to play the notes. Touches presented here include legato, staccato, and notes that must be held, but also separated from each other, as in m.4. Staccato and legato are even presented simultaneously at a later point in the piece, presenting the student with an additional challenge that requires good control of each individual hand.

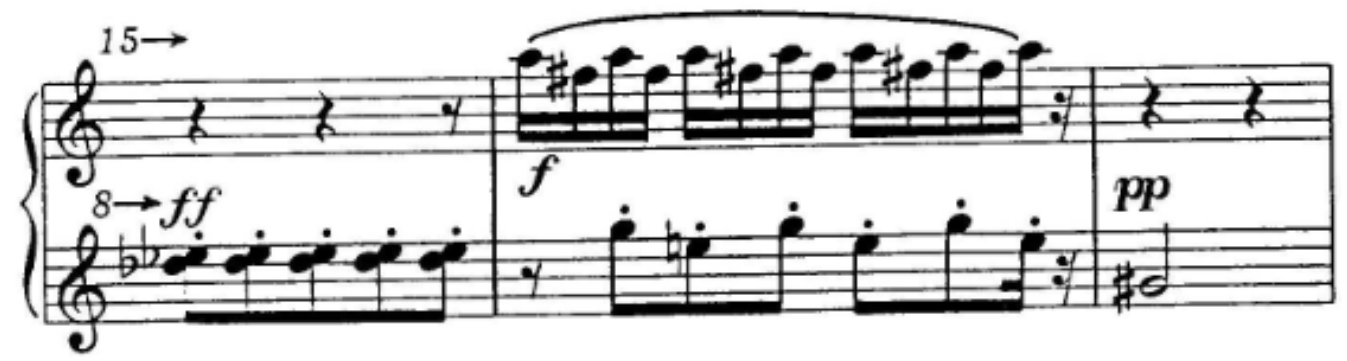

Example 5.14. William Bolcom, "The Bitty Town" from Monsterpieces, mm. 15-17. ${ }^{105}$

The above passages of "The Bitty Town" present not only a variety of different rhythms and articulation marks, but also a variety of dynamics, with occasional accented notes. Ranging from pianissimo to fortissimo, this short composition causes a student to utilize arm weight to achieve a full sound at points, and to be on the extreme soft side of the spectrum at others. The more a student can contrast these passages, the more captivating the performance will be.

\footnotetext{
104 Ibid., 13.

105 Ibid., 13.
} 
The final piece of Bolcom's Monsterpieces (and Others) is "Finale: The Big Bad Mr.

Monster Strikes Again." This work is the longest of the set and again presents a variety of different concepts, including individual uses of pitch and rhythm. Regarding the concept of pitch, an overlying general principle permeates the piece through the extremes of register used in the work. Presented in dual bass clefs, or dual treble clefs with markings to indicate an octave lower or an octave higher, this work allows a student to explore the entire range of the keyboard. The opening of this piece shows one instance of both hands using the low end of the keyboard.

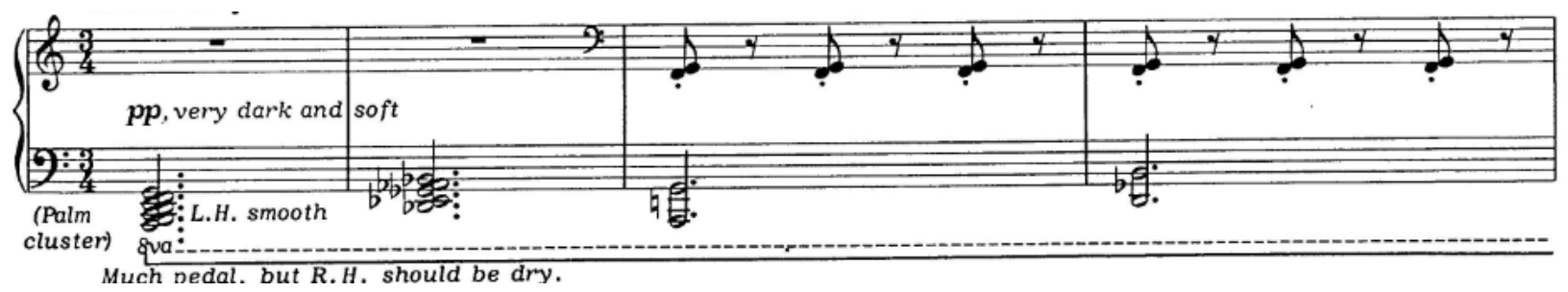

Example 5.15. William Bolcom, "Finale: The Big Bad Mr. Monster Strikes Again" from Monsterpieces, mm. 1-4. ${ }^{106}$ In addition to the extremes of register, we also find many accidentals. Both these characteristics offer a student opportunity to explore the compositional function of pitch in this work.

Finally, the concept of rhythm poses a significant challenge to the student. The piece alternates between duple and triple eighth notes, as musical Example 5.16 illustrates:

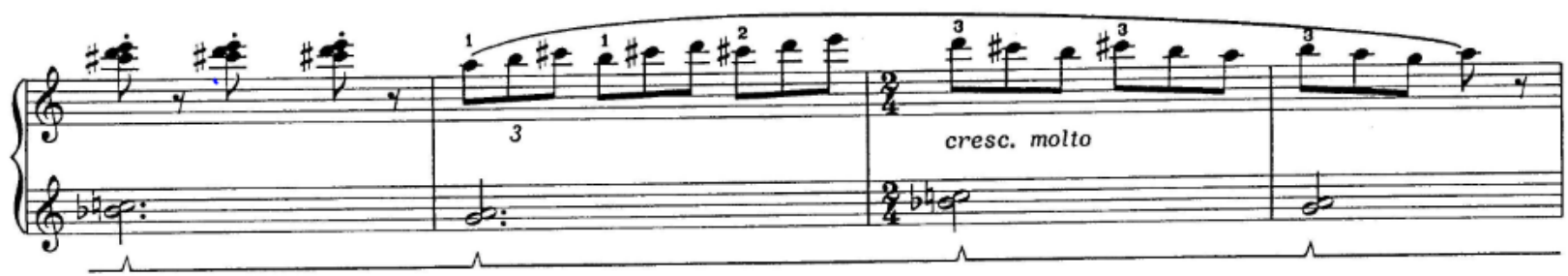

Example 5.16. William Bolcom, "Finale: The Big Bad Mr. Monster Strikes Again" from Monsterpieces, mm. 13$16 .^{107}$

Because of this problem, the student should be advised to practice this piece using a metronome set to pulse in quarter notes. The release of the eighth notes in $\mathrm{m} .13$ should coincide with the

\footnotetext{
${ }^{106}$ Ibid., 14.

${ }^{107}$ Ibid., 15.
} 
subsequent eighth rests. Although the staccato and the pedal will help to blur this release, comfort with the alternation of duple and triple eighth notes will serve a student well in his or her playing of more-advanced literature.

As a whole, Monsterpieces presents a variety of pieces which progress in difficulty and which present conceptual challenges to a student that are not isolated within this single work, but also appear in a wide variety of other literature. Some of these unique elements, such as the use of meter changes, is especially prevalent in works like Bartók's Mikrokosmos, to name just one major instance. While learning these concepts, a student will develop a set of tools which can be transferred to a wider variety of literature, while at the same time exploring a collection by a prominent American composer, William Bolcom. The ability to transfer these concepts from one work to another encourages exposing the student to a body of literature which is fairly uncommon, while at the same time learning concepts which can be applied to other repertoire encountered over the course of a student's entire life. More specific examples will be touched upon at the end of the following chapter.

Another pedagogical success of Monsterpieces is its attractiveness to students. The ideas of different kinds of monsters, games like badminton, or tangible things such as small towns formulate the types of titles associated with each piece in this collection. The descriptive nature of each of these titles allows it to resonate with a student's imagination. A student who can closer relate to a piece is more apt to be able to express musically what a piece is trying to convey. A piece about a particular monster, whether it be sad or happy, can give a student an idea as to the sentiment of the piece at hand. Similarly, pieces about mountains, towns, and games give a student an initial impression of what the music is all about. This introduction can serve as a basis for how to teach musicality. In a piece about a game, the picture needs to be fun. In a piece about 
a mountain, the piece needs to reflect majesty and grandeur. Bolcom's titles in Monsterpieces offer a student these starting points for improving their expressiveness through these pieces. 


\section{Chapter Six}

\section{Analysis of Bolcom's Seven Easy Piano Pieces}

In the year 2009, William Bolcom wrote a collection of seven piano pieces dedicated to his wife, Joan Morris. Several of these pieces find inspiration in forms and styles of the past, namely in waltzes and inventions. At first glance, this collection of miniatures appears relatively simple; however, these pieces do present particular concepts that are invaluable to a student's course of piano study. These lie in several areas including form, pitch, articulation, and dynamics, to name a few. Although this collection is likely the easiest technically among the three sets of pieces analyzed in this study, they do warrant exploration, first because of their own charm, and second because they offer challenges that will undoubtedly assist a student in learning other works with similar technical hurdles.

The first of these pieces is entitled, "Pussycat Waltz No. 1." Although it is only fourteen measures in length, it poses several concepts which a student can examine, namely compositional elements relating to rhythm, articulation, and dynamics. In the second line of this piece, one notices a simple texture consisting of a single-note melodic line accompanied by block chords in the left hand below. The challenge of this lies in the placement of the chords. Notice in the following example that the chords occur on the second beat of each measure, a traditionally weak beat in 3/4 time. 


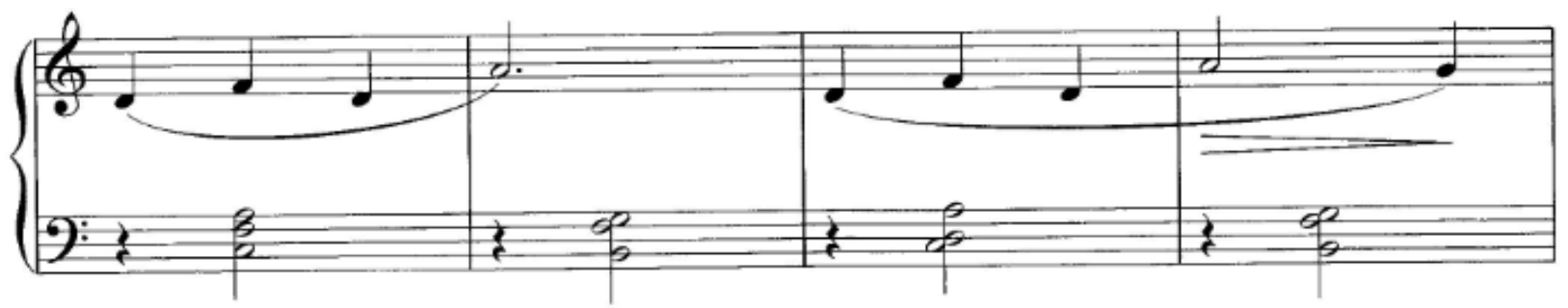

Example 6.1. William Bolcom, "Pussycat Waltz No. 1" from Seven Easy Piano Pieces, mm. 5-8. ${ }^{108}$

Here the difficulty for a younger student is to set up an appropriate rhythmic motion or pulse.

The waltz still needs to have a strong downbeat in each measure followed by the two upbeats. In order to accomplish this, it will be necessary for the teacher to assist the student in finding ways to ensure a light left hand when the chords are presented, in part so that the left-hand chords will not be heard as downbeats.

Another concept presented in this short work relates to articulation. Mm. 9-11 highlight the variety Bolcom includes in this piece.

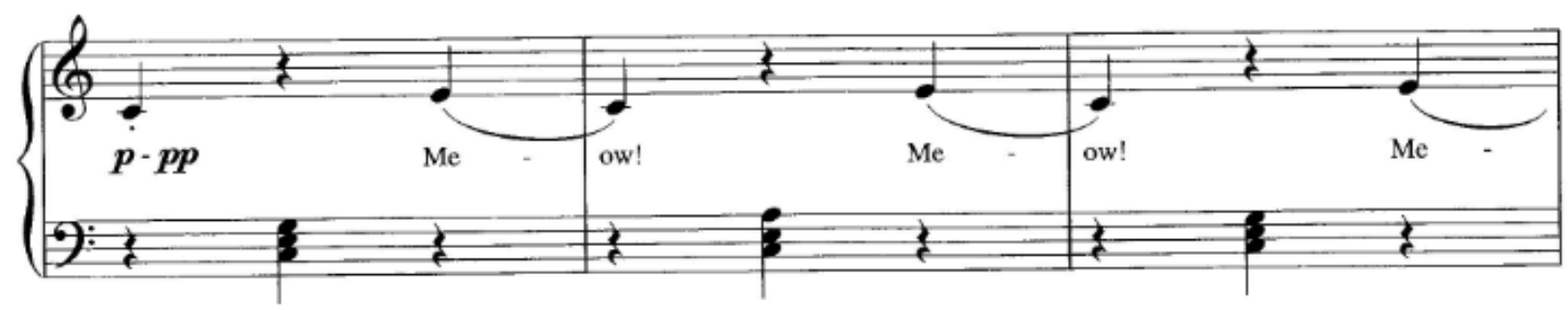

Example 6.2. William Bolcom, "Pussycat Waltz No. 1" from Seven Easy Piano Pieces, mm. 9-11. ${ }^{109}$

The two-note slurs of the right hand can be cumbersome for younger students, especially when trying to accomplish the down-and-up motion characteristic of this type of articulation. Emphasis within this type of articulation typically falls on the first member of each two-note group, followed by a gentle lift on the second note. Bolcom includes the word "meow" in each instance of the two-note slur. Discussing and demonstrating appropriate emphasis through the text Bolcom provides will give the student a concrete way of presenting what can seem like an

\footnotetext{
${ }^{108}$ William Bolcom, Seven Easy Piano Pieces (New York: Edward B Marks Music Company, 2009), 1. ${ }^{109}$ Ibid., 1.
} 
abstract idea interpretively. The addition of the word "meow" in this piece helps a student to achieve more easily a sense of the gesture necessitated by the articulation in this piece, thus resulting in a more musical performance of the piece.

The palette of articulations presented in this short segment of music also includes the use of staccato at the beginning of the line. In addition, proper attack and release of the left hand quarters is necessary in order to adequately highlight the sound of a cat in the right hand. Too short an attack will result in a staccato-like effect. Investigation of proper attack and release will ensure a more artistic and accurate performance.

Finally, the music offers a range of dynamic markings, from pianissimo to forte. Moreover, diminuendo and crescendo markings appear in the piece. This offers variety in the sound, while at the same time challenging a student to use a wide range of arm weight to achieve proper dynamic control. Bolcom's inclusion of a repeat allows a student to explore the possibility of altering the dynamic range the second time, for added variety. These three concepts together give the student a wealth of compositional elements to explore within the framework of a short, yet compelling, piece of music.

The second of the collection Seven Easy Piano Pieces is called "Winter Trek." This work is significantly longer than the previous piece and is also slightly more difficult. It explores a wider register of the piano, requiring more frequent movement on the part of the player. In this work, a student is able to explore concepts of articulation, the topography of the keyboard, and pitch.

The opening line of the piece highlights perfectly the first two of these three concepts. 


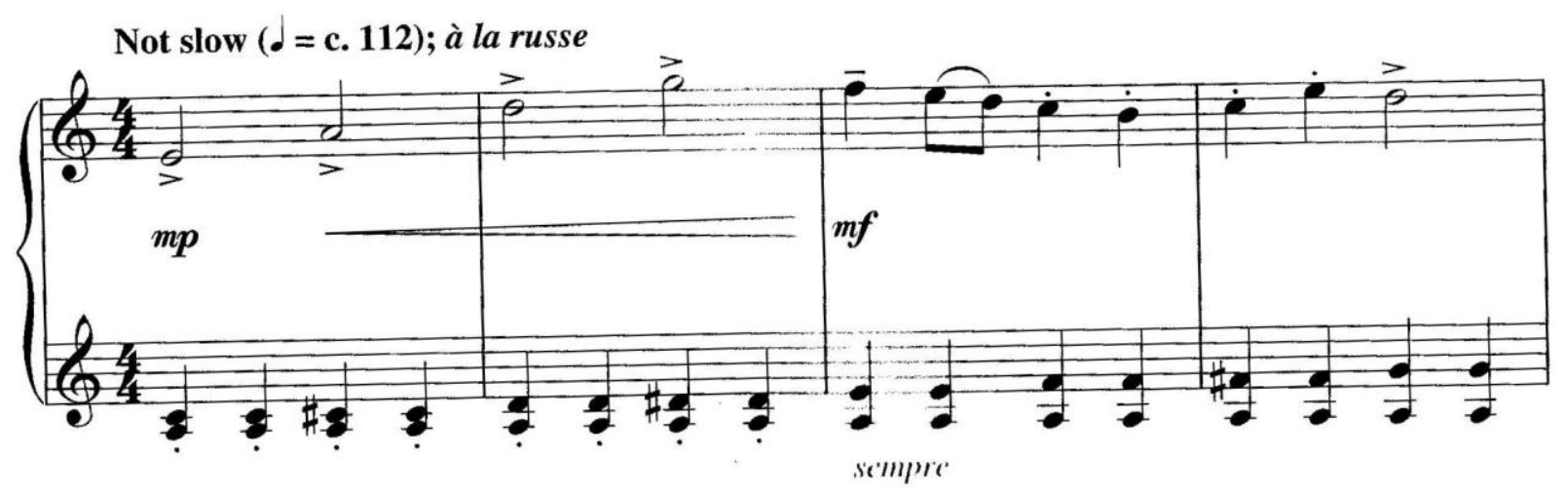

Example 6.3. William Bolcom, "Winter Trek" from Seven Easy Piano Pieces, mm. 1-4. ${ }^{110}$

There are three different articulation markings present which a student must understand, in addition to the accent marks. These include staccato, tenuto, and two-note slurs. A student can use these individually to achieve a greater depth and variety in the sound he or she is able to produce. A potential obstacle to this variety is the simultaneous presentation of several forms of articulation at once, such as the slurring against the staccato, or the tenuto against the staccato. A student must be able to have each hand function independently in order to execute these various forms of articulation properly.

The opening of the piece immediately provides opportunity for exploring the topography of the keyboard through the presentation of differing successive intervals. Bolcom uses the pitch A in the left hand as a pedal point throughout much of the work. However, the chromatically moving pitch above this pedal point is where the exploration comes into place. By chromatically changing the upper pitch of the left hand, Bolcom forces a student to feel the differences among the intervals under the hand through a series of repeated yet constantly changing intervals in the accompaniment. This figure is reversed later in the piece when the bottom pitch of the interval begins to move and the top pitch remains constant. Given the nature of this bass line, a student is

\footnotetext{
${ }^{110}$ Ibid., 2.
} 
able to feel the shape of every interval spanning a minor third to a minor seventh within a single composition.

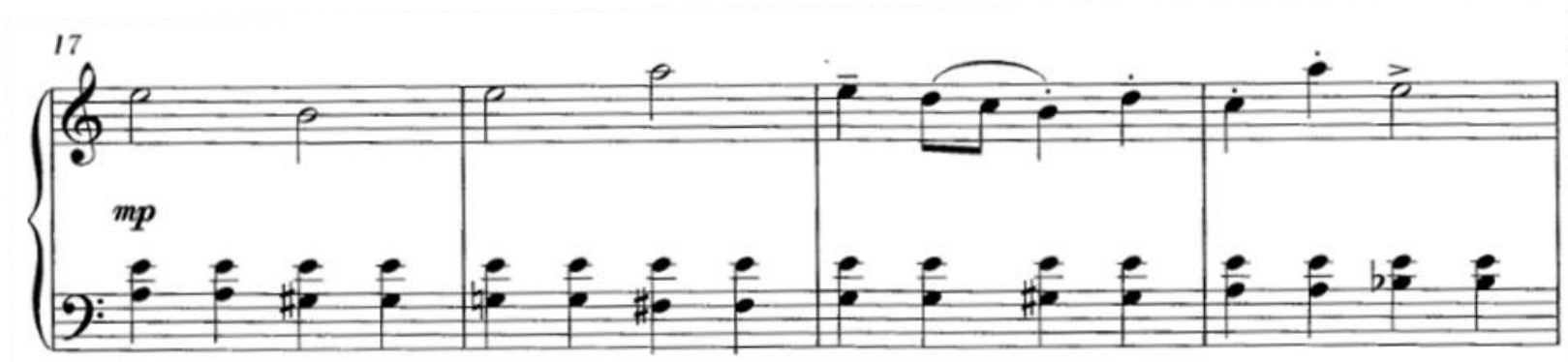

Example 6.4. William Bolcom, "Winter Trek" from Seven Easy Piano Pieces, mm. 17-21. ${ }^{111}$

"Winter Trek" also challenges the student to explore the concept of pitch. Each of these passages contains several accidentals. The chromatic changes simplify this concept for the student in that much of the piece can be easily read by examining the changes in intervals. However, to challenge a student's reading ability, a teacher might isolate certain measures apart from one another to see if a student really recognizes the notes or is simply relying on the patterns presented in the piece. Intervallic examples might also be taken out from the piece to reinforce a student's understanding of intervals. By using examples from this piece to enhance the student's knowledge of these concepts, a student will already have some familiarity with the piece prior to an actual practice or performance.

The third piece of this collection, "Little Song," is certain to challenge a student's understanding of musical concepts, primarily in the areas of pitch, texture, rhythm, and articulation. Although the piece is written in the key of F Major, several accidentals are present in the first few measures of music. Again, the presentation of accidentals offers an initial reading challenge to the student. To build strength and security and to gain greater facility in working through passages with accidentals, it would be advisable to encourage students to practice each ${ }^{111}$ Ibid., 3. 
hand separately. Ideally, this will increase their awareness of the sonorities caused by the accidentals, as well as awareness of the feeling under the hand and how it appears visually to the player.

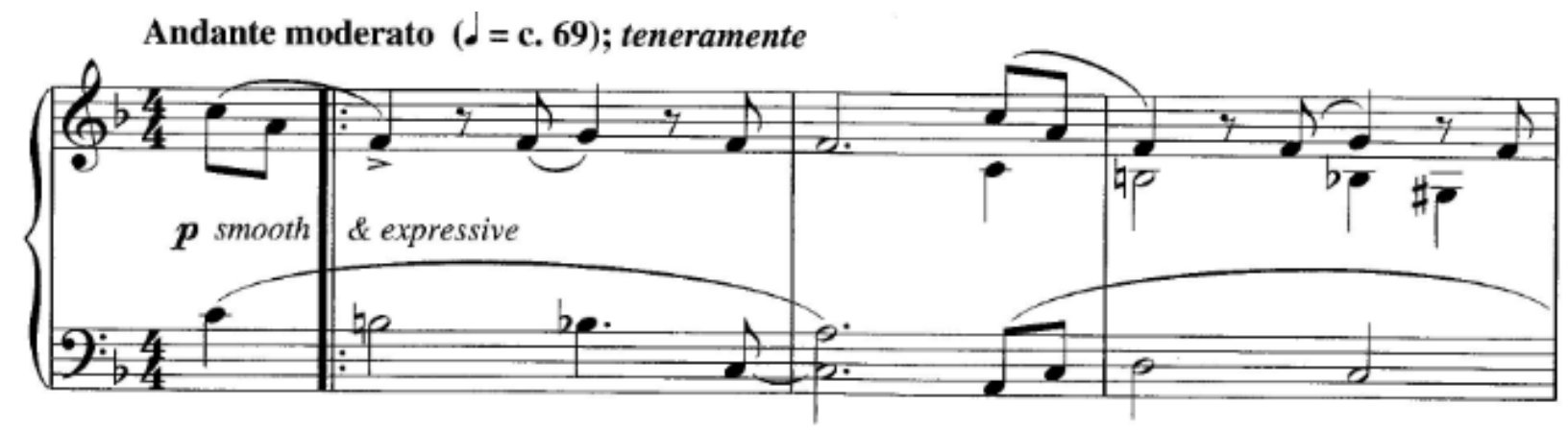

Example 6.5. William Bolcom, "Little Song" from Seven Easy Piano Pieces, mm. 1-3. ${ }^{112}$

Secondly, this collection presents opportunities for exploring textures. The musical example above shows the presence of as many as three independent voices, beginning at the end of the second measure and continuing into the third measure. This three-part texture is present throughout most of the composition and offers a challenge for the student to hear each of the voices and to decide which voices are dominant and which are subordinate. Making voicing decisions can be challenging, and accomplishing these decisions technically in performance is also a skill that requires practice. "Little Song" presents a great exercise in both of these areas.

Third, Bolcom explores changing meters in "Little Song." Pieces at this level of technical difficulty are often written in fairly traditional meters such as $2 / 4,3 / 4,6 / 8$, etc. It is not often that teachers are able to give students compositions which present not only more-complex meters, but also changing meters. In "Little Song," Bolcom explores this concept by shifting from 4/4 to 5/4 and again back to $4 / 4$ meter. This gives students the opportunity to experience music written in quintuple meter and also to be appropriately aware of the emphasis this shift conveys within the context of the overall structure.

\footnotetext{
112 Ibid., 6.
} 


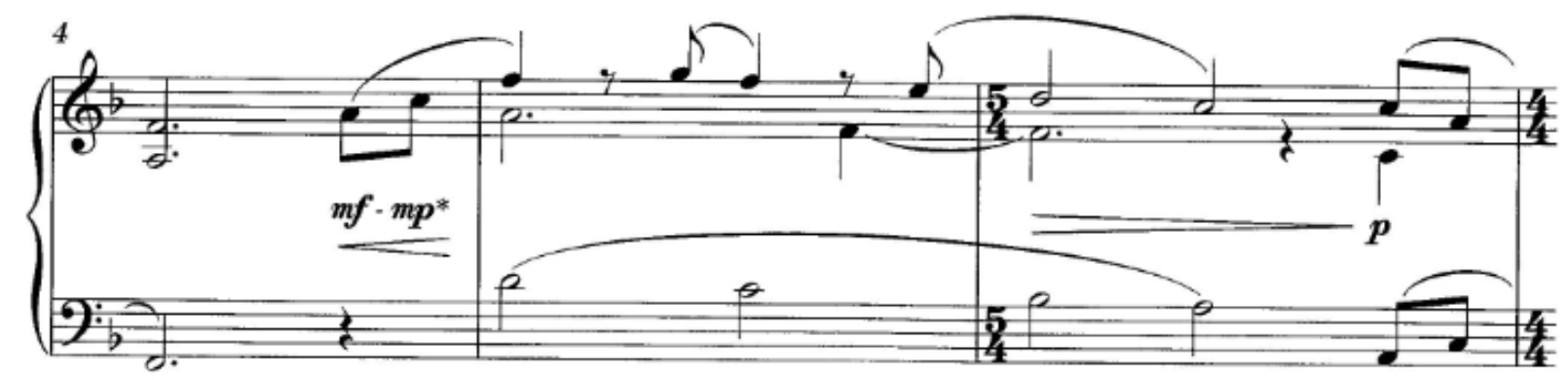

Example 6.6. William Bolcom, "Little Song" from Seven Easy Piano Pieces, mm. 4-6. ${ }^{113}$

Finally, as in the previous two examples, we see that Bolcom presents a variety of articulations in "Little Song." The longer phrases, which are accompanied by shorter two-note slurs, staccatos, rests, and fermatas, demand that a student be familiar with a wide variety of ways to attack and release a particular note. The more comfortable a student is with these different articulation markings, the more successful the performance will be.

Bolcom chose the name "Pussycat Waltz No. 2" for the fourth song of this set. Pitch, rhythm, and form are among the major concepts present in this short work. Regarding pitch, for example, Bolcom presents a wide array of sharps, flats, and naturals throughout the 25 bars of this work. The following excerpt illustrates this point clearly.

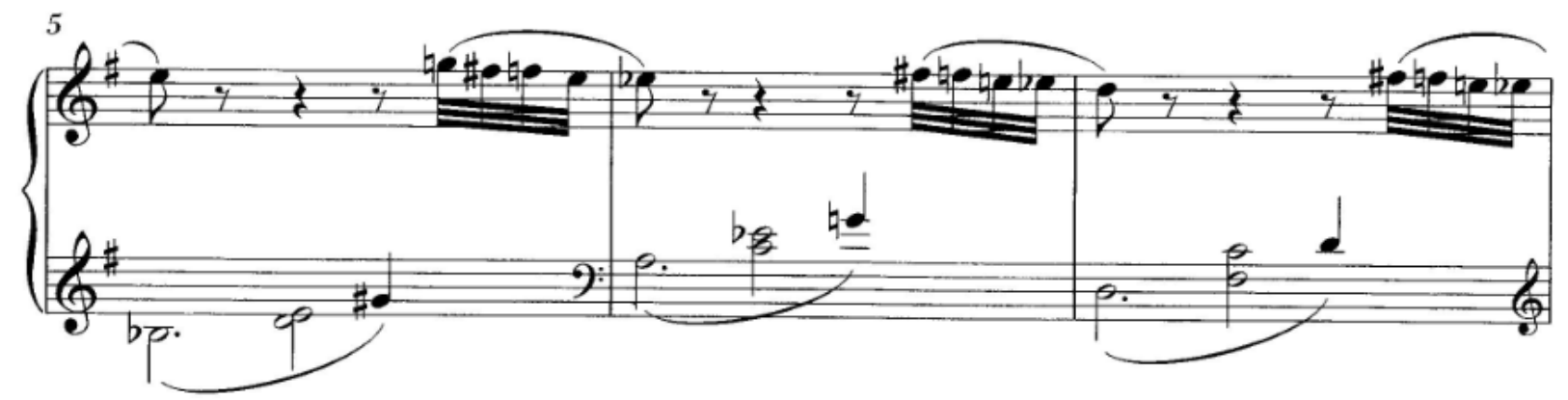

Example 6.7. William Bolcom, "Pussycat Waltz No. 2" from Seven Easy Piano Pieces, mm. 5-7. ${ }^{114}$

Present among these assorted accidentals are groupings of thirty-second notes. Many method books present rhythms as complicated as sixteenth notes, but rarely include pieces which

\footnotetext{
113 Ibid., 6.

${ }^{114}$ Ibid., 8.
} 
contain notes with rhythmic durations smaller than that. Because of this, Bolcom's "Pussycat Waltz No. 2" is a perfect segue into more complex rhythmic values beyond sixteenth notes. Because the other elements in this piece are simple, a student will be able to focus on the rhythmic challenges provided by these thirty-second notes.

A final concept presented in this short composition pertains to form. At the end of the composition, Bolcom writes, "D. C. al Fine" and presents the end of the piece at a point that seems to be just over halfway through the score. These performance directives give the teacher opportunity to explore ternary form with a student through this short composition. Comparisons could be made to other simple compositions to highlight differences or similarities between this piece and other pieces with the same form. Whichever path is preferred, "Pussycat Waltz No. 2" presents several concepts which are invaluable to a student's musical understanding.

The fifth piece of this work bears the title, "Little French Invention: L'Orangerie." In this short piece, Bolcom allows students to explore dynamics and texture. Dynamics present within the ten measures of this piece range from piano to fortissimo. In addition, two crescendos are also present, giving the student the ability to explore how to transition from one dynamic level to another within a short period of time.

Texturally, this work is probably the most complex of the seven pieces of the collection. Four voices are present and, although the contours of the melodies are similar, they do not appear in unison at all during the entire piece. Example 6.8 helps to illustrate what is happening texturally. As we see at the beginning of m. 4, the bass and soprano voices are being sustained while the alto and tenor voices play at the interval of a third. Once the inner voices have played their melodic material, the bass and soprano voices resume, again playing small motives in 
similar motion. This type of alternation between voices occurs in the remainder of Example 6.8, and through the work.

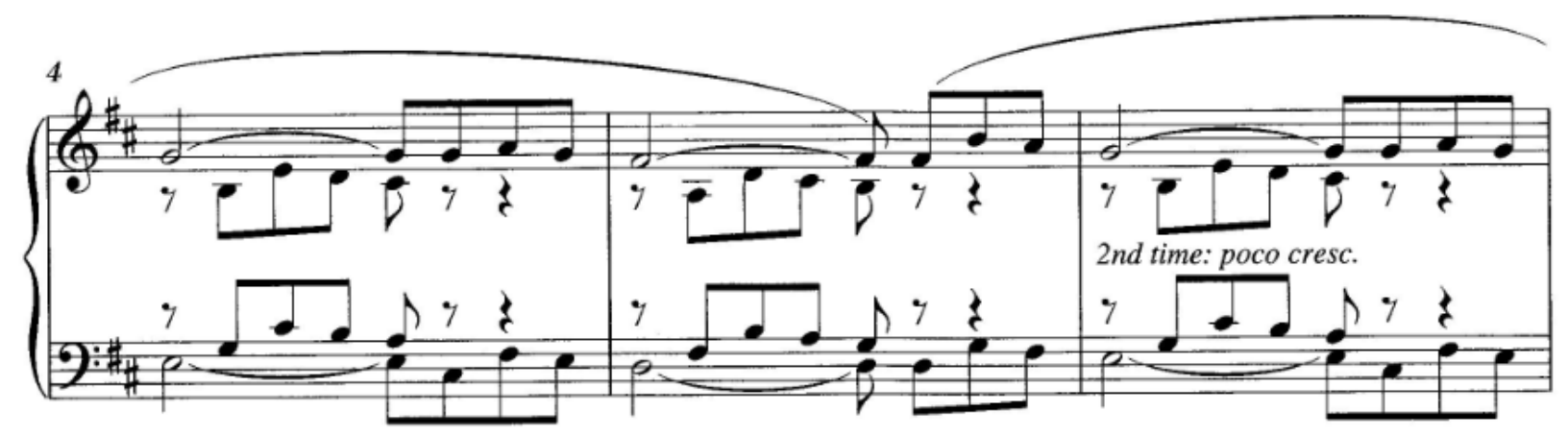

Example 6.8. William Bolcom, "Little French Invention: L'Orangerie" from Seven Easy Piano Pieces, mm. 4-6. ${ }^{115}$

Although this example reveals a four-voice texture, voices do not typically present themselves individually. Usually only two voices appear simultaneously, simplifying the textural issues. As we have already seen, one of the main challenges in this piece is the contrapuntal writing Bolcom employs. With four voices appearing, a student's attention might be focused on simply the quantity of notes present at the onset of studying the piece. However, by helping a student to see the complementary nature of the voices - that is, how the soprano and bass voice always enter at the same time or how the alto and tenor play together-the initial complexity of the piece may no longer seem as difficult to a student.

Piece number six, entitled "Carillon," presents an array of concepts; these include scale, tempo, and texture. The unique key of the work, C-flat Major, is not often found in music of this difficulty level; the use of double flats is also rare in music of this level. In this way, Bolcom gives us a piece which explores an unfamiliar key, but presents it in the context of an intermediate technical level.

\footnotetext{
${ }^{115}$ Ibid., 10.
} 


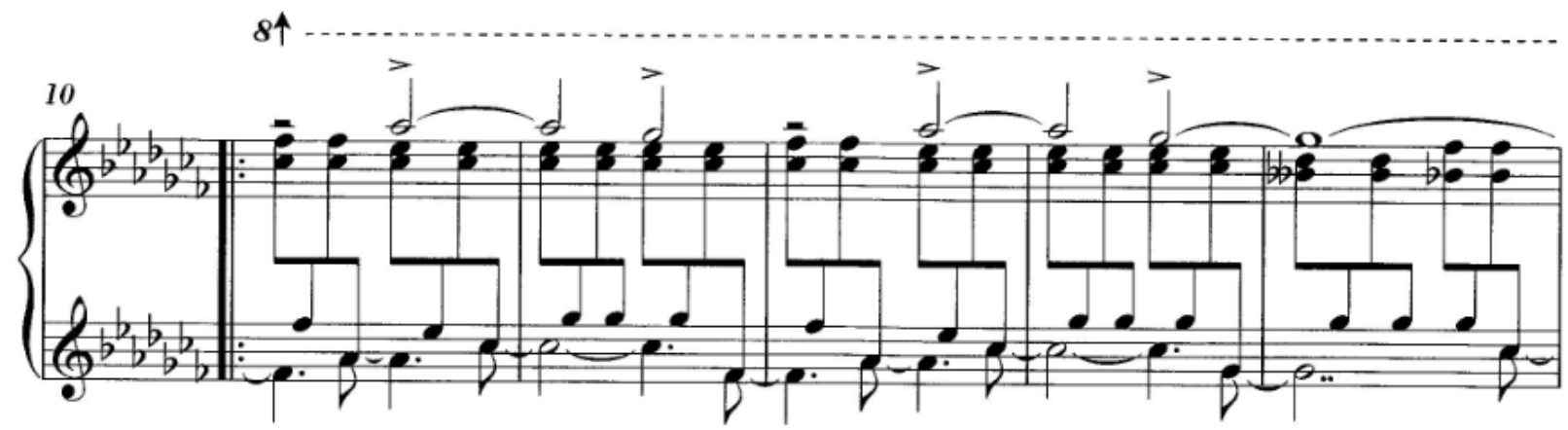

Example 6.9. William Bolcom, "Carillon" from Seven Easy Piano Pieces, mm. 10-14. ${ }^{116}$

The entire piece is meant to be played at 100 beats per minute. Bolcom indicates an initial tempo of "Not Slow" and the consistent barrage of eighth notes reinforces this lively pulse. In order to achieve such a quick tempo, students must have an awareness of the overall harmonic structure as well as the main events, or main melody, taking place in this work. Simplifying this work by having a student block the chords or play just the melody will facilitate a structural understanding of the work. When a student is able to accomplish this simplification comfortably, he or she will have a better chance of playing the written work up to tempo successfully.

Finally, this work poses a textural challenge for students. It is clear in the left hand's part that Bolcom presents an underlying melody in the midst of the forward motion of the pulsating eighth notes. Having a student play only the main notes in this passage at tempo with correct rhythm will directly increase the student's chance of successfully performing this passage up to tempo with the required accompaniment patterns.

For the seventh and final piece of the collection, Bolcom chose the title, "Pussycat Waltz No. 3." In this work, students are able to explore the concepts of pitch, articulation, and rhythm. Unlike several of the other pieces in this set, there are relatively few accidentals in this piece. Instead, pitch is explored through intervals, the relationships from one note to another, with thirds and sixths predominating. The right-hand figures are almost exclusively comprised of

\footnotetext{
${ }^{116}$ Ibid., 11.
} 
these two intervals. Underneath these intervallic melodies we find various styles of accompaniment figures. The following examples show how Bolcom employs the intervals of a sixth and of a third respectively.

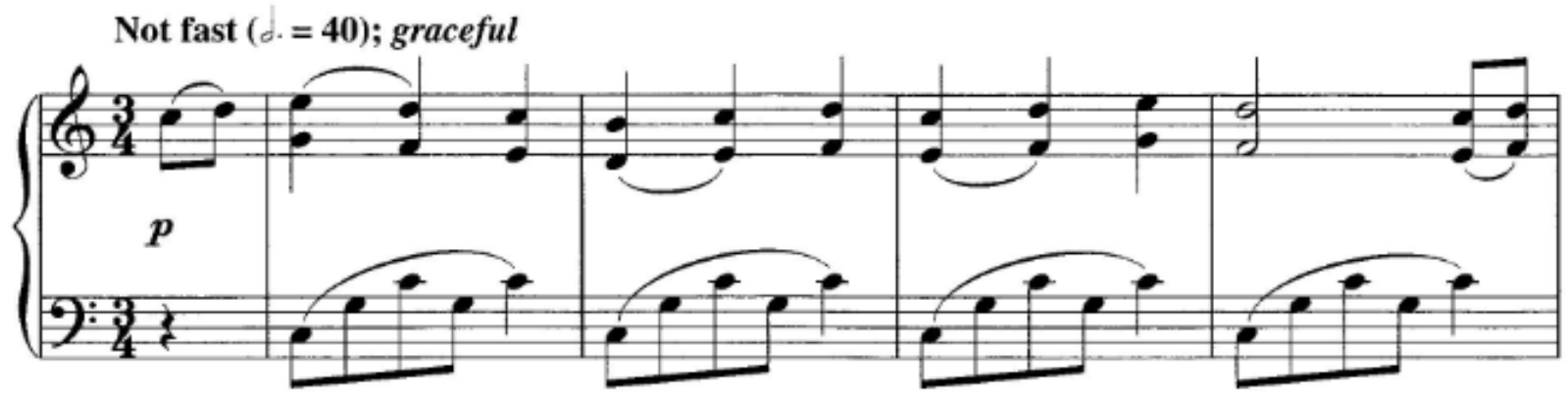

Example 6.10. William Bolcom, "Pussycat Waltz No. 3" from Seven Easy Piano Pieces, mm. 1-4. ${ }^{117}$

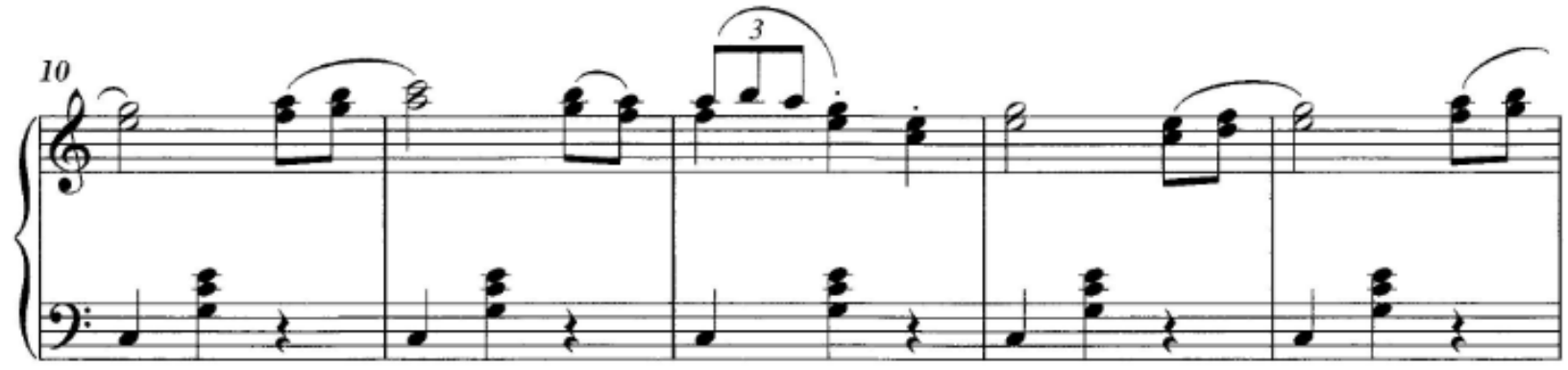

Example 6.11. William Bolcom, "Pussycat Waltz No. 3" from Seven Easy Piano Pieces, mm. 10-14. ${ }^{118}$

These examples highlight Bolcom's use of specific intervals and they also show a variety of articulation markings as well. From simple quarter notes and rests to two-note slurs, and from short staccato markings to longer legato figures, these two lines present a variety of sounds which demand that the performer understand how to interpret and perform a wide variety of articulations.

Finally, these passages illustrate a slight rhythmic challenge that Bolcom inserts, primarily in m. 12 and subsequent measures which contain the same triplet figure. As we have seen in other examples, some of these intermediate works demand that a student be able to hear,

\footnotetext{
${ }^{117}$ Ibid., 12.

${ }^{118}$ Ibid., 12.
} 
feel, and switch between duple and triple divisions of the beat. Of course this skill is also necessary in music of greater difficulty, and early understanding and exposure to this concept will help to construct a solid foundation upon which the student can build throughout their subsequent musical study.

These two collections by William Bolcom provide worthwhile supplemental or alternative pieces to other works of similar difficulty. For example, several of the metrical features, such as the shifting meters or nontraditional meters that Bolcom uses have parallels in the works of other composers, including Bela Bartók's, Mikrokosmos. Contrapuntal works such as "Little French Invention: L'Orangerie" might be introduced in preparation for works of J. S. Bach which also employ similar procedures. A Bolcom piece in ternary form might also be used in conjunction with fantasies by Telemann that contain similar formal structures.

Of course there are numerous parallels which can be drawn between these pieces and many others within the vast body of literature available to us as teachers and pianists. These parallels paint a clear picture of how connections can be made to other pieces and how we can use contemporary literature in our teaching. Furthermore, Monsterpieces and Seven Easy Piano Pieces both present students with descriptive titles that have the ability to spark their imagination. Beyond any doubt, imagination can play a huge part in students' expressive development, enhancing their ability to convey a truly communicative and moving performance of a piece of music. The composer presents starting points for discussion and for developing the student's musicianship, and it is our pleasant duty to follow up on the opportunities at hand. 


\section{Chapter Seven}

\section{Conclusions}

The discussion thus far has presented an overview of concept-based teaching and how we can apply these techniques in the piano studio, along with an exploration of several contemporary musical examples where the application of concept theory can take place. The intention here is not simply to demonstrate how this style of teaching can be applied to works solely by Liebermann and Bolcom; rather, as teachers we need to take such ideas and transfer them into our own teaching. Although the works by Liebermann and Bolcom examined in this research are certainly well written and potentially effective, they may not resonate well with every teacher or student.

Conceptual teaching, when appropriately and creatively used, has the power and potential to open many doors toward more effective teaching. It might lead to a new style of teaching where lessons do not simply focus on paging through lesson books, but where specific concepts are examined and reexamined throughout the course of a student's study, to facilitate greater understanding and learning. It could also lead to the exploration of new composers and to networking with those who are actively composing in our world today. This might even mean the world premiere of a particular composition at one's own studio recital. How exciting! Other possibilities might include engaging with lost works or lesser-known composers, or exploring music of other cultures or looking at music of a particular era that is not traditionally played. This style of teaching opens up endless possibilities.

When looking at music for its conceptual value, we can view each piece for what it has to offer in terms of pitch, rhythm, texture, and scale. When examining concepts within a piece, form, dynamics, articulation, and tempo are universal to all pieces in that they all manifest 
themselves in one way or another. From this angle, every piece can be said to have some teaching merit and has the potential to broaden a student's musical understanding. Whether we are approaching what might seem to be the most mundane piece of popular music or the most advanced and complex jazz or classical piece, if we look at their value through the rubric of the eleven musical concepts Sylvia Coats describes, almost any piece can be used to teach a variety of musical skills which fall within these concepts.

Creatively exploring a variety of new and exciting literature with our students could exponentially broaden the body of piano literature being performed. Students might engage with pieces that resonate more personally for them, teaching styles could be refreshed and revitalized, and there might truly be a revolution in the world of piano literature. The benefits and the possibilities are endless. Just imagine! 


\section{Bibliography}

"2013-2014 CAPMT Piano Competition: Piano Auditions Guidelines." Accessed Dec. 5, 2013. http://capmt.org/California_Association_of_Professional_Music_Teachers/Student_Progr ams_files/2013-14\%20Piano\%20Auditions.pdf

"Bachelor of Music and Diploma Audition Dates, Pre-Screening and Live Audition Repertoire for Fall 2014." Accessed Dec. 5, 2013. http://www.juilliard.edu/applyaudition/application-audition-requirements/bachelor-music-and-diploma/bachelor-musicand-2\#piano

Bolcom, William. Seven Easy Piano Pieces. New York: Edward B. Marks Music Company, 2009.

Bolcom, William. Monsterpieces. New York: Edward B. Marks Music Company, 1981.

Bruner, Jerome S. The Process of Education. Cambridge: Harvard University Press, 1999.

Clark, Adam. ""Modern Marvels:" A Pedagogical Guide to Lowell Liebermann's Album for the Young, Op. 43". D.M.A. diss., University of Cincinnati, 2008.

Coats, Sylvia. Thinking as You Play. Bloomington, IN: Indiana University Press, 2006.

Debussy, Claude. "Deux Arabesques." Accessed Dec. 5, 2013. http://conquest.imslp.info/files/imglnks/usimg/e/ef/IMSLP255353-PMLP02383Debussy_Claude-Deux_Arabesques_Durand_4395_scan.pdf

Duckworth, Guy. "What Are We Teaching_Concepts or Details?" Clavier 3, no. 3 (1964): 45$46,50$.

Evans, Sarah. "Lowell Liebermann's Album for the Young, Op. 43: A fresh approach to classical teaching literature." Clavier Companion 1, no. 1 (2009): 48-51.

"Indiana State School Music Association: Required Music List Group I Piano Events." Accessed Dec. 5, 2013. http://www.issma.net/downloads/pianogrp1.pdf

Ishii, Reiko. "The Development of Extended Piano Techniques in Twentieth-Century American Music". D.M.A. diss., The Florida State University, 2005.

Jonassen, David H. "On the Role of Concepts in Learning and Instructional Design." Educational Technology Research and Development, Vol. 54, No. 2, (April 2006): 177196.

Kageyama, Noa and Christine Carter. "Why the Progress You Make in the Practice Room Seems to Disappear Overnight." Accessed Dec. 5, 2013. http://www.bulletproofmusician.com/why-the-progress-in-the-practice-room-seems-todisappear-overnight/ 
Klingenstein, Beth Gigante. The Independent Piano Teacher's Studio Handbook. Milwaukee, WI: Hal Leonard Corporation, 2009.

Liebermann, Lowell. Album for the Young. King of Prussia, PA: Theodore Presser Company, 1994.

"Lowell Liebermann::Biography." Accessed Dec. 4, 2013. http://www.lowellliebermann.com/biography/index.html

Maclellan, Effie. "Conceptual Learning: The Priority for Higher Education." British Journal of Educational Studies, Vol. 53, No. 2, (June 2005): 129-147.

Magrath, Jane. The Pianist's Guide to Standard Teaching and Performance Literature. Van Nuys: Alfred Publishing Co., Inc., 1995.

McArthur, Lisa R. "Lowell Liebermann: His Compositional Style as Derived from Three Flute Works and Applied to Other Selected Instrumental Works." Ph. D. diss., University of Kentucky, 1999.

Nichols, Dean Alan. "A Survey of the Solo Piano Works of Lowell Liebermann." DMA diss., University of Kentucky, 2000.

"Ohio Music Education Association: Solo and Ensemble Required Music List - High School." Accessed Dec. 5, 2013. http://www.omea-ohio.org/SEP/HS.html

Palmer, Caroline and Rosalee K. Meyer. "Conceptual and Motor Learning in Music Performance." Psychological Science, Vol. 11, No. 1, (January 2000): 63-68.

"School of Music, University of Wisconsin-Madison: Piano Undergraduate Admission Requirements." Accessed Dec. 5, 2013. http://music.wisc.edu/performance/piano

Uszler, Marienne, Scott McBride Smith, and Stewart Gordon. The Well-Tempered Keyboard Teacher. New York: Schirmer, 1999.

"William Bolcom: Meet the Composer." Accessed Dec. 4, 2013. http://williambolcom.com/index.php?contentID=1011

"WSMA 2013-2014 Festival Music List." Accessed Dec. 5, 2013. http://www.wsmamusic.org/music_list/search_13-14.html

Yang, Chia-Shan. "Exploring New Techniques in Contemporary Piano Music: a Guide for the Intermediate-Grade Student". D.M.A. diss., University of Washington, 2004. 